University of Louisville

ThinkIR: The University of Louisville's Institutional Repository

Electronic Theses and Dissertations

$5-2010$

\title{
Experiential learning : a review of college health centers.
}

Elizabeth J. Greaney

University of Louisville

Follow this and additional works at: https://ir.library.louisville.edu/etd

\section{Recommended Citation}

Greaney, Elizabeth J., "Experiential learning : a review of college health centers." (2010). Electronic Theses and Dissertations. Paper 527.

https://doi.org/10.18297/etd/527

This Doctoral Dissertation is brought to you for free and open access by ThinkIR: The University of Louisville's Institutional Repository. It has been accepted for inclusion in Electronic Theses and Dissertations by an authorized administrator of ThinkIR: The University of Louisville's Institutional Repository. This title appears here courtesy of the author, who has retained all other copyrights. For more information, please contact thinkir@louisville.edu. 


\title{
EXPERIENTIAL LEARNING: A REVIEW OF COLLEGE HEALTH CENTERS
}

\author{
By
}

Elizabeth J. Greaney

B.S. University of Vermont, 1984

M.S. University of New Hampshire, 1992

M.H.A. Western Kentucky University, 1997

M.B.A. Western Kentucky University, 2003

A Dissertation Submitted to the Faculty

of the School of Interdisciplinary and Graduate Studies University of Louisville and

School of Graduate Studies and Research Western Kentucky University in Partial Fulfillment of the Requirements for the Degree of

\section{Doctor of Philosophy}

Department of Leadership, Foundations \& Human Resource Education

University of Louisville

and

College of Education and Behavioral Sciences

Western Kentucky University

May 2010 
EXPERIENTIAL LEARNING: A REVIEW OF COLLEGE HEALTH CENTERS

\author{
By \\ Elizabeth J. Greaney \\ B.S. University of Vermont, 1984 \\ M.S. University of New Hampshire, 1992 \\ M.H.A. Western Kentucky University, 1997 \\ M.B.A. Western Kentucky University, 2003
}

A Dissertation Approved on

March 15, 2010

By the following Dissertation Committee

Dissertation Director 


\section{ACKNOWLEDGMENTS}

I would like to thank my Dissertation Committee Chair, Dr. Randy Capps, for serving as my Chair and for his support though out this process. I would like to thank Dr. Fred Gibson and Dr. John Bonaguro from Western Kentucky University and Dr. Bridgette Pregliasco and Dr. Karen Miller from the University of Louisville for their willingness to serve on this committee and for their assistance and recommendations. In addition, I would like to thank my mother Helen for her support and my friends and cohorts who have gone before me in this doctoral program and helped me along the way. A final expression of appreciation goes to Little Puss, Buster, Charley, Big Puss, Pearlsie and Sandy for keeping me company during those long hours of typing at the computer. 


\section{ABSTRACT \\ EXPERIENTIAL LEARNING: A REVIEW OF COLLEGE HEALTH CENTERS Elizabeth Greaney}

May 8, 2010

This exploratory study was conducted using a descriptive design and examined the use of college health centers for academic internships and clinical rotations. In addition, the study examined the relationship among health center director and school characteristics and the presence of academic internships or clinical rotations and the directors' satisfaction with these activities. The population consisted of 267 health center directors responding to a survey containing 21 questions. The demographics of the directors consisted of 64 (24\%) males and 203 (76\%) females; school classifications; 106 (39.7\%) Research/Doctoral, 68 (25.5\%) Masters, 87 (32.6\%) and $3(1.1 \%)$ Associates/Community College, 147 (55.1\%) Public and 117 (43.8\%) Private.

Logistic Regression analyses indicated the presence of three predictor variables (school classification, scope of services and nursing school) in the overall model for the presence of clinical rotations, $X^{2}(12, \mathrm{~N}=261)=68.23, p<.001, \mathrm{R}^{2}=.23$; and two predictor variables (scope of services, director credential) for the presence of academic internships, $X^{2}(12, \mathrm{~N}=258)=50.10, p<.002, \mathrm{R}^{2}=.18$. Results from Multiple Regression analyses indicated no significance in the overall model for satisfaction with clinical rotations $\mathrm{R}^{2}=.08, F(7,135)=1.75, p=.10 ;$ however, the presence of a nursing school was a significant individual predictor variable. The overall model for satisfaction with 
academic internships was significant $\mathrm{R}^{2}=14, F(7,95)=2.24, p=.04$. Scope of services was a significant predictor. Of note, results indicated a trend toward significance for school classification and a nursing school.

The findings suggest the presence of a nursing school was a significant predictor variable regarding satisfaction with clinical rotations and displayed a trend toward significance for satisfaction with academic internships. The presence of a medical school was not a predictor in this particular study. The findings indicated more frequent use of clinical rotations than academic internships at these college health centers. The findings suggest more academic integration for college health centers may be warranted. 


\section{TABLE OF CONTENTS}

\section{PAGE}

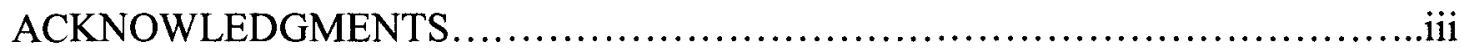

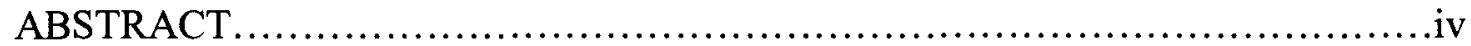

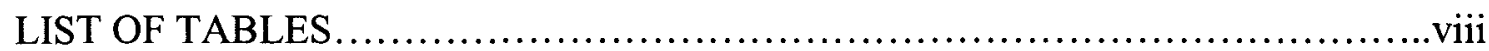

\section{CHAPTER 1}

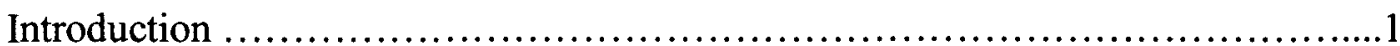

Statement of the Problem................................................... 3

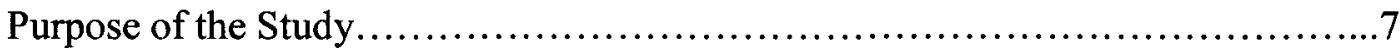

Research Questions.................................................9

Limitations................................................................

CHAPTER 2

Historical Perspectives on Experiential Learning Theory........................ 15

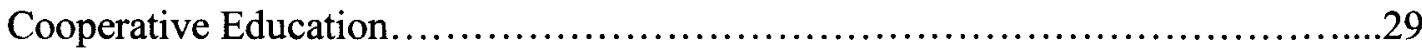

College Health Services................................................. 34

Summary.................................................................. 43

\section{CHAPTER 3}

Methodology ...........................................................47

Design.............................................................49

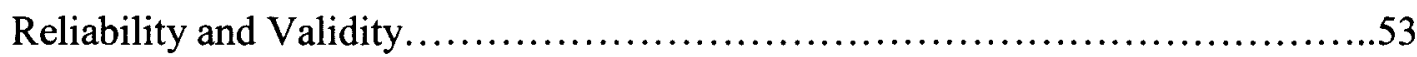

Procedure.....................................................................

Data Analysis.........................................................59 


\section{CHAPTER 4}

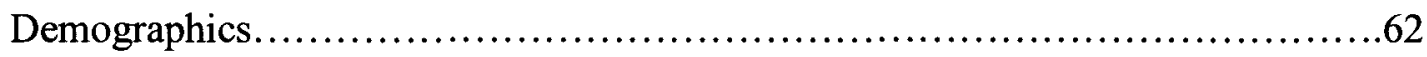

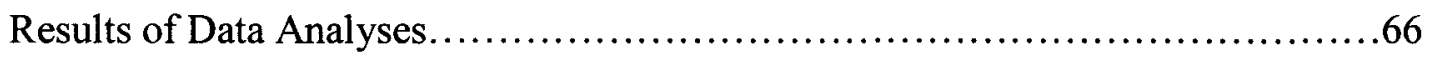

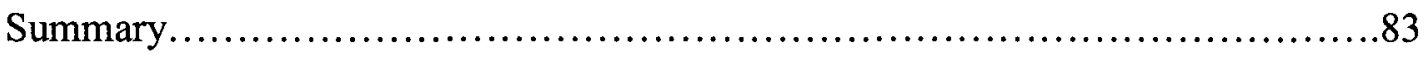

\section{CHAPTER 5}

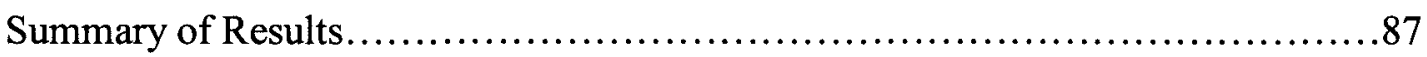

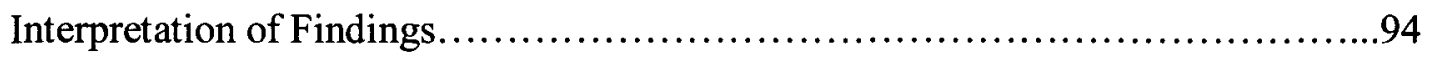

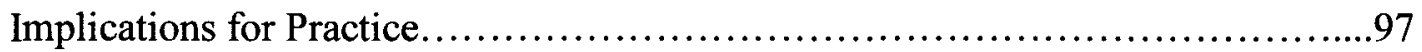

Suggestions for Further Research...............................................98

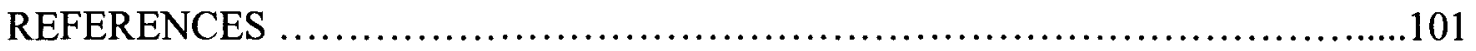

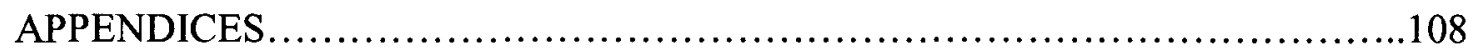

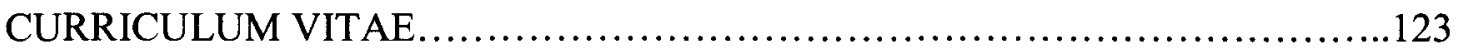




\section{LIST OF TABLES}

TABLE

PAGE

1. Test-Retest Pearson Correlation..........................................56

2. Director Demographics..............................................62

3. Cross Tabulation: Gender, Scope of Services, Credential......................64

4. School Characteristics....................................................66

5. Clinical Rotations.................................................... 68

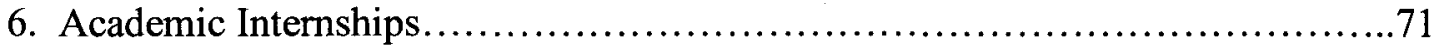

7. Logistic Regression: Academic Internships................................ 75

8. Logistic Regression: Clinical Rotations................................... 77

9. Multiple Regression: Satisfaction with Clinical Rotations....................79

10. Multiple Regression: Satisfaction with Academic Rotations..................80

11. Directors' Satisfaction.................................................. 81

12. Barriers to Academic Internships.................................... 82

13.Enablers to Academic Internships..................................... 83

14. Cross Tabulation: Medical School, Nursing School, Rotations................90

15. Open-ended Question Summary......................................94 


\section{CHAPTER I}

\section{INTRODUCTION}

Experiential learning is defined as the essence of learning by doing (Kolb, 1984). Experiential learning theory (ELT) is grounded in the belief that deeper learning is realized when students (a) learn by interacting with the environment and (b) actively reflect upon the learning process. For this study, two specific forms of experiential learning were examined, academic internships and clinical rotations. Each of these experiential learning activities encompasses the essence of learning by doing.

Experiential learning is an umbrella term that includes experiential education, cooperative education, externships, internships, field study, and clinical rotation. The common theme among these terms is that all incorporate the combination of academic learning (theory) with on-site workplace assignments, to enhance development of jobrelated skills. This chapter includes an introduction to ELT, a statement of the problem, a sample of experiential learning literature in various curricula, the purpose of the study, and a summary.

\section{Experiential Education}

Experiential education is grounded in the theory of experiential learning. Although experiential learning is not new, the concept continues to gain attention from educators and reformers seeking more effective learning outcomes for students. These 
learning outcomes focus on the development of critical-thinking skills and the ability to solve problems, commonly referred to as higher order thinking. David Kolb's formulation of ELT was drawn from observations of college undergraduates, graduates, and adult learner populations as well as from earlier learning theories. According to David Kolb (1984), John Dewey was the most influential educational theorist of the 20th century. The experiential learning movement is attributed to Dewey's educational philosophy, which Dewey termed a theory of experience (Dewey, 1938, p. 20).

Throughout the last 40 years, many of Dewey's ideas have been incorporated into traditional education programs (Kolb, 1984). Dewey's conceptual studies focused on the learning process and enhancement of lifelong learning. These concepts have been adopted by many experiential educators. The best of traditional and experiential education has been integrated with the following programs and methods in higher education: internships, medical training, work-study programs, cooperative education, laboratory studies, and independent studies (Kolb, 1984). This concept is further explained by Keeton and Tate: "The learner is directly involved with the realities being studied rather than merely thinking about the encounter or considering the possibility of doing something with it." (Keeton \& Tate, 1978, p. 18)

David Kolb's ELT and his Learning Style Inventory have steadily gained acceptance and recognition as useful tools to improve teaching and learning in higher education (Kolb, Rubin, \& McIntyre, 1971). The terms included under the umbrella of experiential education (cooperative education and internships) are experiences many educators consider to be a prerequisite to getting hired (Brougham \& Casella, 1996). Several studies document the benefit and value of internship experiences for both 
students and employers (Allen, 1998; Gardner \& Liu, 1997; Kretovics \& McCambridge, 1998; National Association of Colleges \& Employers, 2000; Reardon, Lenz, \& Folsom, 1998). Although many scholars have examined the concept and theoretical bases of experiential learning, no studies examined the use of on-campus facilities for these activities.

\section{Statement of the Problem}

The increasing interest in experiential learning explains the current sense of urgency and calls for improvement of learning in higher education. This interest is supported in statements by the National Research Council (Bransford, Brown, \& Cocking, 2000); the American Psychological Association Board of Affairs (1997); Boyatzis, Cowen, and Kolb (1995); and Mentkowski and associates (2000)-all of whom urge administrators, scholars, and educators to create educational initiatives that enhance student learning.

In addition, a growing body of research points to the limitations of traditional teacher-centered pedagogy in fostering holistic education that respects students' intellectual and emotional integrity and capacity to become independent learners (Palmer, 1998; Terenzini \& Pascarella, 1994). Many educational reform acts have been created to enhance accountability for effective learning. Standardized testing required by these federal mandates has created the need for many teachers to teach the students how to take the test rather than teaching higher order critical-thinking and problem-solving skills. These high-stakes tests measure lower order knowledge and skills (e.g., recall and comprehension) as opposed to higher order thinking (e.g., analysis, synthesis, evaluation; Chudowsky \& Pellegrino, 2003). These observed deficiencies call for significant change 
from the teacher-centered, knowledge-transfer approach to a focus on the learner as an active participant in the process (Keeling, 2006). The available research related to experiential education and academic outcomes discusses both the higher order and lower order dimensions of academic achievement. Many studies document this shift toward more experiential education in various curricula (Kolb, Boyatzis, \& Mainemelis, 2001; Mentkowski \& Strait, 1983).

Goodenow's (1992) study of school-based service-learning practices found that students who were seen by others as more engaged earned higher grades. It is not clear whether more engaged students earn better grades because of their engagement or because of how they are perceived by others (Goodenow, 1992). Reynolds (1991), conducted a study examining student achievement in both science content skills (science measurement and graphing) and science process skills such as hypothesis testing, in middle school science students. Using a pretest-posttest model, the researcher found no evidence that the number of experiments would predict higher achievement outcomes on a measure of science content. However, the results suggested that the number of experiments is a predictor for higher achievement outcomes on a science process measure.

Laney (1989) taught basic economic principles to first-grade students using either a real-life experience or a storytelling approach. A 6-week delayed posttest showed a significantly greater retention of these concepts for students taught through real-life experiences. The call for greater accountability and more effective learning outcomes is found at all levels of education: primary, secondary and postsecondary institutions. The 
following examples highlight studies in higher education and various curricula that have incorporated experiential learning modalities.

\section{Experiential Learning in Various Curricula}

Frontczak (1998), suggested that marketing education curricula is shifting from a traditional, knowledge-transfer approach to the experiential and more interactive classroom methodology. Fleming, Mauriello, Stice, Mckaig, and Ludlow (2003) reported a changing trend in dental education, noting a growing recognition that traditional lecture-based instruction is efficient when comparing measurement of the knowledge itself but deficient when the measurement is focused on retention of knowledge, problemsolving skills, or ability to transfer the newly acquired knowledge to a clinical situation. Carland, Carland, and Dye (1994) introduced experiential learning to their Principle of Accounting course after they experienced "tremendous frustration in striving to make sophomores literate in accounting." (p. 224). The change in this teaching paradigm led to a successful increase in students' rate of learning and significant reduction in failure and withdrawals from the course.

Bennis and O'Toole (2005) wrote a critique of MBA programs in their article How Business Schools Lost Their Way. The authors claimed that business schools are institutionalizing their own irrelevance by focusing on scientific research rather than reallife business practices. They concluded that business schools are too focused on theory and quantitative approaches and, as a result, because so little of it is grounded in actual business practices, the focus of graduate business education has become increasingly circumscribed - and less and less relevant to practitioners. They further asserted that business schools are graduating students lacking applicable business skills and sound 
decision-making abilities. Partly in response to this assessment, various institutions are applying for grants provided through the National Society for Experiential Education to incorporate and assess experiential learning activities into their business curricula (Johnson, 2005). Henry Mintzberg, Professor of Management at McGill University, has supported Bennis and O'Toole's viewpoint in various studies and interviews.

In a video interview at the MIT Leadership Center, Mintzberg (2005) claimed that most MBA programs are simply training students in analytical skills like investment banking and consulting. He described a complete lack of personal development and realworld learning and development for the student. He further stated that "management is a practice that needs to be developed by providing real life scenarios and more mentoring from currently practicing managers, rather than straight lecture and textbook case studies guided by non-experienced Ph.D's" (Mintzberg, 2005).

Mintzberg (2004) called for a more realistic and practical approach to schooling and training people to manage effectively. He is a strong advocate for faculty in business schools being required to be practicing managers, similar to medical school faculty who are practicing physicians or surgeons and teach in addition to this primary duty. $\mathrm{He}$ stated,

It is time to recognize conventional MBA programs for what they are-or else close them down. They are specialized training in the functions of business, not general educating in the practice of managing. Using the classroom to help develop people already practicing management is a fine idea, but pretending to create managers out of people who have never managed is a sham. It is time that our business schools gave proper attention to management. (Mintzberg, 2004, p. $5)$.

The economics or cost of experience-based higher education has been examined as well. In one study, the fixed costs of traditional lecture-based education was compared to that of experience-based education. According to Len Lawson (2007), 
Comparisons of cost between coursed relying on lecture-based education and those that are experience-based suggest that the latter are, in fact, more expensive to deliver. However, the benefits derived by students, faculty, the institution, and the community may be correspondingly —or perhaps even disproportionately higher as well. The evidence adduced thus far from researchers across the disciplinary spectrum concerning the advantages of experience-based education is persuasive, and much of this evidence has been drawn from experiences in business and economics education. As higher education is called upon to respond to public pressures to both ensure affordability and, at the same time, provide educational experiences with practical relevance, the debate about experiencebased education could not be more timely. (p. 30).

Opportunities for these experience-based learning activities for the student may exist right on college campuses. The present study examines the use of on-campus service departments and their use for experienced-based learning activities.

$$
\text { Purpose of the Study }
$$

Experience-based, cooperative education assignments utilizing on-site college facilities may be a modality for increasing learning capacity in students. According to the literature, many researchers have examined the use of experiential education in various curricula, such as business, education, and health care services. The results of these studies support the use of experiential education for enhancement of learning and the development of job skills for students; however no researcher has assessed the use of oncampus college facilities for these experience-based, work-site learning assignments. These on-campus business units provide services to a variety of customers and constituents. These services may include dining, housing, postal services, printing and copier services, recreational and fitness services, laundry services, tanning salons, clinical psychology, and health services.

Experiential learning has been reported in the health services literature regarding its use in medical and nursing students and learning styles (see, e.g., Lassan, 1984; 
Merritt, 1983; Whitney \& Caplan, 1978). These studies focused on the concept of experience-based learning and learning styles but not the work-site locations of these learning assignments. This investigator was unsuccessful in finding literature assessing the use of on-campus facilities for these studies. The current study addressed this gap in the literature by examining the use of on-campus college health centers for experiential learning activities. The two forms of experiential learning explored in this study were clinical rotations and academic internships. The use of college health centers for these activities has not been explored in previous research.

The purpose for this study was (a) to establish baseline data on the current use of college health centers as on-the-job placement sites for experiential education assignments and (b) to explore the relationship among health center director characteristics, school characteristics, and the presence of academic internships or clinical rotations at college health centers. College health centers are very diverse in terms of their scope of services, director characteristics, and school characteristics within their respective institutions.

Due to this complexity of services delivered and competencies needed to manage them, college health centers provide a varied opportunity for experiential learning in a diverse array of academic majors. Examples of these majors include business, marketing, finance, health education, health administration, medical and nursing training, management, leadership, and allied health specialties. This investigator was unable to find literature that assessed the current use of these facilities as on-site placement opportunities for experiential education. Six research questions were established to guide this study. 


\section{Research Questions}

The research questions were designed to gather baseline data regarding the use of on-campus health centers for clinical rotations and academic internships. In addition, the investigator examined the relationships among health center director demographics, school demographics, and the presence of clinical rotations and academic internships and the directors' satisfaction levels with these activities. The research questions used to guide this study were as follows.

Research Question 1: Are college health centers being utilized for on-site experiential learning assignments (academic internships or clinical rotations)?

Research Question 2: What academic departments are using college health centers for academic internships?

Research Question 3a: What is the relationship among the following variables: (a) school classification, (b) scope of services, (c) public-private, (d) teaching classes, (e) medical school, (f) nursing school, and (g) credential of director with the presence of academic internships? (e.g., Can these variables predict directors' use of academic internships?)

Research Question 3b: What is the relationship among the following variables: (a) school classification, (b) scope of services, (c) public-private, (d) teaching classes, (e) medical school, (f) nursing school, and (g) credential of director with the presence of clinical rotations? (e.g., Can these variables predict directors' use of clinical rotations?)

Research Question 4a: What is the relationship among the following variables: (a) school classification, (b) scope of services, (c) public-private, (d) teaching classes, (e) medical school, (f) nursing school, and (g) credential of director with directors' 
satisfaction with clinical rotations? (e.g., Can these variables predict directors' satisfaction with clinical rotations?)

Research Question 4b: What is the relationship among the following variables: (a) school classification, (b) scope of services, (c) public-private, (d) teaching classes, (e) medical school, (f) nursing school, and (g) credential of director with directors' satisfaction with academic internships? (e.g., Can these variables predict directors' satisfaction with academic internships?)

Research Question 5: What are the directors' perceived barriers to their health center serving as a placement site for academic internships?

Research Question 6: What are the directors' perceived enablers to their health center serving as a placement site for academic internships?

This study addressed a gap in the literature regarding the use of on-campus college health facilities and experiential education assignments. The study also established empirical data regarding the relationship among health center director characteristics, school characteristics, and the presence of academic internships or clinical rotations and the directors' satisfaction levels with these activities. The limitations for this study are discussed in the following section.

\section{Limitations}

The population of respondents consisted of college health center directors. The results of this study may contain self-selection bias due to convenience sampling. The results of this study represent cross-sectional data, which gathers responses, attitudes, or other measurements at a particular point in time. The results of this study are limited to the accuracy and perceptions of the respondents for that time period only. In addition, the 
investigator was unable to control for the level of detail and honesty with which the respondents answered the survey questions. The interpretations of the results of this study are limited solely to those directors who provided responses to the survey questions.

The survey was designed by the investigator to answer the stated research questions for this study. The survey questionnaire was designed as a rating scale measuring both nominal- and ordinal-level data. The questions that measured the directors' perceived satisfaction were in a typical five-level Likert-item format: 1 (Very dissatisfied) to 5 (Very satisfied). Likert items may be subject to distortion from many causes, such as central tendency bias, acquiescence bias, or social desirability bias. These biases may be present due to the design of the survey questions and are a limitation to this study. The delimitations and the definitions of terms established for this study are addressed in the following section.

\section{Delimitations and Definitions}

Experiential learning and experiential education are umbrella terms that involve activities utilizing the concept of learning by doing. These terms are vast and may include, but are not limited to, any of the following: cooperative education, internships, externships, clinical rotations, field study, practicum, or independent study. These terms are often used interchangeably in higher education and in the corporate sector (Metzger, 2002). There may be very slight differences among the terms; however all are centered on the concept of students learning by doing and developing skills for employment. For the purposes of this study, the literature review includes empirical citations to research that used the terms interchangeably. For example, cooperative education is a very common term used interchangeably with experiential education. 
Furthermore, the two experiential education terms, academic internship and clinical rotation, were chosen by the investigator as the two choices on which the respondents could report. These two terms were chosen to cover the two main categories of experiential learning considered by the investigator to be most relevant at a college health center: an academic internship (nonclinical) and a clinical rotation (clinical training). The choices were limited to these two in order to keep the length of the survey manageable and to focus on the purpose of the study. The use of more defined delineations regarding the global term of experiential learning may be warranted for future studies after baseline data has been established. The following definitions were used to guide this study:

Academic Internship: A nonclinical academic on-the-job placement designed to afford students an opportunity to develop skills for employment related to their chosen academic field of study. These may include business, public health, student affairs, or other area of study. The students currently enrolled and receive academic credit for the internship assignment. The duration of these internships may vary from 6 to 16 weeks, according to the individual school's requirements. The internship may be paid or unpaid. Clinical Rotation: An on-site clinical rotation for students enrolled in medicine, nursing, psychology, medical assistance, counseling, physical therapy, or other ancillary service. These students are completing a required on-site rotation for licensing requirements and client contact hours. Time periods for these can vary from 1 week of observation to 1 month or longer of active hands-on training in the clinical specialization.

School Categories: For the purposes of this study, the Carnegie Foundation Classifications (2008) were used to define the four basic classifications for institutions of 
higher education: (a) doctoral-research universities, (b) master's colleges and universities, (c) baccalaureate colleges, and (d) associate's colleges.

This investigator chose to limit the school classification categories to the four main broad categories in order to provide more clarity and brevity for the respondents. The purpose was to avoid too much detail regarding further categorization such as specialized majors, religious affiliation, research and grant dollars, or other defined criteria not deemed relevant for the purpose of this study. Future studies utilizing these further delineations may be warranted. A summary of this chapter and introduction to the next chapter is presented in the following section.

\section{Summary}

This study was designed to establish baseline data on the current use of college health centers as on-the-job placement sites for experiential education assignments (academic internships and clinical rotations). In addition, the relationships among college health center director characteristics, school characteristics, and the presence of these activities and the directors' satisfaction with them was explored. The research findings provide information for college health professionals and experiential learning scholars regarding the relevance of college health centers as placement sites for experiential education assignments.

This empirical data contributes to the field of knowledge regarding ELT and the college health profession. As stated earlier, there is increasing demand for more effective learning outcomes for students and better development of real-world skills in preparation for employment (Caine, Caine, McClinitic, \& Klimek, 2005). College health centers offer many opportunities for providing opportunities for experiential education in many fields 
of academic study as well as clinical training. The following chapter provides a review of the literature regarding ELT, including relevant literature in various academic curricula, the historical and contemporary perspectives of college health, and a summary. 


\section{CHAPTER II}

\section{REVIEW OF LITERATURE}

This study is grounded in Experiential Learning Theory (ELT). This chapter provides a review of the literature in relation to ELT and is arranged by topical format. The topics include the contributions of early 20th century scholars to the establishment of learning theory, David Kolb's ELT, the use of experiential learning in various curricula, cooperative education, the historical and contemporary aspects of the college health profession, and a summary.

\section{Historical Perspective on ELT}

Experiential learning is based on the premise of active engagement by the student. This is opposed to lecture-based learning, which generally implies a passive transfer of knowledge to students by an instructor. Lecture-based (theoretical) learning occurs through abstract classroom-based techniques, whereas experiential learning actively engages the learner in a concrete experience. The early contributions of John Dewey and Kurt Lewin preceded the more recent work of David Kolb and the development of his ELT.

\section{John Dewey}

John Dewey is considered by many to be the most influential educational theorist of the 20th century (Kolb, 1984). John Dewey's work was driven by his desire to address the gaps between "traditional" education and "progressive" education and to formulate direction for change in higher education and learning (Hickox, 1991). John 
Dewey's model originally presented concepts similar to the four stages of Kolb's learning cycle. Dewey's conception of impulse, observation, knowledge, and judgment correlates essentially with Kolb's concrete experience, reflective observation, abstract conceptualization, and active experimentation (Hickox, 1991). In 1938, John Dewey wrote his book Experience \& Education in an effort to address the growing debates among scholars regarding the traditional education and progressive education. In this book, Dewey explained progressive education as follows: "Fundamental unity of the newer philosophy is found in the idea that there is an intimate and necessary relation between the processes of actual experience and education" (Dewey, 1938, p. 20).

These contrasting approaches regarding traditional and experiential education remain evident in the 21st century literature. Dewey's work postulated that learning transforms the impulses, feelings, and desires of concrete experience into higher order purposeful action. Dewey acknowledged the transactional relationship between the person and the environment, which is symbolized in the dual meaning of the work experience: (a) both personal and subjective, a person's internal state, and (b) the objective and environmental. These two forms of experience interrelate in very complex ways (Dewey, 1938). Kurt Lewin's work added to this environmental aspect of learning theory with his laboratory-training movement and his concept of life space.

\section{Kurt Lewin}

Kurt Lewin was an early 20th century social psychologist whose work influenced the field of organizational behavior as well as the field of experiential learning. The consistent theme in Lewin's work was his concern for the integration of theory and practice. This theme was most evident in his work on the dynamics of change theory and 
was most established by his work on group dynamics and laboratory-training methods for problem-solving exercises for leaders and decision makers in organizations. These action-oriented training sessions were grounded in Lewin's belief that personal development and true growth of one's intellect required an interaction with one's environment (life space) and the active processes required to adapt to it. The term $T$ group (where $T$ represents training) was one of Lewin's most significant contributions to organizational psychology and experiential learning (Kolb, 1984). Lewin's statement, "There is nothing so practical as good theory" symbolizes his commitment to the integration of scientific inquiry and social problem solving (Kolb, 1984, p. 9). This commitment is demonstrated with the historical event that created the discovery of the Tgroup.

In 1946, a group of four researchers, Lewin, Lipitt, Bradford, and Bennet (cited in Hickox, 1991) designed a new approach to leadership and group-dynamics training for the Connecticut State Interracial Commission. The 2-week training program focused on group discussion and decision making, in which staff and participants treated one another as peers. When the daily sessions were over the staff met nightly to report and analyze the data. Soon the participants requested to be included in the interpretation analysis sessions. When these joint sessions occurred with the participants (subjective views) and the staff (objective views), the discovery was made that learning is facilitated in an environment where there is a dialectic tension and conflict between immediate, concrete experience and analytic detachment (Kolb, 1984). By bringing the experiences of participants and the conceptual models of the staff in an open atmosphere, where inputs from each perspective could challenge the other, a learning environment occurred with 
exceptional vitality and creativity. This series of events started the T-group theory and laboratory-training method (Hickcox, 1991).

During Lewin's studies within organizations, there existed a struggle between the "here and now" experiential orientation and the "there and then" theoretical orientation. To this day, there remains conflict among proponents of the two approaches. Overall, the conflict between experience and theory is not unique to the laboratory-training process and is a primary dynamic of experiential learning itself. This emphasis on the subjective personal experience in learning stood in sharp contrast to the behaviorist theories of learning. The behaviorists supported the classical physical science definitions of knowledge acquisition as an impersonal, logical transaction based on detached, objective observation (Marrow, 1977).

The latter theorists emboldened the belief that learning was a transaction of knowledge or transfer of facts from teacher to student. In contrast, Lewin professed learning to be more of an interactive exchange, emphasizing the active process of learning and reflecting rather than the end product of being taught. Additionally, Lewin professed a strong link between the learning process and the interaction with one's environment (Kolb, et al, 2001). Lewin's theories were deeply grounded in the interaction between environment and learning, with the two always present, interacting and affecting the learning of the individual.

\section{Learning Environments}

Lewin's philosophies on life space (learning and the environment) were closely aligned with the philosophy of contextualism, which focuses on the quality and texture of the immediate event as experienced. In essence, contextualism is associated with 
phenomenology. These two theories are grounded in the concept of the experience of a deeper meaning for the individual involved in the experience. Lewin's laboratory-training movement has had a profound influence on the practice of adult education, training, and organizational development (Kolb, 1984). The T-groups and laboratory method gave primary emphasis to the value of subjective personal experience in learning. Late in the 20th century David Kolb integrated Lewin's life space concept into his learning space concept in experiential learning.

\section{Kolb's Experiential Learning Theory (ELT)}

David Kolb's ELT was developed from and built upon the earlier works of various scholars and emphasized the value of direct hands-on experience for effective learning and also the learning styles of the individual learner. ELT defines learning as "the process whereby knowledge is created through the transformation of experience." According to Kolb (1984), "knowledge results from the combination of grasping and transforming experience" (p. 41). Kolb's ELT is modeled on two dialectically related modes of grasping experience - concrete experiences (CE) and abstract conceptualization (AC) - and two dialectically related modes of transforming experience-reflective observation (RO) and active experimentation (AE).

Kolb and Kolb, (2005a) posited that learning is a process of constructing knowledge that involves a creative tension among the four learning modes that is responsive to contextual demands. The environmental influences on learning are reflected in this learning cycle concept that touches all the bases-experiencing, reflecting, thinking, and acting — in a recursive process that is responsive to the learning situation and what is being learned. 
Kolb developed the Learning Style Inventory in order to assess an individual's preferred learning style. This instrument has identified four learning styles: diverging, assimilating, converging, and accommodating. An individual with diverging style has $\mathrm{CE}$ and RO as dominant learning abilities. These learners perform better in situations that call for generation of ideas, such as "brainstorming." In formal learning situations, people with the diverging style prefer to work in groups, listening with an open mind, and receiving personalized feedback. These learners are interested in people, embrace culture, are emotional, and tend to specialize in the arts and human service professions (Kolb \& Kolb, 2005a).

An individual with an assimilating style has $\mathrm{AC}$ and $\mathrm{RO}$ as dominant learning abilities. People with this preferred learning style are best at assimilating a wide range of information into concise, logical form. These individuals are less focused on people and more interested in ideas and abstract concepts. These learners are more interested that a theory has logical soundness than practical value. In formal learning situations, people with an assimilating style prefer readings, lectures, and exploring analytical models. This style is evident in people working in information and science careers.

An individual with a converging style has $\mathrm{AC}$ and $\mathrm{AE}$ as dominant learning abilities. People with this learning style are best at finding practical uses for ideas and theories. They are good decision makers and problem solvers. These learners prefer to deal with technical tasks rather than with social issues and interpersonal issues. In formal learning situations, people with this style prefer to experiment with new ideas, simulations, laboratory assignments, and practical applications. These individuals tend to work in technology and specialist careers. 
An individual with an accommodating style has $\mathrm{CE}$ and $\mathrm{AE}$ as dominant learning abilities. People with this learning style prefer a hands-on experience. They enjoy carrying out plans and involving themselves in new and challenging experiences. They tend to act on "gut" feelings rather than solely on logical analysis. People with the accommodating style of learning rely more heavily on people for information than on technical analysis. In formal learning situations, they prefer to work with others, to set goals, to do field work, and to test different approaches to completing a project. People with this learning style tend to be employed in action-oriented careers such as marketing, management, and those positions requiring active coordination of activities among various groups. In addition to the formulation of these individual preferences for learning style, experiential learning has been associated with a deeper, more meaningful learning experience due to the engaging nature between the learner and the environment (Kolb \& Kolb, 2005a).

In order to enhance this deeper meaning and active learning experience for their students, many faculty in higher education are incorporating experiential learning into their classroom teachings. Mounting criticisms of the inadequacy of higher education to promote critical-thinking skills and marketable applicable job skills has increased the demand for a more defined and integrated experiential learning curriculum at colleges and universities. The following sections highlight higher education literature examining the use of experience-based learning in a various curricula.

\section{Business and Management}

In one study, Sims and Sauser (1985) incorporated experiential learning into the design of a management curriculum intended to develop managerial competencies in 
business students. They determined that there were seven significant differences in this curriculum that led to increased ability of the students to effectively apply what they have learned: (a) opportunity to face new situations, (b) emphasis on practice versus theory, (c) opportunity to practice direct management scenarios, (d) reliable assessment methods, (e) effective feedback, (f) self-knowledge reflection, and $(\mathrm{g})$ reflection and integration as a key final step in the acquisition of competency.

Gopinah and Sawyer (1999) developed a computer-based enterprise simulation utilizing experiential education methods to bridge the gap between knowledge and direct application to the business world. They specifically noted that theory alone does not prepare the business student to think critically when faced with case scenarios. They supported the contention that the simulation showed that the recursive nature of experiential learning or learning by doing promoted a higher level of strategic decisionmaking ability and the formulation of long term strategy when compared to students who received only lecture-style modalities.

Dyer and Schumann (1993) developed an experiential learning laboratory applied to their marketing course due to their dissatisfaction with the traditional lecture pedagogy:

We believe that, to date, the application of experiential methods in the business classroom has frequently been incomplete and has therefore diluted the promise of experiential process. Educators have spent their time "parroting" the instructional approaches of other teachers rather than "partnering" experience and knowledge as intended by experiential learning models. (p.34).

Dyer and Schumann created a true laboratory component to the senior-level marketing class. They developed the knowledge/experience integration learning model, in which the text assignments and lectures were integrated with experiences generated from two types 
of learning tasks, multiple group projects and multiple individual case studies. Of particular note is their complete elimination of the traditional performance evaluations (multiple choice and essay exams), which were replaced with a focus on the recursive cycle of lecture, discussion, feedback, and hands-on experiences. At the completion of the course, students reported increased levels of critical-thinking skills and the capacity to apply and connect theoretical knowledge with real-life business application.

David Kolb's theory of experiential learning is particularly relevant to education in business and management, nursing, and other health professions. Students in the health professions share a common need to practice knowledge gained from classroom lectures and readings with actual, concrete situations with clients and patients. Kolb's shared emphasis on conceptualization and experience in the development of knowledge is congruent with the goals of a professional nursing education (Laschinger, 1990).

\section{Health Professions and Nursing}

Several studies in the nursing literature have reported that students in nursing and other human service professions tend to fall into the concrete learning style preference, as defined by Kolb's Learning Style Inventory (Hodges, 1988; Huch, 1981; Laschinger \& Boss, 1984). These findings support Kolb and Kolb's (2005a) contention that members of human service professions have concrete, people-oriented learning styles. Laschinger and Boss (1984) found that senior nursing students were significantly more concrete in learning style than were incoming 1st-year students, reflecting Kolb's notion of accentuation of learning style in professional educational programs. It appears nursing students tend to have concrete learning styles and become more active learners as they 
complete their education. This change very likely reflects their increased competence in implementing nursing care as they gain experience in nursing environments.

Kolb's (1984) cycle of learning, which requires the use of a variety of learning modalities, appears to be a valid and useful model for instructional design in nursing education. Kolb (1984) maintained that the current emphasis of professional education programs on the development of specialized learning competencies at the expense of others may interfere with adaptation to later career demands. He further advocated a curriculum that promotes the development of all types of learning competencies to produce balanced learning styles among members of the discipline. This promotion of the development of all types of learning is supported by other researchers who have studied the benefits of learning by doing or active learning versus passive learning.

Holbert and Thomas (1988) referred to Kolb's model as one that provides a "whole brain education." (p. 32).They agreed with Kolb that such an educational approach will more fully develop the potential capabilities of nursing students to enable them to adapt to rapidly changing environments in today's health care system. Another interpretation of this is the concept of bedside manner. Often a clinician has been taught the "hows" and "whys" of disease recognition and diagnosis but not the human element attached to it. Exposure to this aspect of health care- not found in a classroom or textbook — can be afforded the student by participation in a field study or practicum at a work site.

Rush, Peel, and McCracken (2004) conducted a qualitative study on externships in the nursing profession to assess the effect of this training on students' perceptions of their learning experience. The data were collected during the 6-week externship and at a 
6-month follow-up. Focus groups, student journals, and interviews were used to collect data. A major finding of the study was the core theme that the students felt empowered by learning from the inside. Due to the externship experience, the nursing students experienced what it is like to be a "real nurse," as one student commented. In the 6-month follow-up survey, all students reported that their externship experience had the greatest impact on their overall learning experience. Another benefit to the externship is that students begin to self-identify as nurses and to take more ownership in their learning process. In another qualitative study, Turnock, et al examined the needs of those professionals who serve in mentoring roles for students.

Using a case study design and qualitative methods, Turnock, Moran, Scammell, Mallik, and Mulholland (2005) explored the perspectives of practice educators and their role with experienced-based student learning. A common theme that emerged was the mentor's need for better and more standardized training for those serving in these roles. The five disciplines participating in the focus groups were nursing, occupational therapy, dietetics, physiotherapy, and radiography.

A key finding of Turnock et al.'s (2005) study was the recognition that as demand for experiential learning assignments rises, the role of the practice educator needs to be more formalized and recognized with standards and training. Two other professions that advocate the use of active learning and engagement with the environment are counseling and teacher education.

Counseling and Teacher Education

As part of a counseling curriculum, Pelsma and Borgers (1986) developed an experience-based ethics course around the experiential learning cycle, with focus on the 
"how" rather than "what" of learning. Pelsma and Borgers contended that the emphasis on four modes of the learning cycle promotes a deeper learning and development of skills for a responsible and ethical counselor. By providing time for purposeful reflection in a teacher education program, McGlinn (2003) used experiential learning to overcome students' lack of reflection in their teaching. McGlinn claimed that the experiential learning model is effective in promoting change and development in students' selfknowledge about their teaching practices by providing time for reflection.

Engaged learning with the application of learned skills in a work environment in preparation for employment is the hallmark of experiential education (i.e., cooperative education, internships, and clinical rotations). These contemporary terms are grounded in Kolb's concept of learning space, which is related to the learner's interaction with the environment and learning space. This concept regarding the learner's interaction with the environment and learning space deserves revisiting; therefore, this discussion follows in the next section of this literature review.

\section{Learning Space}

In ELT, the experiential learning space is defined by the attracting and repelling forces (positive and negative valences) of the two poles of the dual dialectics of actionreflection and experiencing, creating a two-dimensional map of the regions of learning space. An individual's learning style positions him or her in one of these regions, depending on the equilibrium of forces among action, reflection, experiencing, and conceptualizing. As with the concept of life space, learning space is determined by a combination of individual disposition and characteristics of the learning environment (Kolb \& Kolb, 2005a). 
Kolb's concept of learning space builds upon the earlier works of three previous learning theorists: (a) Kurt Lewin's field theory and his concept of life space (1951), (b) Urie Bronfrenbrenner's work on the ecology of human development (1979), and (c) Lave and Wenger's situated learning theory (1991). Lewin's field theory was grounded in the belief that both person and environment are interdependent variables, which he translated into a mathematical formula: $B=f(p, e)$, where behavior is a function of person and environment (Hickcox, 1991). Life space includes all facts that have existence for the person and excludes those which do not. It embraces needs; goals; unconscious influences; memories; beliefs; events of a political, economic, and social nature; and anything else that may have a direct effect on the learning process of the individual.

Lewin (1951) postulated that these various factors in a given life space are to some degree interdependent, and he strongly maintained that only the dynamic concepts of tension and force can deal with these sets of interdependent facts. This belief that learning takes place best when these different forces are working interdependently is evidenced in Kolb's (1984) four domains of his learning style theory. Urie Bronfrenbrenner's (1979) theories, grounded in ecology, defined the relationship between the learner and the environment in terms of systems.

Bronfrenbrenner (1979) defined the ecology of learning-development spaces as structures he labeled the microsystem, mesosystem, exosystem, and macrosystem. The learner's immediate setting, such as a course or classroom, is called the microsystem, whereas other concurrent settings in the person's life, such as other courses, the resident hall, or family, are referred to as the mesosytem. The formal and informal social structures that influence the person's immediate environment, such as institutional 
policies and procedures and campus culture, are called the exosystem. The overarching institutional patterns and values of the wider culture, such as cultural values favoring abstract knowledge over practical knowledge, that influence actors in the person's immediate microsystem and mesosytem are called the macrosystem (Bronfrenbrenner, 1979). This theory provides a framework for the social-system factors that influence learners' experience of their learning spaces. Situated learning theory is also grounded in the interactions between the learner and the environment. This theory illustrates the dynamics of active learning as a result of situational changes in the environment.

\section{Situated Learning Theory}

Situated learning theory draws on activity theory of social knowledge that professes learning as a transaction between the person and the social environment. These can be constructs of the person's experience in the social environment and not necessarily physical spaces. Situated learning theory builds on the concept that knowledge resides not in the individual's head but in communities of practice (Lave \& Wenger, 1991). Learning is thus a process of becoming a member of a community of practice through legitimate participation (e.g., apprenticeship, internship).

Situated learning theory enriches the learning space concept by reminding researchers that learning spaces should be defined by situations that extend far beyond the teacher and the classroom. Furthermore, these learning spaces include (a) socialization into various communities of practice (e.g., a workplace), (b) identity formation, (c) the transformation of a learner from novice to expert through mentorship and experience in the activities of the practice, and (d) the reproduction and development 
of the community of practice itself as newcomers replace old-timers (Kolb \& Kolb, 2005b).

This concept relates to the contemporary discussions presented in chapter one regarding the call for more active learning of meaningful job-related skills versus the focus on theory and research. John Dewey's extensive writings emphasized his own desire to fill the gaps between traditional and progressive education and he expressed similar views to the contemporary scholars of today. Situated learning theory is embedded in the learning-by-doing philosophy versus the traditional approach (passive teacher-to-student transfer) in the classroom. The concept and working definitions of cooperative education, a form of experiential education, is easily traced back to these earlier learning frameworks incorporating the foundations of sociology, human development, and psychology. Furthermore, cooperative education is deeply grounded in the foundation of situated learning theory. The next section of the literature review focuses on this direct experience approach to learning, namely in the form of cooperative education and its place in higher education.

\section{Cooperative Education}

Cooperative education is a form of experiential learning as well as a form of experiential education. In the literature, these terms have been used interchangeably. This holds true as well for the interchangeability of terms that fall under the umbrella of experiential education, such as internship, externship, apprenticeship, practicum, and cooperative education. Learning is best considered as the process of change that occurs for the individual. Education, on the other hand, is best considered as a transactive process between an educator and student (Itin, 1999). 
For the purpose of this study, these two constructs, learning and education were treated interchangeably, with the belief that they work in concert with one another. In other words, experiential education is rooted in the philosophy of experiential learning, and therefore it is not the intent of this investigator to consider them mutually exclusive but rather wholly integrated. Experiential education was defined by the Association for Experiential Education (1994, p. 1) as, "experiential education is a process through which a learner constructs knowledge, skill and value from direct experience." Cooperative education is an example of the progressive approach to learning as proposed by Dewey (1938) and later by Lave and Wenger (1991) in their discussion of situated learning theory. Experiential education, or learning by doing, includes a number of subsets of individual programs within it. The most common of these programs are cooperative education, internship, externship, college work-study, field experience and research, service learning, practicum, student teaching, clinical rotation, and apprenticeship (Metzger, 2002).

The common thread within all of these types of programs is that they provide students with practical experience. With the exception of college work-study another key commonality is the combination of practical experience and academic study (Chickering, Frank, \& Robinson, 1996). This practical experience is commonly understood to be the development of real-world job skills (e.g., employment skills) in preparation for a successful transition into the workforce for the college graduate. As Kolb (1984) stated, learning is the major process of human adaptation, mastery of an approach that bridges the critical connections between education, work and personal development and empowers students with new skills that they can employ far beyond their search for a career and into all realms of individual growth. (p. 32) 
Cooperative education and internships both combine academic credit with practical work experience. Typically, cooperative education combines classroom-based education with practical hands-on training within a semester-long class. An internship awards academic credit; however, all of the activities take place at the internship site. An internship is typically longer in duration (8-12 weeks) and serves as the culmination of the undergraduate or graduate curriculum. Additionally, an internship can be paid or unpaid. A practicum is a college course, often in a specialized field of study, that provides students with supervised practical application of a previously studied theory (Metzger, 2002). The common theme found among all definitions is the essence of learning by doing. Experiential education (also known as cooperative education) has been well documented and reported in higher education and health professions literature.

During the 1960s James W. Wilson and Edward H. Lyons conducted a national study of cooperative education to establish academic credibility for a major expansion of programs. Their study provided the testimony and credibility for the benefits of these programs, and their primary recommendation was that American education makes wider use of cooperative education (Godfrey, 1989). The Wilson-Lyons Report became the major impetus for the integration of more cooperative education programs in higher education (Heinemann, 1982). The underlying philosophy of cooperative education summarized within this report covered eight educational values, as reported by Ricks, Cutt, Branton, Loken, and VanGyn (1993):

(a) Coordinating work experience with academic curriculum, theory and practice are more closely related, which gives students more meaning to their studies, (b) coordinating work and study increases student's motivation because they develop greater interest, (c) work experience contributes to a greater sense of students' responsibility, greater dependence on themselves, and develops maturity, (d) most students also develop a greater understanding of other people and gain 
communication skills from working with co-workers, (e) the experience helps expose students to the world of work so that students more fully understand and appreciate the meaning of work and the function of the occupation, (f) the experience can help students who lack financial resources to be able to attend and afford to go to colleges, and it also shows the practical, job-related side of education to individuals who may be skeptical about the benefits of higher education, (g) participating faculty are better able to keep abreast with the world of work and plan their curriculum accordingly, and (h) since half of the student body is on site half of the time, cooperative education programs help to utilize college facilities more efficiently. (pp. 8-9)

This last point is of particular interest to this investigator and supports the rationale for this study. Although the merits to both student and employer have been noted for the benefits of experiential education, the selected sites or locations of these work-site learning experiences have not been a focus in the literature. In particular, this investigator was unable to find one study examining the use of on-site college facilities or departments for experiential education (internships or clinical rotation) assignments.

This phenomenon may be explained by the often-held assumption or perception by faculty and students that internships are more valid if experienced at long-established businesses or other employment sectors located off campus. This may be shortsighted. Many campus service and auxiliary departments run legitimate and complex businesses right on campus, serving a wide variety of customers and constituents. These business units afford students the real-world training ground for a variety of professional majors and interests. Anecdotal evidence suggests that many students are repeatedly steered toward the same long-standing off campus businesses due to the faculty advisors' comfort levels or previous exposures to certain options. Anderson, et al (2002) noted that not-for-profit agencies are not as readily used as for-profit entities for internships and cooperative education assignments. 
Anderson, Pulich, and Sisak (2002) examined nonclinical health care internships in not-for-profit health care agencies. They emphasized that these agencies can increase their visibility and help to bridge this perceptual gap by increasing their use of internships and partnering more with colleges and universities. Internships give students an opportunity to apply classroom theory to a work setting in their major area of study. Anderson et al.(2002) noted that an effective intern program can lower recruitment and selection costs, such as advertising for permanent employment staffing.

Offering student internship programs also has value for the educational institutions; such programs can assist them with student recruitment, fund raising, and community-employer partnerships. These programs are viewed as tangible evidence of a school's commitment to providing the valuable work experience for students that will assist in their career goals as well as provide potential employers with skilled employees. Anderson et al. (2002) contended that not-for-profit agencies exposing the faculty advisors and students to their worksite will help to ensure a flow of skilled employees who understand their organizational cultures and provide opportunities to students for future employment. Institutions of higher education provide one such employment opportunity.

Many of the auxiliary departments within these higher education institutions are essentially operating as business units, demanding the same requisite business skills for their students and employees as does private industry. These units are often defined as auxiliaries, student services, or revenue-dependent units. As mentioned earlier, the economy and global market is affecting higher education as well as other sectors of the economy, especially in regards to decreasing public funding and the increasing demand 
to educate students more effectively and efficiently. The demand for the development of critical-thinking skills for students is increasing, given the perception that higher education needs to do a better job in preparing students for a competitive marketplace. One such department in higher education institutions experiencing major transformation due to these major economic and institutional priorities is student health services (also known as college health services).

\section{College Health Services}

College health services arose mainly through the development of adolescent medicine and the dramatic expansion of higher education in the late 19th century and early 20th century (Turner, 2002). By the 1920 s, growing numbers of parents and young people - especially those from racial and ethnic minorities - saw higher education as a means of upward social and economic mobility. Although elite colleges tended to reinforce the status quo by using entrance physical examinations as part of their admissions process to deny admission to those with undesirable physical and mental characteristics, public institutions and more progressive private ones used college hygiene programs to salvage and even rehabilitate unhealthy student bodies. Thus, expanding preventive health measures and clinical services became a way for institutions to deal with the new issues created by an increasingly diverse student population (Prescott, 2007). The main emphases for college health professionals in the mid 19th to early 20 th centuries was to ensure proper physical fitness, high moral standards, proper hygiene, and safety practices for the student body.

\section{Physical Education and Hygiene}


A common title for health center directors was Hygiene Director or Director of Physical Education. During this time period (mid $19^{\text {th }}$ century), the advantage of physical activity on an individual's health status was being recognized and physical education as a field of medical study was being validated. At this time, medical doctors were filling these positions and combining activities in the gymnasium with proper hygiene education in the dormitories and the classroom. This hygiene education included schooling in sexuality, religion, spirituality, and morality. One such medical doctor was Edward Hitchcock, Jr., the Hygiene Director at Amherst College (Prescott, 2007).

Hitchcock, Jr., was profoundly influenced by his father, who was a congregational minister and a strong advocate of the connection between evangelical Christianity and public health reform. Hitchcock, Sr., was appointed to the Amherst faculty in 1825 and was instrumental in establishing an Antivenean Society dedicated to stamping out the consumption of alcohol, tobacco, narcotics, and other "poisons" (cited in Prescott, 2007, p. 32). Hitchcock, Sr., also lectured extensively on the evils of gluttony, which he believed contributed to the "premature procrastination and early decay of students and professional men in our country." (cited in Prescott, p. 32). His son, Edward Hitchcock, Jr., graduated from Harvard Medical School in 1853, studied anatomy in England, and later returned to his alma mater, Amherst College, to assume the position of Hygiene Director in 1854.

Hitchcock, Jr., continued the work of his father in promoting the interconnectedness of spiritual and physical health. He believed that exercise could prevent a variety of morally abhorrent behaviors, including drinking, carousing, and other sexually deviant behavior. According to Hitchcock, Jr., "The best medical authorities 
now regard regular and tolerably severe gymnastic exercise not only as a preventive of this vice, but as a curative agent where this habit has been already formed." For others, regular exercise provides a wholesome way to disperse "superfluous animal spirits" that "built up during long hours of study and prayer" (cited in Prescott, p. 34). This philosophical approach to health care, combining physical health with morality, was ubiquitous in colleges developing during this time period.

In 1885 , Penn State required all students to receive a physical examination upon entry into the college, a practice that had become common at many institutions of higher education by the turn of the century. The Physical Education Director, R. Tait McKenzie, received full faculty status, thereby setting the stage for the validation of the collaborative approach for the physical health and academic education of the student body. Students could not graduate unless they fulfilled the physical education requirement, and they were not allowed to sit for final examinations if they had skipped physical education classes during the preceding semester (McKenzie, 1932). Some students protested this requirement, and some faculty thought that physical education was not a legitimate academic pursuit. It is interesting to note that these differences in opinion among faculty and student affairs personnel continue today. The evolvement and increasing demands of college health services continued transforming, and in the early 1900s the emphasis turned toward public health concerns regarding communicable diseases.

\section{Public Health and Communicable Diseases}

Cornell University experienced a Typhoid epidemic in 1900-1902 due to a tainted water supply. Ithaca fever had been diagnosed and treated in 40-150 Cornell University students at the student infirmary in each of these years (Prescott, 2007). Student infirmary 
had become a common term to describe the evolving role of student health services. This term developed due to the advent of medical and clinical services being added to the hygiene (health and physical education) component initiated during the $1800 \mathrm{~s}$. The flu pandemic of 1918, sexually transmitted diseases, tuberculosis, and smallpox were among several communicable diseases leading to greater parental pressure on colleges to provide proper medical protection - as well as dormitory monitoring - to ensure the safety and well-being of their children. The demands for college health professionals to serve many different needs regarding health education as well as medical treatment continued to grow. At this point college health was forming its own identity as a medical specialty and the perception of the validity of their role continued to grow into the formation of their own professional society (Turner, 2002).

\section{American College Health Association}

To meet these needs, a group of 20 college health professionals organized and formed the American Student Health Association (renamed in 1948 to the American College Health Association [ACHA]). This original meeting was held March 4-5, 1920, and was led by University of Minnesota Health Service Director, John Sundwall (Prescott, 2007). During the decades following World War I, physicians and administrators in college health sought to prove that they were more than company doctors, making a self-conscious effort to upgrade their field by establishing claims to knowledge that other physicians lacked. The formation of the ACHA served to establish the mission, credentials, and standards for the field of college health. This attempt at legitimizing the practice of college health was met with swift opposition from the American Medical Association (AMA). Universities and colleges located in areas with a 
surplus of medical professionals tended to encounter more tensions with local physician groups.

\section{College Health and the AMA}

When the University of Wisconsin established a student health service in 1902, local physicians condemned the university's actions as "a step toward socialized medicine" (Steven, 1989, p. 8). At rural campuses where medical institutions and practitioners were scarce, college health services faced little opposition and quickly established themselves as centers of medical expertise not only for students but also for faculty, their families, and members of the surrounding community. As Princeton University Health Service Director Joseph E. Raycroft (1914) commented, "Since the health interests of the university are closely bound up with those of the town, a natural and harmonious relationship has grown up between these two parts of the community for the promotion of the general health." (p. 708). The AMA also opposed the idea of contract practice, originally proposed by Edward Hitchcock, Jr., in the 1860s for the financing of student health at Amherst College.

The term contract practice refers to a system in which the physician or group of medical providers renders care for a set group of individuals for an annual fee. This is very similar to the term capitation fees, used by health maintenance organizations in the 1980s. In present-day terms, this contract practice fee is understood to be the student health fee at many universities and colleges. Despite opposition from the AMA, who declared this practice "contrary to medical ethics" and sought to have these contract practice physicians "classified as irregular practitioners," (Rosen, 1977, p. 375) contract

practice became increasingly common in the late 19 th and early 20 th centuries. This was 
particularly true in urban areas inhabited by immigrant workers and their families who could not afford traditional fee-for-service (FFS) medical care (Rosen, 1977).

This perception of college health practitioners and other contract practice medical doctors as not as real to those in the community practicing FFS medicine is fading but remains evident today. The reasons for this are rooted is the previously mentioned aggressive opposition by the AMA. The AMA campaigned strongly against this attempt to legitimize this model of medical care. The AMA posited that the contract practice represented substandard care and mimicked that of socialized medicine (cited in Prescott, 2007).

The concept of socialized medicine is misunderstood by many and continues to be politicized to be inferior by various lobbying groups (Goodman, 2005). To this day, the preventive nature of prepaid contract medicine, whether in terms of contracted fees or tax dollars, is misunderstood and since the 1930s -spurred by the Depression and the election of Franklin Roosevelt—socialized medicine emerged as a robust rhetorical weapon to blunt reform (Greenberg, 2007). Interestingly, these same issues are being debated and politicized in Congress for health care reform in 2010. Although the debate regarding health care reform is beyond the scope of this literature review, the early development and lingering perceptions of contemporary student health services (with the original student fee funding model) as a form of socialized medicine is inherently and presently affected by these historical and politicized differences of opinion.

This historical perception also relates to the purpose of this study, which was to determine the current use of college health centers as perceived valid placement sites for cooperative education assignments for students enrolled in their institutions. As noted 
earlier, the demands and complexities for services rendered at college health centers continues to evolve and grow to meet the needs of patients, administrators, parents, and various other constituents in contemporary times. In recent years the greatest challenge has been in the funding and sustainability of health care services, given the increasing costs of health care and declining allocations from tuition dollars and other state funding sources.

In the early 20th century, colleges and universities set up student health fees to fund vaccinations and other treatments for communicable diseases. Colleges added student infirmaries to offer sick students a place to rest overnight with observation. Student health fees were then raised to accommodate these needs as well as the staffing and personnel required to run these units. The benefits of well-trained medical professionals and staff on campus were driven home by the influenza epidemic of 1918 . Even institutions with long-established infirmaries used the epidemic to justify an expansion of campus health care services. University of California, Berkeley, received funding for an infirmary only after the 1906 earthquake, despite repeated earlier requests by the students and opposition from skeptical faculty who believed it was not part of a university's role (Prescott, 2007).

To this day, the competition for funds and the differing perceptions and opinions among faculty regarding the proper place for student services in the hierarchy of importance within an institution of higher education still exists. In response to these home-turf battles, as well as the outside pressures from local physicians and the AMA, college health professionals continue to work on enhancing their image and relationships 
with their constituents. One way to do this was to modify the funding models in college health centers.

\section{Funding Models for College Health Centers}

The traditional student health fee model, which is designed to cover most primary care, including medical office visits, is being increasingly challenged by college administrators, parents, students, taxpayers, and other constituents of higher education. In present day, the student health fee varies greatly among colleges, and the variety and complexity of the services covered by that fee varies greatly. Due to steadily decreasing state appropriations, as well as the high cost of health care, colleges need to supplement their declining or stagnating student fee allocations with other sources of revenue. This other form of revenue can be found by establishing FFS billing in college health facilities. A positive outcome to establishing this model is the ability to increase access to primary health care to faculty, staff, dependents, and the community, who can use their health insurance card right on campus.

This is a progressive initiative in college health and is perceived by some as putting college health centers on par with the established "real" medical community. As mentioned earlier, this FFS model is what the AMA had consistently touted as higher in value than a contracted price or set (student fee) arrangement. As mentioned earlier, this "socialized" approach was politicized and proclaimed by the AMA and others to be inferior to the established FFS financing approach of the community physician groups.

This investigator has noted that the debate among contemporary college professionals as to whether student health centers should bill for services and contract with insurance companies (FFS) tends to be divided among those resistant to change and 
those more contemporary and more open to change. According to Jon Englund (2008), Executive Director of the Center for Student Health and Life, "budgets are too tight to allow the cultural barriers to continue to stand. Accepting a family's current health insurance policy can eliminate the need for fee increases and prevent staffing cuts." (p. 2).

Many school administrators are looking at the feasibility of FSS billing at their college health centers due to increasing complaints from students and parents regarding the ever-increasing student health fee. The cost of health care has grown exponentially in the past two decades and continues to do so. The student health fee alone cannot sustain the required sophistication in staffing and complexity of services needed in college health centers today. This student fee is charged to all students and placed on their tuition bill. Many constituents are questioning why they are paying a set fee for something they may never use and are advocating for a more pay-as-you-go arrangement. Many are proposing the use of FFS billing to augment the student health fee for this purpose.

Increasing amounts of attention are being paid to this topic in the college health arena. Englund (2008) pointed out the increasing complaints from parents and students that they cannot use their insurance card at their student health center that does not contract with health insurance payers. On the other hand, a college health center prepared to bill insurance companies will accommodate the majority of college students who are covered under their parent or parents' plan or the student health insurance sponsored or endorsed by their respective schools (Englund, 2008).

According to a recent report of the Government Accountability Office (2008), $80 \%$ of traditional age (18-23 years) college students have health insurance, namely 
through their parent or parents' plan. This report lends empirical support to those college health centers that have initiated this FFS billing model at their health centers. It is clearly evident that the capacity to bill $80 \%$ of students' insurance plans versus continuing to provide these services at no charge can substantially enhance the revenue and sustainability of these progressive health centers. Many college health professionals opposed to this practice claim that it would put an undo financial hardship on students, claiming that most do not have insurance (LMG, 2009)

This debate among old school and more contemporary leaders in college health centers may continue, however, the empirical as well as anecdotal evidence of change is hard to ignore. In addition, as noted in the previous section, varying opinions and resistance to change has been ever-present in the profession. Most students have health insurance, and the business models of the health centers may need to accommodate that fact. As noted in the previous section, the contemporary college health center is in transition and more in need of well-trained management and business professionals, matching that of the private health care sector and the "real" world of medicine based on a FFS model. The next section of this literature review serves as a summary and synthesizes the literature in relation to the purpose of this study.

\section{Summary}

The practice of college health has transformed greatly over the past 150 years and continues to evolve to this day. It is transforming due to the many economic and social pressures occurring in our society. These include the many regulatory requirements, high cost of health care, the privacy and information protection requirements, and the increasing demand for access to primary care for students, faculty, and staff on college 
campuses. State funding continues to decrease for higher education institutions, and the health care needs of students are becoming more complex.

Health care services are among the most complicated organizational structures in society. The college health service on most campuses is not only a microcosm of the health care and prevention activities existing is society and thus subject to the influence of external health care market and regulatory forces but also must function within a complex institution of higher education (Ericson, Mills, \& Ledlow, 2002).

Within this framework, important guidelines and principles for college health professionals include service quality and economy, patient sensitivity, enabling student personal growth and development, continuous evaluation and improvement, ethical decision making, and the removal of barriers to access by students and employees relating to cost, hours of service, facilities, location, scope of care, and referrals. The more recent changes in college health in the late 20 th and early 21 st centuries involve the organizational transformation of most centers to out-patient, ambulatory facilities from the historical in-patient infirmaries.

These overnight accommodations are no longer offered due to the legal and economic constraints involved with staffing and monitoring them. In addition, more progressive college health facilities are serving more faculty and staff and offering increasing access to primary care and the option for employees and students to use their insurance card conveniently on campus. Access to primary care physicians is anticipated to be one of the most significant health care challenges in the early 21 st century. Most college health facilities today operate as a physician group practice or urgent care model and operate mainly during the day and early evening hours. 
College campus enrollments in the United States range from 100 to over 50,000 students (Ericson et al., 2002). The college health centers are just as diverse in terms of their size, scope of services, and financial acumen. The spectrum of services ranges from a single nurse staffing level with limited services to college health centers offering comprehensive services with medical doctors, ancillary services, health education, and care to faculty, staff, dependents, and community members.

This diversity in college health and the special needs of the varied patient population is one of the profession's greatest strengths (Ericson et al., 2002). According to Kevin Kruger (as cited in McDaniel \& Weiland, 2006), Associate Executive Director of the National Association of Student Personnel Administrators, "Gone are the days when there was just a nurse handing out aspirin. Campuses today recognize that student health issues are directly connected to student retention and academics, requiring more sophisticated response and room for comprehensive services." (p. 1).

This variation in services and emphasis on prevention, acute care medical needs, human development, mental health, regulatory requirements, and financial demands make the college health center an excellent placement site for experiential education, cooperative education, internships, or clinical rotations. This diverse setting is particularly relevant for students seeking work-site internship placements exposing them to the skills needed for employment in health administration, business administration, public health, or applied clinical fields of study such as medicine or nursing.

As noted earlier, one of the major benefits of cooperative education, as listed in the Wilson-Lyons Report, was that "since half of the student body is on site half of the time, cooperative education programs help to utilize college facilities more efficiently" 
(as cited in Metzger, 2002, p. 21-22). Despite this recommendation, this investigator found no studies examining on-campus facilities for work-site cooperative education assignments. The investigator's intent for this study was to address this gap in the literature. This gap was addressed by researching the relationship among heath center director characteristics, school characteristics, and the presence of academic internships and clinical rotations and the directors' satisfaction with them. The following chapter reviews the methodology for this study. 


\section{CHAPTER III}

\section{METHODOLOGY}

As noted in the previous chapter, there is an increasing interest in experiential learning and its importance in enhancing learning outcomes. Although experiential learning opportunities, such as internships and clinical rotations, have been touted as prerequisites to preparing students for employment, no researchers have investigated the use of on-campus auxiliary service departments as placement sites for these assignments.

The purpose of this study was to establish baseline data regarding the use of college health centers as placement sites for experiential education assignments and to explore the relationship among director characteristics, school characteristics, and the presence of academic internships and clinical rotations. This chapter provides information about the research questions, design, methodology, instrumentation, population, procedure, data analysis, and a summary.

\section{Research Questions}

The six research questions used in this exploratory study were designed to establish baseline data on the use of college health centers as placement sites for experiential learning (e.g., academic internships, clinical rotations). Secondarily, the questions were designed to explore the relationships among director characteristics, school characteristics, and the presence of experiential learning activities and the directors' reported satisfaction with these activities. The following variables were 
included in the analyses: (a) school classification, (b) scope of services, (c) publicprivate, (d) teaching classes, (e) medical school, (f) nursing school, and (g) credential of director. The research questions were as follows:

Research Question 1: Are college health centers being utilized as placement sites for experiential learning (academic internships or clinical rotations)?

Research Question 2: What academic departments are using college health centers as placement sites for academic internships assignments for their students, as reported by health center directors?

Research Question 3a: What is the relationship among the following variables: (a) school classification, (b) scope of services, (c) public-private, (d) teaching classes, (e) medical school, (f) nursing school, and (g) credential of director with the presence of academic internships? (e.g., Can these variables predict directors' use of academic internships?)

Research Question 3b: What is the relationship among the following variables: (a) school classification, (b) scope of services, (c) public-private, (d) teaching classes, (e) medical school, (f) nursing school, and (g) credential of director with the presence of clinical rotations? (e.g., Can these variables predict directors' use of clinical rotations?)

Research Question 4a: What is the relationship among the following variables: (a) school classification, (b) scope of services, (c) public-private, (d) teaching classes, (e) medical school, (f) nursing school, and (g) credential of director with directors' satisfaction with clinical rotations? (e.g., Can these variables predict directors' satisfaction with clinical rotations)? 
Research Question $4 \mathrm{~b}$ : What is the relationship among the following variables: (a) school classification, (b) scope of services, (c) public-private, (d) teaching classes, (e) medical school, (f) nursing school, and (g) credential of director with satisfaction with academic internships? (e.g., Can these variables predict directors' satisfaction with academic internships?)

Research Question 5: What are the directors' perceived barriers to their health center serving as a site for academic internships?

Research Question 6: What are the directors' perceived enablers to their health center serving as a site for academic internships?

\section{Design}

The investigator employed a descriptive design with survey methodology for this study. Descriptive design is appropriate for an exploratory study seeking to establish baseline data on a subject or topic being naturally observed. Furthermore, descriptive design is warranted when the researcher seeks the opinion, perceptions, or naturally occurring observations from a given population. An entire population is observed, rather than a sample from which inferences can be made to an entire population. Descriptive studies seek only to observe naturally occurring events in a population. The intent was to establish baseline data on the demographics of college health center directors and their perceptions of experiential learning.

Descriptive statistics, correlation, analysis of variance, chi-square, and regression were utilized to describe the population demographics and to investigate relationships among variables as they related to the satisfaction levels of the directors and the presence of experiential learning activities. Correlation is a statistical technique that measures and 
describes the relationship between two variables. Usually the two variables are simply observed as they exist naturally in the environment- there is no attempt to control or manipulate the variables (Gravetter \& Wallnau, 2004). Correlation measures the direction of the relationship between variables (positive or negative), the form of the relationship (linear or curvilinear), and the degree of the relationship (a perfect correlation identified by a 1.00). Regression seeks to predict an outcome based on one or more predictor variables. Regression is considered by many to a more powerful tool than correlation or analysis of variance because it can reveal the predictive power of a certain variable and it's affect on the outcome (dependent variable) rather than solely establishing a relationship or significant difference between variables. For this study, the investigator employed multiple regression. Multiple regression seeks to predict an outcome from several predictors (independent variables; Field, 2005). The purpose of this study was exploratory in nature and designed to observe and describe any naturally occurring relationships among the established variables. Therefore, the descriptive research design was the most appropriate to carry out this purpose.

This study also employed survey methodology. Survey methodology is conducted for the purpose of obtaining descriptive data from a large population on a phenomenon that cannot be readily observed. According to Winter (2007), the objectives of survey research are description, explanation, and exploration. Therefore, this methodology was appropriate for this study, due to the limited research on this topic. This investigator found no studies examining college health centers and experiential education taking place in those facilities. The following section defines the population surveyed. 


\section{Population}

The population surveyed consisted of college heath center directors. The investigator obtained a mailing list as well as an Excel spreadsheet containing all member institutions and all individual members of the ACHA. In addition to this, the investigator utilized the Internet and professional contacts to gather all information on current health center directors from each state and then integrated this list with the member list acquired from ACHA. This was done in order to ensure that all health centers could be included rather than just those possessing a current membership in ACHA. A total of 849 directors' names, addresses, and emails were tabulated during this process. This process took place over a period of two months in the summer of 2009. All 50 states were included in this final list of health center directors. The investigator used the mailing list to send the presurvey postcards alerting directors that they would be receiving a survey by email within the week. Once the final email list was tabulated, the investigator used a software package survey tool to send them out anonymously.

\section{Survey Tools}

The investigator utilized the StudentVoice assessment software tool to send the emails anonymously and to send out automatic reminders to non-respondents.

StudentVoice is a Web-based online assessment tool for higher education institutions across the United States. The company was founded in 2002 and now has over 400 client schools. Today, StudentVoice is the only specialized, comprehensive assessment program that combines elements of data collection, reporting, organization, and integration (StudentVoice, 2010). The investigator constructed an original survey questionnaire for this study in order to answer the stated research questions. The development of this 
survey instrument was essential, as no previous research existed addressing this particular population and topic. In other words, the questions have not been empirically examined.

The first section of the survey included various demographic information, which included information about the director (e.g., gender, academic credentials, years of experience as the director) and the institution (e.g., the school classification, public versus private). The school classifications were determined using the Carnegie Broad Categories (Carnegie Foundation Classifications, 2008). The four major broad categories used for this study were (a) doctoral-research universities, (b) master's colleges and universities, (c) baccalaureate colleges, and (d) associate's colleges.

The middle section included questions regarding the experiential learning activities (e.g., academic internships, clinical rotations), the scope of services offered at the health centers (e.g., limited versus comprehensive), and the perceived enablers or barriers to experiential learning. The last part of the survey included two questions regarding the directors' reported satisfaction levels with the clinical rotations or academic internships at their institution. The directors' reported levels of satisfaction with these activities was measured using a rating scale using the following format $(1=$ Very dissatisfied, 2 =Somewhat dissatisfied, 3 = Neither satisfied nor dissatisfied, $4=$ Somewhat satisfied, $5=$ Very satisfied) to the question, "How satisfied are you with the academic internships activities at your health center?"

The survey concluded with one open-ended question soliciting any further comments about one thing they would do to improve the academic internships or clinical rotations at their health center. The purpose of including the open-ended question was to gain further perceptions of the health center directors not captured in the previous 
questions (see Appendix A for the survey). The investigator asked specifically for just one response on this last question in order to assist with categorizing the responses for data analysis.

The investigator developed an original survey and established content validity through various meetings and feedback sessions and established reliability for the research questions by conducting a test-retest on the survey questions.

$$
\text { Reliability and Validity }
$$

\section{Content validity}

The investigator solicited an expert panel of 10 college health professionals in order to establish the content validity of the survey items. The investigator solicited the feedback from these volunteers to determine the clarity of the questions and to address any ambiguity in the wording of the questions. A review of the literature regarding the recommended number of panel experts for establishing content validity yielded recommendations between 5 and 15 individuals known to have expertise in the profession being studied (Siegle, 2009). The members of this panel solicited by the investigator were known to have a minimum of one years experience in college health. The investigator solicited this panel while attending the ACHA Annual Meeting in May 2009. The panel met in a group in a room reserved by the investigator. The panel was specifically asked to read the survey questions and to make any recommendations for more clarity. The investigator recorded these comments and made minor changes to the questions as needed to improve clarity and content.

For example, the listed choices on the survey, such as perceived barriers or enablers to academic internships, were determined by asking this expert panel of 
directors to report their own anecdotal observations with these situations in their own schools. The most common ones were listed as choices to check on the survey, and a choice for "other" was included as well. These answers provided the rationale for the choices and content listed in the survey questions. Anecdotal evidence from these sessions revealed a higher use of clinical rotations as opposed to academic internships at college health centers. Further discussion on this observation is presented within the results section in the following chapter. The use of academic internships was indeed reported less frequently by the health center directors. The results of these expert panel discussions proved valuable in the formulation of the survey questions. In particular, the investigator's choice to focus on academic internships for Research Questions 5 and 6 was due to the feedback during these sessions.

\section{Test-Retest Reliability}

The term reliability refers to the consistency of different measurements of the same thing. More specifically, a measurement procedure is said to be reliable if one can make two different measurements of the same thing and obtain identical (or nearly identical) values (Gravetter \& Wallnau, 2004). The correlation between the two scores, and often between individual questions, indicates the stability of the instrument (DeVon et al., 2007). The recommended time intervals between the original test and the retest are somewhat controversial and varied. Recommendations range from a few hours to 6 months. According to Trochim (2005), the longer the time between test administrations, the lower the reliability. This investigator chose a period of one week between test administrations. 
A group of 10 health center directors were solicited to volunteer to do a test-retest to establish reliability. They received the email and link to the survey exactly one week apart, on Mondays. The survey software was programmed to send the survey by email exactly one week apart. Only seven of the original 10 completed both tests, so the other three were not included in the correlation analysis. The investigator found varied opinions in the literature, regarding the recommended correlation coefficient for reliability. Many social science researchers consider a coefficient of .70 to be acceptable (Siegle, 2009). The test-retest results for the categorical questions for the survey yielded an average Pearson correlation of .83 (see Table 1). 
Table 1

Test-Retest Pearson Correlations

\begin{tabular}{lr}
\hline Survey item & $r$ \\
\hline Gender & 1.00 \\
Credential & .94 \\
Teach academic classes & 1.00 \\
Years as director & 1.00 \\
School classification & .73 \\
Public-private & 1.00 \\
Scope of services & 1.00 \\
Nursing school & 1.00 \\
Medical school & 1.00. \\
Clinical rotations & .75 \\
Academic internships & 1.00 \\
Satisfaction clinical & .35 \\
Satisfaction internships & 1.00 \\
\hline
\end{tabular}

Note. The average test-retest correlation was .83 .

$r=.83 ; p<.01$, two-tailed.

\section{Procedure}

Dillman's (2007) methods for Internet survey methodology served as a guide for this study. The purpose of the study, the survey preamble, and the informed consent were linked to the survey. This investigator utilized the guiding principles outlined by Dillman (2007) for Internet surveys, which recommended the survey preamble and that the survey 
itself be short and concise. Once the participants clicked the icon "I agree," to the informed consent, they were immediately brought to the survey (see Appendix A). The participants' responses were completely protected and kept anonymous to the investigator by the software design. The study was approved by the Human Subjects Review Board of Western Kentucky University and the Institutional Review Board of University of Louisville (See Appendix B and C)

As stated earlier, the tabulation of addresses and email lists were used by the investigator to mail the presurvey postcards and to email the survey, respectively. Postcards were sent on Friday, September 18th, in order to alert the directors that they would be receiving an email containing the link to the survey (see Appendix D). According to Mehta and Sivadas (1995) the use of prenotification for email surveys is mandatory. The purpose of sending the postcard was to serve as the preliminary notice of the email to follow, soliciting voluntary participation in the study. It also served to reduce the risk of the ensuing email being deleted because it was not recognized. Use of the delete key makes disposing of a questionnaire request easier and quicker than for any other survey method, even before the full nature of the request appears on the screen (Dillman, 2007).

The first email with the direct link to the survey (http://studentvoice.com/wku/experientiallearning09) was sent out on Wednesday, September 23, 2009. This first original email list contained the 849 tabulated emails. Eighty-eight of these emails bounced back to the server as undeliverable. The original number from which the investigator could establish the final response rate of $35 \%$ was 761. One-hundred and twenty-two valid responses were received after the first email was 
sent. Exactly one week later (September 30th, 2009) the first email reminder was sent to nonrespondents. After this notice, 55 more were received. The second automatically generated reminder email was sent one week later (October 5, 2009). After this reminder, 41 additional responses were received. The third automatically generated email reminder to nonrespondents was sent one week later (October 12, 2009). This resulted in four additional responses. As a last step, the investigator utilized the student health listserv (shs@utk.listserv) to send out an email in a final attempt to reach any director who had not seen the emails or postcards but were subscribed to the college health listserv. This last attempt yielded an additional 44 responses.

An important note here is the design of the StudentVoice software. This software prevents the online survey from being validated more than one time from the same email address. This control is designed to prevent duplicate responses. The investigator included the hotlink to the survey in this final email sent to the listserv. The inclusion of the hotlink directly into the email makes it easier and less time consuming for the respondents to access the survey. Data collection was closed after one month from the first email to the last request. The final number of respondents was 267 out of 761 emails sent, yielding a final response rate of $35 \%$. The follow-up emails were notably effective in increasing the overall response rate.

The advantages of email and Web-based surveys are, most notably, increased speed regarding transmission and the convenience for the respondent (Dillman, 2007). The survey was designed by the investigator to take participants no more than $5-10 \mathrm{~min}$ to complete. This was validated by the investigator during the test-retest phase of the study. It was designed this way in order to maximize participants' willingness to 
complete the survey and to minimize attrition resulting from participants beginning the survey but not finishing it, due to time constraints. The risk of an incomplete survey increases if a person has to $\log$ out and then $\log$ back on again. As such, the intent was for the survey to be completed online and in one brief sitting. As noted earlier, the investigator had three follow-up emails sent to nonrespondents, which included a direct link to the survey to further entice nonrespondents. Schaefer and Dillman (1977) found that inclusion of the replacement survey in a follow-up notice encouraged faster returns and resulted in a higher final response rate. Once data collection ceased, the investigator commenced with data analysis.

\section{Data Analysis}

Data were downloaded electronically form the StudentVoice Website into Excel format and then moved into the Statistical Package for the Social Sciences (SPSS) software (Version 15.0). The research questions were designed to gather baseline data on the current use of college health centers as placement sites for academic internships and clinical rotations.

Descriptive statistics (i.e., frequencies and percentages) were used to describe and summarize the responses to Research Questions 1 and 2. Research Questions 3a and 3b were addressed utilizing logistic regression to explore the predictive value of director and school characteristic variables to the presence of academic internships or clinical rotations at the directors' health centers. Research Questions $4 \mathrm{a}$ and $4 \mathrm{~b}$ were addressed by employing multiple regression to explore the predictive value of director and school characteristic variables on the satisfaction levels of directors regarding clinical rotations or academic internships at their health centers. Research Questions 5 and 6 were 
summarized with descriptive statistics (e.g., summary charts and frequency tables) to report the directors' perceived barriers and enablers to academic internships at their health centers. The following chapter will present the results of the descriptive data on the population and school demographics, the statistical analyses for the research questions, and a summary of these results. 


\section{CHAPTER IV}

\section{RESULTS}

The purpose of this study was to investigate the use of college health centers for experiential learning (academic internships and clinical rotations) and the relationship among director characteristics, school characteristics, and the presence of these activities and the directors' satisfaction with them. This chapter serves to summarize the demographics of the respondents and school characteristics, review the research questions, present the data analyses, and summarize the findings.

The total number of respondents included 267 college health center directors. This represents an overall return rate of $35 \%$. During the past two - three decades, many scholars had advocated for a minimum response rate of $60 \%$ to be considered a strong response rate for survey research. This is not necessarily the case today.

Since 1986 survey response rates have declined steadily for both mail and Internet-based surveys. This is due to the number of surveys people now receive ranging from their grocery store chain to the U.S. Census. In one meta-analysis study of email surveys sent since 1986, the average response rate was $36.83 \%$ (Sheehan, 2001). The study demonstrated a steady decline in the 15 years from 1986 to 2001 . In the following sections of this chapter, the investigator describes the demographics of these 267 respondents, addresses each research question with the corresponding data analysis, and summarizes the results. 


\section{Demographics}

\section{Director Characteristics}

The respondents consisted of 267 college health center directors (see Table 2)

Table 2

Director Demographic

\begin{tabular}{|c|c|c|}
\hline Demographic & Frequency & $\%$ \\
\hline \multicolumn{3}{|l|}{ Gender } \\
\hline Male & 64 & 24.0 \\
\hline Female & 203 & 76.0 \\
\hline Total & 267 & 100 \\
\hline \multicolumn{3}{|l|}{ Education } \\
\hline Baccalaureate & 44 & 16.5 \\
\hline Master's degree (clinical) & 77 & 28.8 \\
\hline Master's degree (nonclinical) & 49 & 18.4 \\
\hline $\mathrm{PhD}$ & 20 & 7.5 \\
\hline MD & 47 & 17.6 \\
\hline Other & 30 & 11.2 \\
\hline Total & 267 & 100 \\
\hline \multicolumn{3}{|l|}{ Teach academic classes } \\
\hline Yes & 57 & 21.3 \\
\hline No & 210 & 78.7 \\
\hline Total & 267 & 100 \\
\hline
\end{tabular}


The demographics of college health centers and health center directors are very diverse. As displayed in Table 3 the cross tabulation shows than many schools have licensed clinical nurses as directors who may provide triage care and administrative duties at some schools. A summary of the cross-tabulation for credential and gender is as follows: baccalaureate, men, 3 (4.69\%), women, 41 (20.2\%); clinical master's, men, 2 (3.13\%), women, 75 (36.95\%); nonclinical master's, men, 19 (29.69\%), women, 30 (14.78\%); PhD, men 7 (10.94\%), women, $13(6.4 \%)$; MD or DO, men, $26(40.63 \%)$, women, $21(10.34 \%)$.

A clear majority of the female directors held clinical master's degrees in nursing, and a majority of the male directors held an MD or DO degree. The credential coming closest to an even distribution among men and women was the $\mathrm{PhD}(10.9 \%$ and $6.4 \%$, respectively). The scope of services data revealed that 54 (85.71\%) of the male directors reported scope of service as comprehensive, whereas $9(14.29 \%)$ reported limited services. In contrast, 99 (49.25\%) of the female directors reported scope of service as comprehensive, whereas $102(50.75 \%)$ reported limited services (see Table 3 ). 
Table 3

Cross-Tabulation A: Gender, Scope of Services, Credential

\begin{tabular}{|c|c|c|c|c|c|c|}
\hline \multirow[b]{3}{*}{ Response } & \multicolumn{6}{|c|}{ Question 2: "What is your gender?" } \\
\hline & \multicolumn{2}{|c|}{ Men } & \multicolumn{2}{|c|}{ Women } & \multicolumn{2}{|c|}{ Total } \\
\hline & Count & $\%$ & Count & $\%$ & Count & $\%$ \\
\hline \multicolumn{7}{|c|}{ Question 8: "What is the scope of your health center's services?" } \\
\hline $\begin{array}{l}\text { Comprehensive (full time: } \\
\text { MDs, ancillaries, health } \\
\text { education) }\end{array}$ & 54 & 85.71 & 99 & 49.25 & 153 & 57.95 \\
\hline $\begin{array}{l}\text { Limited (part time: nursing } \\
\text { visits with triage, part-time } \\
\text { MD hours) }\end{array}$ & 9 & 14.29 & 102 & 50.75 & 111 & 42.05 \\
\hline Total & 63 & 100.00 & 201 & 100.00 & 264 & 100.00 \\
\hline
\end{tabular}

Question 3: "What is your highest academic credential?"

$\begin{array}{lcccccc}\text { Baccalaureate degree } & 3 & 4.69 & 41 & 20.20 & 44 & 16.48 \\ \begin{array}{l}\text { Master's degree (clinical) } \\ \text { MSN, ARNP, MSW, etc. }\end{array} & 2 & 3.13 & 75 & 36.95 & 77 & 28.84 \\ \text { Masters degree (nonclinical) } & 19 & 29.69 & 30 & 14.78 & 49 & 18.35 \\ \text { PhD } & 7 & 10.94 & 13 & 6.40 & 20 & 7.49 \\ \text { MD or DO } & 26 & 40.63 & 21 & 10.34 & 47 & 17.60 \\ \text { Other (please specify) } & 7 & 10.94 & 23 & 11.33 & 30 & 11.24\end{array}$

School Characteristics

The directors classified their schools in the following ways: $106(39.7 \%)$ as research-doctoral, $68(25.5 \%)$ as masters, $87(32.6 \%)$ as baccalaureate, and $3(1.1 \%)$ as associates or community college; $147(55.1 \%)$ were public, and $117(43.3 \%)$ were 
private. In term of the scope of services offered at their health centers, $153(57.95 \%)$

listed them as comprehensive, and $111(42.05 \%)$ listed the service level as limited. When asked if their school has a nursing school, 158 (59.2\%) indicated that it did, and 106 (39.7\%) indicated that it did not; $34(12.7 \%)$ said that their school had a medical school, and $230(86.1 \%)$ indicated that their school did not have a medical school (see Table 4). 
Table 4

School Characteristics

\begin{tabular}{ll}
\hline Responses & Frequency
\end{tabular}

Classification

Research-doctora

106

39.7

Master's

68

25.5

Baccalaureate

87

32.6

Associate's or community college 3

1.1

Total

264

100

School type

Public

147

55.1

Private

117

43.3

Scope of services

Limited

111

41.6

Comprehensive

153

57.3

Total

264

100

Nursing school

Yes

158

59.2

No

106

39.7

Total

264

100

Medical school

Yes

34

12.7

No

230

86.1

Total

264

100

\section{Results of Data Analysis}

Research Question 1

Research Question 1 focused on whether college health centers were being utilized for experiential learning (e.g., academic internships or clinical rotations). 
According to this group of respondents, 127 (47.6\%) indicated they had clinical rotations, whereas 137 (51.3\%) indicated they did not (see Table 5). 
Table 5

Clinical Rotations

\begin{tabular}{ll}
\hline Responses & Frequency
\end{tabular}

Clinical rotations

Yes

127

47.6

No

137

51.3

Total

264

100

No. per year

1

10

8.1

2

23

18.5

3

18

14.5

$4+$

49

39.5

Varies

24

19.4

Medical residents

Yes

43

16.1

No

224

83.9

Total

267

100

Nurse practitioners

Yes

83

31.1

No

184

68.9

Total

267

100

Physical assistants 
Table 5 (continued)

\section{Clinical Rotations}

\begin{tabular}{|c|c|c|}
\hline Responses & Frequency & $\%$ \\
\hline Yes & 22 & 8.2 \\
\hline No & 245 & 91.8 \\
\hline Total & 267 & 100 \\
\hline \multicolumn{3}{|c|}{ Physical therapy } \\
\hline Yes & 7 & 2.6 \\
\hline No & 260 & 97.4 \\
\hline Total & 267 & 100 \\
\hline \multicolumn{3}{|c|}{ Counseling-therapy } \\
\hline Yes & 29 & 10.9 \\
\hline No & 238 & 89.1 \\
\hline Total & 267 & 100 \\
\hline \multicolumn{3}{|c|}{ Medical assistants } \\
\hline Yes & 9 & 3.4 \\
\hline No & 258 & 96.6 \\
\hline Total & 267 & 100 \\
\hline Nursing stu & & \\
\hline Yes & 58 & 21.7 \\
\hline No & 209 & 78.3 \\
\hline Total & 267 & 100 \\
\hline
\end{tabular}


Table 5 (continued)

Clinical Rotations

\begin{tabular}{llc}
\hline Responses & Frequency & $\%$ \\
\hline Other & & \\
Athletic training & 10 & 40.0 \\
Lab techs & 2 & 8.0 \\
Pharmacy tech & 5 & 20.0 \\
Dietetics & 3 & 12.0 \\
Radiology tech & 3 & 12.0 \\
Optometry & 2 & 8.0 \\
Total & 25 & 100 \\
\hline
\end{tabular}

\section{Research Question 2}

Research Question 2 was designed to gather information regarding the specific academic departments that utilized their campus health center for placement of academic interns. Respondents who indicated that their health centers serve as a placement for academic internships were asked to specify which academic departments collaborate with the centers in order to place interns. These departments included health majors (public, education, or administration), counseling and psychology, student affairs, and business administration. The majority were reported to come from health majors: public, health administration, or health education (see Table 6). 
Table 6

Academic Internships

\begin{tabular}{lcc}
\hline Responses & Frequency & $\%$
\end{tabular}

Academic internships

Yes

No

Total

No. per year

1

2

3

$4+$

Varies

Health administration/public health

Yes

Business administration

Yes

No

Total
225

267

100

9

3.4

73

27.7

70.4

100

33.8

22.5

14.1

19.7

9.9

15.7

84.3

96.6

267

100 
Table 6 (continued)

Academic Internships

Responses
Medical school department

Yes

5

1.9

No

262

98.1

Total

267

100

Student affairs

Yes

20

7.5

No

247

92.5

Total

267

100

Nursing school department

Yes

17

6.4

No

250

93.6

Total

267

100

Other

Education-higher education

4

21.0

Social work

7

36.8

Technical school

3

15.7

Exercise science

3

15.7

Health information management

2

10.5

Total

19

100 
Further review revealed that $45(36.3 \%)$ of the directors indicated that they had both clinical rotations and academic internships at their health centers. As noted above, the majority of directors reported having just one or the other, with clinical rotations (48.1\%) being reported more frequently than academic internships (28.0\%).

\section{Research Question $3 a$}

Research Question 3a examined the relationship among director characteristics, school characteristics, and the presence of academic internships. Logistic regression using simultaneous entry was conducted to determine whether director and school characteristics could predict directors' use of academic internships. Logistic regression is the appropriate method of analysis when the outcome variable is dichotomous. In this case the outcome variable was defined as a Yes or No answer regarding the presence or not of academic internships at the directors' health centers. The predictor variables simultaneously entered into the regression were as follows: (a) school classification, (b) scope of services, (c) public-private, (d) teaching classes, (e) medical school, (f) nursing school, and (g) credential of director. Due to the small number of cases identified as associate's or community colleges $(n=3)$, these cases were excluded from the analysis. Chi-square was utilized to examine the overall model for significance.

Regression results indicate that the overall analysis was significant, $\chi^{2}(12, N$ $=258)=50.10, p<.002, R^{2}=.18$. The analysis correctly classified $77.1 \%$ of the cases in terms of the presence or absence of academic internships. Examination or regression coefficients revealed that scope of service (odds ratio $=.27$ ) and education level of director listed as "other" (odds ratio $=.33$ ) were significant predictors in the overall model. Schools with limited services were only $27 \%$ as likely as comprehensive level 
services to have academic internships, and directors with "other" degrees were only $33 \%$ as likely as nonclinical (e.g, administration) master's degree to have academic internships at their health centers. A summary of predictor variables and coefficients are listed in Table 7. 


\section{Table 7}

Summary of Logistic Regression Analysis: School and Director Characteristics

Predicting Academic Internships

\begin{tabular}{lllllll}
\hline Predictor & $\beta$ & $S E \beta$ & Wald & $d f$ & $p$ & $\operatorname{Exp}(\beta)$ \\
\hline School classification & & & & & & \\
Research-doctoral & -0.51 & 0.43 & 1.39 & 1 & .24 & 0.60 \\
Master's & 0.27 & 0.48 & 0.32 & 1 & .57 & 1.31 \\
Scope of services & & & & & & \\
Comprehensive & -1.30 & 0.42 & 9.74 & 1 & .002 & $0.27^{\mathrm{a}}$ \\
School type & & & & & & \\
Public & -0.45 & 0.37 & 1.43 & 1 & .23 & 0.64
\end{tabular}

Teach academic classes

Yes

$$
-0.56 \quad 0.36
$$

1

$.12 \quad 0.57$

Medical school

Yes

$$
-0.26 \quad 0.46
$$

$$
1
$$

.56

0.77

Nursing school

Yes

$$
-0.22 \quad 0.37
$$

$$
0.34
$$

1

.56

Director credential

\begin{tabular}{lcccccc} 
Baccalaureate & -0.12 & 0.73 & 0.02 & 1 & .88 & 0.89 \\
Master's (clinical) & -0.11 & 0.59 & 0.03 & 1 & .86 & 0.90 \\
Master's (nonclinical) & -1.11 & 0.60 & 3.39 & 1 & .07 & $0.33^{\mathrm{a}}$ \\
PhD & 0.27 & 0.79 & 0.12 & 1 & .73 & 1.31 \\
MD & 0.10 & 0.62 & 0.03 & 1 & .88 & 1.10 \\
\hline
\end{tabular}

Note. Reference categories: school classification = baccalaureate; scope of services =

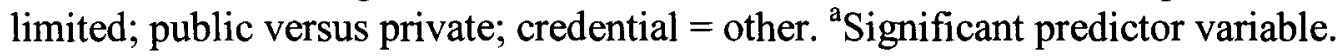




\section{Research Question $3 b$}

Research Question 3b examined the relationship among director demographics, school characteristics, and the presence clinical rotations. Logistic regression utilizing simultaneous entry was utilized to determine whether director and school characteristics could predict directors' use of clinical rotations. The predictor variables simultaneously entered into the regression were as follows: (a) school classification, (b) scope of services, (c) public-private, (d) teaching classes, (e) medical school, (f) nursing school, and $(\mathrm{g})$ credential of director.

Regression results indicate that the overall model was significant, $\chi^{2}(12, N=261)$ $=68.23, p<.001, R^{2}=.23$. The model correctly classified $72.0 \%$ of the cases in terms of the presence or absence of clinical rotations. Examination of regression coefficients revealed that baccalaureate school classification (odds ratio $=.48$ ), scope of services (odds ratio $=.29$ ) and nursing school (odds ratio $=.48$ ) were significant predictors. This result indicates that baccalaureate schools were $39 \%$ as likely as doctoral-research schools to have clinical rotation, health centers with limited services were only $29 \%$ as likely to have a clinical rotation as those with comprehensive services, and those without a nursing school were only $48 \%$ as likely to have clinical rotations as those with a nursing school. The value of $R^{2}=.23$ suggests that $23 \%$ of the variance in the criterion variable is accounted for by the set of predictors. A summary of predictor variables and the coefficients are listed in Table 8. 
Table 8

Logistic Regression Analysis: School and Director Characteristics Predicting Clinical Rotations

Predictor

B

$S E \beta$

Wald

$d f$

$\operatorname{Exp}(\beta)$

School classification

Research-doctoral

$-0.94$

0.39

5.87

.02

$0.39^{\mathrm{a}}$

Scope of services

Comprehensive

$-1.24 \quad 0.35$

12.71

$1<.001$

$0.39^{\mathrm{a}}$

School type

Public

$-0.17 \quad 0.33$

0.27

.60

0.84

Teach academic classes

Yes

$$
-0.11 \quad 0.36
$$

0.09

1

.77

0.90

Medical school

Yes

$0.29 \quad 0.49$

0.35

.55

1.34

Nursing school

Yes

$-074 \quad 0.32$

5.45

.02

$0.48^{\mathrm{a}}$

Director credential

Baccalaureate

$-0.74 \quad 0.60$

1.52

.22

0.48

Master's (clinical)

$-0.83 \quad 0.53$

2.44

.12

0.44

Master's (nonclinical)

$\begin{array}{ll}-0.12 & 0.57\end{array}$

0.05

1

.83

0.89

$\mathrm{PhD}$

$-0.97 \quad 0.69$

2.01

1

$.16 \quad 0.38$

MD

$-0.45 \quad 0.58$

0.62

1.43

Note. Reference categories: school classification = baccalaureate; scope of services =

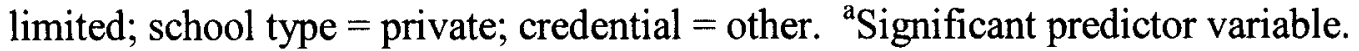




\section{Research Question $4 a$}

Research Question 4a examined the relationship among director characteristics, school characteristics, and satisfaction with clinical rotations. In this case, multiple regression was the appropriate statistical procedure as opposed to logistic regression because the outcome variable was interval level (satisfaction). The predictor variables simultaneously entered into the regression were as follows: (a) school classification, (b) scope of services, (c) public-private, (d) teaching classes, (e) medical school, (f) nursing school, and (g) credential of director.

Multiple regression analysis using simultaneous entry was conducted to determine whether director and school characteristics could predict directors' satisfaction with clinical rotations. Analysis of variance was employed to examine the overall model for significance. Regression results indicate the overall model was not significant, $F(7,135)$ $=1.75, p=.10, R^{2}=.08$. However the presence of a nursing school was a single predictor variable regarding directors' satisfaction with clinical rotations $(p=.005)$. A summary of the predictor variables and the coefficients is listed in Table 9. 
Table 9

Summary of Regression Analysis: School and Director Characteristics Predicting Satisfaction with Clinical Rotations

\begin{tabular}{lcccc} 
Predictor & $\mathrm{B}(S E)$ & $\beta$ & $p$ & $t$ \\
\hline Scope of services & $-0.08(0.18)$ & -.04 & .645 & -0.46 \\
School classification & $-0.12(0.10)$ & -.12 & .234 & -1.20 \\
Public versus private & $0.20(0.17)$ & .11 & .229 & 1.21 \\
Nursing school & $-0.48(0.17)$ & -.26 & .005 & $2.85^{*}$ \\
Gender & $-0.09(0.17)$ & -.05 & .618 & -0.50 \\
Credential & $-0.04(0.05)$ & -.08 & .374 & -0.89 \\
\hline
\end{tabular}

Note. $R^{2}=.08 .{ }^{*} p<.05$. For scope of services, higher values reflect a more limited scope; for school classification, higher values reflect less advanced degree opportunities; for public versus private, higher values reflect private schools; for medical school and nursing school, higher values reflect the absence of these programs; for gender, higher values reflect female gender; and for credential, higher values reflect more advanced degrees.

\section{Research Question $4 b$}

Research Question 4b continued the examination of satisfaction levels, looking this time at academic internships. Multiple regression analysis using simultaneous entry was conducted to determine whether director and school characteristics could predict the directors' satisfaction with academic internships. Analysis of variance was employed to examine the overall model. Regression results indicate the overall model was significant, $F(7,95)=2.24, p=.04, R^{2}=.14$. Scope of services $(p=.046)$ was the only significant predictor variable. Those directors with more comprehensive services at their health centers reported greater satisfaction with the academic internships. Of note, there was 
also a trend toward significance $(p=.06-.09)$ for school classification and nursing school. A summary of the predictor variables and the coefficients is in Table 10.

Table 10

Summary of Regression Analysis: School and Director Characteristics Predicting Satisfaction with Academic Internships

\begin{tabular}{lcccc} 
Predictor & $\mathrm{B}(S E)$ & $\beta$ & $p$ & $t$ \\
\hline Scope of services & $-0.51(0.25)$ & -.24 & .046 & $-2.03^{*}$ \\
School classification & $0.24(0.14)$ & .22 & .073 & 1.81 \\
Public versus private & $-0.13(0.21)$ & -.07 & .518 & -0.65 \\
Medical school & $-0.30(0.25)$ & -.13 & .235 & -1.20 \\
Nursing school & $-0.35(0.19)$ & -.19 & .076 & 1.80 \\
Gender & $-0.19(0.19)$ & -.11 & .324 & -0.99 \\
Credential & $-0.02(0.06)$ & -.03 & .752 & -0.32 \\
\hline
\end{tabular}

Note. $R^{2}=.14 .{ }^{*} p<.05$ For scope of services, higher values reflect a more limited scope; for school classification, higher values reflect less advanced degree opportunities; for public versus private, higher values reflect private schools; for medical school and nursing school, higher values reflect the absence of these programs; for gender, higher values reflect female gender; and for credential, higher values reflect more advanced degrees.

Further descriptive analyses of the directors' reported satisfaction levels, revealed the following: $29.5 \%$ were somewhat satisfied with academic internships, whereas $34.7 \%$ were somewhat satisfied with clinical rotations. Additionally, $35.2 \%$ reported being very satisfied with academic internships, whereas $45.8 \%$ reported being very satisfied with clinical rotations at their health centers (see Table 11). 
Table 11

Directors' Satisfaction

\begin{tabular}{lcc}
\hline Responses & Frequency & $\%$ \\
\hline \multicolumn{1}{c}{ "How satisfied are you with academic internships?" } & \\
Very dissatisfied & 0 & 0.0 \\
Somewhat dissatisfied & 2 & 1.9 \\
Neither satisfied nor dissatisfied & 35 & 33.3 \\
Somewhat satisfied & 33 & 29.5 \\
Very satisfied & 37 & 35.2 \\
Total & 105 & 100 \\
\hline
\end{tabular}

“How satisfied are you with clinical rotations?"

Very dissatisfied

Somewhat dissatisfied

Neither satisfied nor dissatisfied

Somewhat satisfied

Very satisfied

Total

${ }^{\mathrm{a}} M=3.96, S D=0.87 .{ }^{\mathrm{b}} M=4.22, S D 0.86$.
2

1

25

17.4

50

34.7

66

45.8

144

\section{Research Question 5}

Research Question 5 examined the directors' perceptions regarding any barriers they experience to serving as a site for academic internships. Forty-six respondents recorded answers. They were given the option of checking all applicable items, thereby listing more than one barrier. The most common barriers included lack of space for the 
student, lack of awareness from academic units, lack of awareness from career services, lack of interest of health center staff, lack of time for directors to participate, and lack or resources to pay interns. Additionally they were provided an open-ended option to list other barriers; of significant note, all were confidentiality concerns. A frequency of the responses is listed in Table 12 .

Table 12

Barriers to Academic Internships

\begin{tabular}{lcc} 
Responses & Frequency & $\%$ \\
\hline Lack of space to house student & 46 & 17.2 \\
Lack of awareness by academic departments & 24 & 9.0 \\
Lack of awareness of career services & 8 & 3.0 \\
Lack of health care staff interest to be preceptor & 14 & 5.2 \\
Lack of time for directors to participate & 46 & 17.2 \\
Lack or resources to pay interns & 56 & 21.0 \\
None of the above & 14 & 5.2 \\
Total & 194 & 77.8 \\
Other & & \\
Confidentiality concerns & 5 & 6.2
\end{tabular}

\section{Research Question 6}

Research Question 6 examined the directors' perceptions regarding any enablers to serving as a site for academic internships. Fifty-four respondents recorded answers. 
They were given the option of checking all applicable items, thereby listing more than one enabler. See Table 13 for the frequency of responses.

Table 13

Enablers to Academic Internships

\begin{tabular}{lcc}
\hline Responses & Frequency & $\%$ \\
\hline Good relationship with academic units & 54 & 20.2 \\
We have a medical school & 7 & 2.6 \\
We have a nursing school & 29 & 10.9 \\
We are able to pay interns & 7 & 2.6 \\
We have time to mentor the intern & 31 & 11.6 \\
We have room to house the intern & 15 & 5.6 \\
Our staff enjoys working with interns & 63 & 23.6 \\
Interns help get things accomplished & 50 & 18.7 \\
Total & 256 & 100 \\
Other & & \\
Health care staff supports academic mission & 3 & 42.8 \\
Health care staff has strong reputation of campus & 2 & 28.6 \\
Health care staff provides a variety of & 2 & 28.6 \\
opportunities/majors & & 100 \\
Total & 7 & \\
\hline
\end{tabular}

Summary

The descriptive statistics and regression analyses employed in this exploratory study have established the use of clinical rotations and academic internships at these 
college health centers. The results of the logistic regression analyses indicated two predictor variables for the presence of academic internships (scope of services and director credential) and three predictor variables for the presence of clinical rotations (school classification, scope of services, and nursing school). In regard to directors' satisfaction with academic internships, the overall multiple regression analysis was significant, revealing one significant predictor variable (scope of services). There was a trend toward significance $(p=.06-.09)$ for school classification and the presence of a nursing school. Conversely, the overall model for predicting satisfaction with clinical rotations was not significant, but one significant predictor variable emerged (the presence of a nursing school). These repeated findings regarding the presence of a nursing school warrants further discussion.

The presence of a nursing school was evident in both predicting the presence of clinical rotations as well as the directors' satisfaction with both clinical rotations and academic internships at their health centers. Although more directors reported using clinical rotations more frequently than academic internships, the presence of a nursing school emerged in both arenas. Further discussion regarding this finding will be addressed in the following chapter. As noted above, the last two questions of this study examined the directors' perceived barriers or enablers to hosting academic internships at their health centers.

Notably, the focus on further perceptions regarding barriers and enablers for academic internships was warranted given the much lower reported use of academic internships versus the use of clinical rotations. As mentioned in the previous chapter, the investigator included these last two questions—with a focus on academic internships- 
due to the content analysis done during the formulation of the final survey. Most of the expert panel reported less frequent use of academic internships and academic integration as compared to the more ubiquitous use of clinical rotations at their health centers. The results of this study support this contention.

The following chapter provides a discussion of the results, implications and recommendations for practice and suggestions for further research. 


\section{CHAPTER V}

\section{DISCUSSION}

Enhancing the learning outcomes and the development of job-related skills for college students continues to receive attention. Many educators, business leaders, and students have espoused the benefits of experiential learning (or learning by doing) as a way toward this end. According to Charles Osburn, founding trustee of the National Commission for Cooperative Education,

It allows the teacher and the student to gather and contemplate the past as well as to create the future. It provides an atmosphere where students can flourish in the real world of competition and where they can participate actively and effectively in their educational experience. (as cited in Altland, 1990, p. 51)

Although many researchers have studied various private industries and their use of cooperative education (Broughman \& Casella, 1996; Lewis, 2008) and experiential learning with medical students (Meah, Smith, \& Thomas, 2009; Veeser, Hembree, \& Bonner, 2008), there is a paucity of studies examining the use of on-campus facilities for internships and clinical rotations.

It is this investigator's belief, based on anecdotal evidence, that internships do take place at these on-campus departments, but these activities are not widely studied or noted in the literature. Although cooperative education and experiential learning is touted in many industries, there is little apparent research on the use of college health centers for this purpose. The purpose of this study was to explore the use of college health centers for clinical rotations and academic internships as reported by health center directors. 


\section{Summary of Results}

As noted in the previous chapter, the use of academic internships or clinical rotations was reported by these health center director respondents. $48.1 \%$ reported the use of clinical rotations and $28.0 \%$ reported using academic internships The data clearly indicate that clinical rotations are used to a greater degree than academic internships.

Further analyses on Questions $3 a, 3 b, 4 a$, and $4 b$ were performed to explore the relationships among director characteristics, school characteristics, and the presence of academic internships or clinical rotations and the directors' satisfaction levels with these activities.

Question 3a examined the relationship among director characteristics, school characteristics, and the use of academic internships. As noted in the previous chapter, the logistic regression results indicated two predictor variables, scope of services and directors' listing “other" credential versus clinical master's degree. In other words, for this particular group of respondents, those with limited services versus comprehensive were $27 \%$ less likely to have academic internships and directors with a credential classified as "other" (education) were $33 \%$ as likely as nonclinical (e.g, administrative) master's credentialed directors to have academic internships at their health centers. Those schools with less resources and scope of service may have fewer learning opportunities for students, and those directors listing other degrees as compared to nonclinical (e.g., administration) master's may be less inclined toward the academic mentoring role inherent in these student learning internships.

Question $3 \mathrm{~b}$ examined the same variables in relationship to the presence of clinical rotations. The logistic regression results indicated that the overall model was 
significant, with three significant predictor variables: school classification (baccalaureate), scope of services, and nursing school. Baccalaureate schools were $39 \%$ as likely as doctoral-research schools to have a clinical rotation, centers with limited services were $29 \%$ as likely as those with comprehensive services to have clinical rotations, and schools without a nursing school were $48 \%$ as likely as those with a nursing school to have clinical rotations.

Interpretation of these results is fairly intuitive. Those schools classified as baccalaureate tend to be smaller and focused more toward liberal arts as their primary mission. The health centers at these schools may inherently have fewer opportunities—as well as the inclination—at their health centers for sponsorship of clinical rotations. The significance of the scope of services (limited) supports this trend as well. Health centers with a limited scope of service as opposed to a comprehensive level of service may have fewer clinical opportunities for student rotations. Comprehensive levels of service would also tend to offer a fuller array of clinical training in areas such as medicine, nursing, counseling, and allied health opportunities (e.g., physical therapy or radiology technician opportunities). The regression results from Question 3a yielding the significance of a nursing school as a predictor variable regarding the presence of clinical rotations, whereas the presence of a medical school was not a predictor, was one of the most unexpected findings in this study.

In this present study, the presence of a medical school did not serve as a significant predictor for the presence of clinical rotations at these particular college health centers. This finding is interesting in that most observers may inherently assume the presence of a medical school would be a more significant predictor for the presence of 
clinical rotations than that of a nursing school. Future studies examining these two variables is warranted. The data from this study indicated that more schools reported the presence of a nursing school than a medical school. This may be an explanation for this finding. Another explanation maybe that the nursing school faculty or students are more inclined to participate in a clinical rotation at the college health center. Further empirical research may shed light on these possibilities.

For those reporting the presence of a medical school, $24(70.6 \%)$ indicated that they had clinical rotations, whereas $10(29.4 \%)$ indicated that they did not. For those with no medical school, 103 (44.8\%) indicated that they had clinical rotations, whereas 127 (55.2\%) indicated that they did not. For those reporting the presence of a nursing school, $96(58.7 \%)$ indicated that they had clinical rotations, whereas $65(41.1 \%)$ indicated that they did not. For those with no nursing school, 34 (32\%) indicated that they did have clinical rotations, whereas $72(67.9 \%)$ indicated that they did not.

The summary of these categorized responses in percentages augments the regression results indicating that those without a nursing school are $49 \%$ less likely to have clinical rotations. Clearly, nearly $70 \%$ of those respondents with no nursing school did not sponsor clinical rotations, whereas only $45 \%$ of those with no medical school did not have clinical rotations. Table 14 displays the percentage responses regarding the presence of a medical school or a nursing school with the presence of clinical rotations as well as academic internships (see Table 14). The cross-tabulation in Table 14 reiterates the less frequently reported use of academic internships than clinical rotations. Further analysis examined the directors' satisfaction with these activities. 
Table 14

Cross-Tabulation B

\begin{tabular}{lllllll}
\hline & \multicolumn{2}{c}{ Yes } & & & \multicolumn{2}{c}{ Total } \\
\cline { 2 - 3 } \cline { 5 - 6 } Response & Count $\%$ & & Count $\%$ & Count $\%$ \\
\hline
\end{tabular}

Question: 10 "Does your school have a medical school?"

Question 11: "Does your health center serve as a site for clinical rotations?"

Yes

$24 \quad 70.59$

$103 \quad 44.78$

$127 \quad 48.11$

No

$10 \quad 29.41$

$127 \quad 55.22$

$137 \quad 51.89$

Total

$34 \quad 100.00$

230

100.00

$264 \quad 100.00$

Question 14: "Does your health center serve as a placement site for academic internships (nonclinical)?"

$\begin{array}{lrrrrrr}\text { Yes } & 15 & 45.45 & 58 & 25.44 & 73 & 27.97 \\ \text { No } & 18 & 54.55 & 170 & 74.56 & 188 & 72.03 \\ \text { Total } & 33 & 100.00 & 228 & 100.00 & 261 & 100.00\end{array}$

Question 9: “Does your school have a nursing school?"

Question 11: "Does your health center serve as a site for clinical rotations?"

Yes

$93 \quad 58.86$

$34 \quad 32.08$

127

48.11

No

$65 \quad 41.14$

$72 \quad 67.92$

$137 \quad 51.89$

Total

$\begin{array}{llllll}158 & 100.00 & 106 & 100.00 & 264 & 100.00\end{array}$


Table 14 (continued)

Cross-Tabulation B

\begin{tabular}{|c|c|c|c|c|c|c|}
\hline \multirow[b]{2}{*}{ Response } & \multicolumn{2}{|c|}{ Yes } & \multicolumn{2}{|c|}{ No } & \multicolumn{2}{|c|}{ Total } \\
\hline & Count & $\%$ & Count & $\%$ & Count & $\%$ \\
\hline \multicolumn{7}{|c|}{ Question 9: "Does your school have a nursing school?" } \\
\hline $\begin{array}{l}\text { Question } 14: \text { "Does your } \\
\text { health center serve as a } \\
\text { placement site for academic } \\
\text { internships (nonclinical)?" }\end{array}$ & & & & & & \\
\hline Yes & 52 & 33.33 & 21 & 20.00 & 73 & 27.97 \\
\hline No & 104 & 66.67 & 84 & 80.00 & 188 & 72.03 \\
\hline Total & 156 & 100.00 & 105 & 100.00 & 261 & 100.00 \\
\hline
\end{tabular}

Question $4 \mathrm{~b}$ investigated the relationship with these same variables to the satisfaction levels with academic internships. The overall regression model was significant. Only scope of services was a significant predictor variable. Those with more comprehensive services reported greater satisfaction with academic internships.

In addition to this significant predictor, there was a trend toward significance for school classification and nursing school. Again, the presence of a nursing school indicates a potential influence on the results of this study. Those from schools with nursing schools tend to be more satisfied with academic internships. This finding is one of the most significant of this study, along with the empirical data demonstrating the less frequently reported use of academic internships as opposed to the more ubiquitously reported use of clinical rotations at these college health centers. The last two research questions for this study were designed to probe this phenomenon further. 
Research Question 5 examined the directors' perceived barriers to having academic internships at their health centers: $56(21.0 \%)$ of the respondents checked lack of resources to pay interns, $46(17.2 \%)$ checked lack of time for directors to participate and lack of space to house the student, $24(9.0 \%)$ checked lack of awareness by academic units, 14 (5.2\%) checked lack of interest for staff to participate, 8 (3.0\%) listed lack of awareness from career services to recommend the health center, and $16(15.2 \%)$ listed "other" (confidentiality issues, too many other demands, and limitations in staffing).

Research Question 6 examined the successors (enablers) to serving as a site for academic internships: $63(23.6 \%)$ checked Our staff enjoys working with the students, 54 (20.2\%) checked We have a good relationship with academic units, 50 (18.7\%) checked Interns help get things accomplished, $31(11.6 \%)$ checked We have time to mentor the intern $29(10.9 \%)$ checked We have a nursing school, 15 (5.6\%) checked We have room to house the intern, $7(2.6 \%)$ checked We are able to pay interns, $7(2.6 \%)$ checked We have a medical school, and $12(11.4 \%)$ listed other (college of pharmacy, a variety of majors that can benefit from exposure to college health, strong reputation on campus for providing good student learning experiences, and a good relationship with the medical college serving as a research site). (See Appendix A for all responses.)

The fact that $29(10.9 \%)$ of the respondents signified that one of the enablers to serving as an academic internships site was the presence of nursing school is an interesting observation. As discussed earlier, regarding Research Question 3b, logistic regression analysis revealed that the presence of a nursing school was a significant predictor for the presence of clinical rotations. In addition, there was a trend toward significance with this variable when examining the presence of academic internships. As 
noted here, 29 of the directors reported that the presence of a nursing school enables the success of their academic internships. Of note, those reporting that the presence of a medical school was an enabler to providing academic internships was much lower at 7 responses. The investigator concluded the survey with an open-ended question for the respondents to augment the results of these questions.

The investigator included an open-ended question at the end of the survey in order to solicit further descriptive information. The question read, "What is the one thing you would do to improve upon the academic internships or clinical rotations at your health center?" A total of 113 individuals responded to this last question. The responses were tabulated into the categories representing the major themes in these open-ended responses (see Table 15). A detailed list of each of the individual responses can be seen in Appendix A. 
Table 15

Open-Ended Question Responses

\begin{tabular}{ll}
\hline Theme & Frequency \\
\hline
\end{tabular}

More time

Additional staffing

Additional space

Additional funding

Quality students

Better communication with academics

More specific goals

More internship areas

Not applicable-no change

Miscellaneous

Total

113

Note. The open-ended question was "What is the one thing you would do to improve upon the academic internships or clinical rotations at your health center?"

In the previous sections, a thorough review of the research questions, discussion of the results, additional cross-tabulations, and a summary of responses to the open-ended question on the survey have been presented. The interpretation of the findings, implications for practice, and suggestions for further research is addressed in the following sections.

\section{Interpretation of Findings}

This exploratory study was conducted using a descriptive design with survey methodology. The descriptive data of these 267 health center directors provide a view of 
the demographics of these respondents' schools, scope of services, and the use of clinical rotations or academic internships at these college health centers. The high female response rate supports the general perception that many college health centers have licensed clinical nurses as the director $(36.9 \%)$; the males with clinical masters degrees was a mere $3.1 \%$. The majority of male directors $(29.7 \%)$ had a non-clinical master's (e.g., administration) or an MD or DO degree (40.6\%). The female directors with nonclinical (e.g., administration) masters degrees was $14.7 \%$, and those women with MD or DO degrees was $10.3 \%$.

The majority of the male directors were reported being at schools with comprehensive services (85.7\%); female directors at these full service centers was $49.3 \%$. Half of the female directors were located at schools with limited services (50.7\%), whereas $14.3 \%$ of the male directors were. A common phenomenon readily observed in the field of college health is seen in those schools with limited services. As noted above, most of these centers have nurse-trained female directors. They serve dual roles as the source of nurse triaging services as well as conducting the administrative duties inherent within these service levels.

College health nursing has a rich and proud tradition (Crihfield, 1995). At the ACHA Annual Meeting, there are often sectional meetings specifically for nurse-directed health centers. They have unique demands, which would merit future study in order to glean further insight to these centers in comparison to others. The descriptive data in the present study serve as an effective snapshot of the various demographics of college heath centers and that of the directors. 
As noted in the historical perspectives of college health in chapter II, the complexities of college health centers are increasing due to the rising cost of health care, financial pressures, and a growing patient population due to increases in college enrollment. This is followed by an increasing demand for the skilled administrative personnel to manage them, especially in regards to the billing and financial aspects more inherent at college health centers today. It is a common understanding that the need and demand for business training and health care administration is a growing need in college health as well as in the private sector. It is this concept that supports the intent of this study, which was to explore the use of college health centers as a place to train these students in these fields with academic internships in various business and health care administration majors.

As described earlier, the empirical data in this study clearly indicated a more frequent use of college health centers for clinical rotations than for academic internships. Although it is positive that clinical rotations are ubiquitous, the low usage of college health centers for academic internships is information about which college health professionals may make note and upon which they can strive to improve. As discussed earlier, the need for administrative and business trained leaders in college health is growing, yet according to these responses, few college health centers are being used as placement sites for these academic interns.

This may be because of the perceived barriers mentioned by the directors; namely, academic units' lack of awareness of health center availability, lack of space, and lack of time. Barriers will always remain unless someone begins the effort of removing 
them. However, the enablers to successful academic internships mentioned can be adopted by more campus health centers, and these have implications for practice.

\section{Implications for Practice}

One enabler in particular was having a good relationship with academic units on campus. These relationships, like any other, are initiated, fostered, and then maintained. In order for these health centers to be recognized as available, it is incumbent upon the directors and health center staff to participate in outreach and educational endeavors with the academic units on campus. It is this investigator's experience that most academic advisors are unaware of the nonclinical, administrative training opportunities available at college health centers. This holds true for both health centers with comprehensive services as well as those with limited services. In addition to expanding awareness of the student learning opportunities which benefits the health center, the faculty advisors see this as a help to them in placing their various interns. Higher education in general is under pressure from businesses as well as students to continually adapt to changes in the environment and improve upon the training in job skills for their students (Fischer \& Glenn, 2009).

Another enabler commonly described was that the interns help the health center get things accomplished. This describes the true intent of experiential learning: learning by doing. As state allocations continue to decline for state-funded universities, many departments are revisiting their business practices and strategic initiatives. College health centers are meeting these changes by embracing staffing efficiencies, billing and insurance, expanding primary care to all campus members and their families, and in essence, joining the medical community. This enhances the need for interns to be placed 
in college health centers for the same reasons they have traditionally been placed in hospitals and academic medical centers. The understanding in the health care industry is that the need for effective medical practice administrators is increasing and that hospitals are not seen as the only path to health care administration any longer. College health centers serving as primary care and urgent care facilities can serve to enhance the learning outcomes of students by providing them with on-site academic internships.

Due to the evolving complexities and levels of service, college health centers can provide a wide variety of experiential learning for their students. They provide the opportunity for clinical rotations and academic internships in various areas, such as business (marketing, finance, accounting, and management), health administration (billing and collections, patient satisfaction and safety, and provider credentialing), counseling, and training in leadership studies. The results of this study demonstrate that the use of clinical rotations is more frequently used than academic internships at college health centers.

It is incumbent upon the health center staff to conduct outreach efforts and relationship building with academic units in order to increase the awareness of these opportunities for academic internships. As mentioned earlier, this can provide a win-win situation for the faculty advisors, the student's learning experience, and the health center staff's ability to get things accomplished. The aforementioned implications for this study and recommendations for practice offers other scholars baseline data upon which they can continue further empirical research in this area.

Suggestions for Further Research 
This present study focused specifically on the health center directors' satisfaction with clinical rotations and academic internships. Further study, specifically focusing on overall job satisfaction of the health center directors, is warranted. This would be a particularly prudent study given the demonstrated diverse organizational structures, director demographics and credentials, and scope of services among college health centers. A comparison study examining any potentially significant differences based on these variables may prove enlightening and useful to college health professionals.

As mentioned in the previous chapter, the significance of the presence of a nursing school in predicting the presence of clinical rotations as well as satisfaction with them, in addition to demonstrating a trend toward predicting satisfaction with academic internships, was unexpected and a significant finding of this study. Further research into what variables relate to this perception regarding the predictive role of nursing schools is warranted.

In addition, this investigator recommends further research focusing on the perceptions of other health center staff members, students, or faculty regarding academic internships and clinical rotations at college health centers. It would be interesting to see whether the significance of the same predictors would correlate with those emerging for the directors examined in this study (e.g., the presence of a nursing school). This present study added to the field of knowledge by establishing baseline data in the field of experiential learning and college health that was specifically limited to the perceptions of college health center directors regarding academic internships and clinical rotations.

Further empirical work is recommended to educate decision makers and various constituencies regarding the availability and effectiveness of on-campus college health 
centers for both academic internships as well as clinical rotations. Furthermore, these studies may promote discussion and interest in integrating the use of on-campus facilities into the experience-based learning curricula being increasingly examined in higher education. 


\section{REFERENCES}

Allen, C. (1998). NACE employer benchmark recruitment activities. Journal of Career Planning and Employment, 58(3), 25-30.

Altland, J. T. (1990). A study of the contributions of Major Albert Sobey to American industrial cooperative education. Dissertation Abstracts International, 51 (05), 158.

American Psychological Association Board of Affairs. (1997). Learner-centered psychological principles: A framework for school redesign and reform. Retrieved April, 11, 2009 from http://www.apa.org/governance/bea/learner-centered.pdf

Anderson, P., Pulich, M., \& Sisak, J. (2002). A macro perspective of non-clinical student internship programs. Health Care Manager, 20(3), 59-68.

Association for Experiential Education. (1994). AEE definition of experiential education. Boulder, CO: Association for Experiential Education.

Bennis, W. G., \& O'Toole, J. (2005). How business schools lost their way. Harvard Business Review. Retrieved March 4, 2010, from http://hbr.org/2005/05/howbusiness-schools-lost-their-way/ar/1

Boyatzis, R. E., Cowen, S. S., \& Kolb, D. A. (1995). Innovation in professional education: Steps on a journey from teaching to learning. San Francisco: JosseyBass.

Bransford, J. D., Brown, A. L., \& Cocking, R. R. (2000). How people learn: Brain, mind, experience and school. Washington, DC: National Academy Press.

Bronfrenbrenner, U. (1979). The ecology of human development. Cambridge, MA: Harvard University Press.

Brougham, C. E., \& Casella, D. A. (1996). The new entry level for career jobs: Student working pays off. In R. Kincaid (Ed.), Student employment: Linking college and the workplace (pp. 95-101). University of South Carolina: National Resource Center for the Freshman Year Experience \& Students in Transition.

Caine, R., Caine, G., McClinitic, C., \& Klimek, K. (2005). Brain/mind learning principles in action. Thousand Oaks, CA: Corwin Press. 
Carland, J. W., Carland, J. C., \& Dye, J. L. (1994). Accounting education: A cooperative learning strategy. Accounting Education, 3(3), 223-236.

Carnegie Foundation Classifications. (2008). Retrieved January 24, 2009, from $\mathrm{http}: / / \mathrm{www} . c a r n e g i e f o u n d a t i o n . o r g /$ classifications/index.asp?key=791

Chickering, A. W., Frank, L., \& Robinson, V. (1996). Encouraging student development through student employment. In R. Kincaid (Ed.), Student employment: Linking college and the workplace (pp. 11-24). University of South Carolina: National Resource Center for the Freshman Year Experience \& Students in Transition.

Chudowsky, N., \& Pellegrino, J. W. (2003). Large-scale assessments that support learning: What will it take? Theory Into Practice, 42, 75-83.

Crihfield, C. (1995). College health: A nursing perspective. Journal of American College Health, 43(6), 253-261.

DeVon, H. A., Block, M. E., Moyle-Wright, P., Ernst, D. M., Hayden, S. J., Lazzara, D. J., et al. (2007). A psychometric toolbox for testing validity and reliability. Journal of Nursing Scholarship, 2, 155-164.

Dewey, J. (1938). Experience \& Education. New York: Collier MacMillan.

Dillman, D. A. (2007). Mail and Internet surveys (2nd ed). Hoboken, NJ: Wiley.

Dyer, B., \& Schumann, D. W. (1993). Partnering knowledge and experience: The business classroom as laboratory. Marketing Education Review, 3, 32-39.

Englund, J. (2008). The economy and college student health. Retrieved November 14, 2009, from http://insidehighered.com/views/2008/

Ericson, W. H., Mills, D. M., \& Ledlow, G. R. (2002). Administration and financing of college health. In S. H. Hurley \& J. L. Hurley (Eds.), The history and practice of college health. Lexington, KY: University of Kentucky Press.

Field, A. (2005). Discovering statistics using SPSS ( $2^{\text {nd }}$ ed.). Thousand Oaks, CA: Sage Publications.

Fischer, K., \& Glenn, D. (2009). Students and businesses demand more training in job skills. Retrieved January 5, 2009, from http://chronicle.com/article/StudentsBusiness-Demand/48216

Fleming, D. E., Mauriello, Stice, S. M., Mckaig, R. G., \& Ludlow, J. B. (2003). A comparison of slide/audiotape and Web-based instructional formats for teaching normal intraoral radiographic anatomy. The Journal of Dental Hygiene, 77(1), 27-35. 
Frontczak, N. T. (1998). A paradigm for the selection, use and development of experiential learning activities in marketing education. Marketing Education Review, 8(3), 25-33.

Gardner, P. D., \& Liu, W. (1997). Prepared to perform? Employers rate work force readiness of new grads. Journal of Career Planning and Employment, 57(3), 33 56.

Godfrey, J. T. (1989). What created the climate for the growth of cooperative education? Journal of Cooperative Education, 25(2), 30-37.

Goodenow, C. (1992). School motivation, engagement and sense of belonging among urban adolescent students. Paper presented at the American Educational Research Association, San Francisco.

Goodman, J. (2005). Five Myths of Socialized Medicine. Cato Institute Letter. Winter 2005, Vol 3 no 1 Retrieved March 4, 2010 from

http://www.cato.org/pubs/catosletter/catosletterv3n1.pdf

Gopinah, C., \& Sawyer, J. E. (1999). Exploring the learning from an enterprise simulation. Journal of Management Development, 18(5), 477-489.

Government Accountability Office. (2008). Report to the Committee on Health, Education, Labor, and Pensions, U.S. Senate. Special Report: College students and health insurance. Retrieved September 2, 2008, from http://www.gao.gov

Gravetter, F. J., \& Wallnau, L. B. (2004). Statistics for the behavioral sciences (6th ed). Belmont, CA: Wadsworth/Thomson Learning.

Greenberg, D. (2007). Who's Afraid of Socialized Medicine? Two dangerous words that kill health-care reform. Retrieved March 4, 2010 from http://www.slate.com/id/2175477/

Heinemann, H. N. (1982). Cooperative education in the United States of America: An historical perspective. Journal of Cooperative Education, 19(1), 1-14.

Hickox, L. K. (1991). An historical review of Kolb's formulation of experiential learning theory. Dissertation Abstracts International. (UMI No. 9125144)

Hitchcock, E. (1861). Amherst College Archives and Special Collections. Edward and Mary Judson Hitchcock Family Papers. Retrieved March 4, 2010 from http://asteria.fivecolleges.edu/findaids/amherst/ma2 bioghist.html

Hodges, S. (1988). Individual learning styles of student nurses, their teacher and ward sisters. Journal of Advanced Nursing, 13, 341-344.

Holbert C., \& Thomas, K. (1988). Toward whole-brain education in nursing. Nurse Educator, 13(1), 30-34. 
Huch, M. (1981). Adult students locus of control, learning style and satisfaction with a baccalaureate nursing program. Unpublished doctoral thesis, University of Mississippi.

Itin, C. M. (1999). Reasserting the philosophy of experiential education as a vehicle for change in the 21st century. The Journal of Experiential Education, 22(2), 91-98.

Johnson, J. L. (2005). The use of experiential learning in improving $M B A / E M B A$ program outcomes Retrieved November 2, 2009, from http://www.nsee.org

Keeling, R. P. (Ed). (2006). Learning reconsidered 2: Implementing a campus-wide focus on the student experience. NASPA. Washington, D.C.

Keeton, M., \& Tate, P. (Eds). (1978). Learning by experience-What, why, how. San Francisco: Jossey-Bass.

Kolb, D. A. (1984). Experiential learning: Experience as the source of learning and development. Englewood Cliffs, NJ: Prentice-Hall.

Kolb, D. A., Boyatzis, R., \& Mainemelis, C. (2001). Experiential learning theory: Previous research and new directions. In R. Sternberg \& L. Zhang (Eds.), Perspectives on cognitive learning and thinking styles (228-247). Mahwah, NJ: Erlbaum.

Kolb, A. Y., \& Kolb, D. A. (2005a). Learning styles and learning spaces: A review of the multidisciplinary application of experiential learning theory in higher education. Unpublished working paper, Case Western Reserve University, Cleveland, Ohio. Retrieved November 3, 2008, from http://www.nsee.org

Kolb, A. Y., \& Kolb, D. A. (2005b). Learning styles and learning spaces: Enhancing experiential learning in higher education. Academy of Management Learning \& Education, 4(2), 193-212.

Kolb, D. A., Rubin, I. M., \& McIntyre, J. (Eds.). (1971). Organizational psychology: An experiential approach. Englewood Cliffs, NJ: Prentice Hall.

Kretovics, M. A., \& McCambridge, J. A. (1998). Determining what employers really want: Conducting regional stakeholder focus groups. Journal of Career Planning and Employment, 58(2), 25-27.

McDaniel, S., \& Wieland, G. (2006). Good medicine: How institutions can meet the needs of the modern student with a state-of-the-art healthcare facility. Retrieved December 1, 2008, from http://www2.universitybusiness.com/viewarticle.aspx?articleid=214\&pf $=1$

Laney, J. D. (1989). Experience and concept-label-type effects on first-graders' learning, retention of economic concepts. Journal of Educational Research, 82, 231-236. 
Laschinger, H. K. (1990). Review of experiential learning theory research in the nursing profession. Journal of Advanced Nursing, 15, 985-993.

Laschinger, H. K., \& Boss, M. W. (1984). Learning styles of nursing students and career choices. Journal of Advanced Nursing, 9, 375-380.

Lassan, R. (1984). Learning style differences: Registered nurse students vs. generic student nurses at the baccalaureate level. Educational Resources Information Center. (ERIC Document Reproduction No. ED240318)

Lave, H., \& Wenger, E. (1991). Situated learning: Legitimate peripheral participation. Cambridge, UK: Cambridge University Press.

Lawson, L. (2007). The economics of experience-based higher education. Atlantic Economics Journal, 35, 23-31.

Lewin, K. (1951). Field theory in social science; selected theoretical papers. D. Cartwright (ed.). New York: Harper \& Row.

Lewis, C. (2008). Experiential learning: Higher education curriculums put students in real world, think-on-their-feet settings. San Diego Business Journal. Retrieved December 31, 2009, from http://www.sdbj.com

LMG (Lookout Mountain Group) (2009). Position Paper. Considering Health Care Reform for the College Student Population. Retrieved March 4, 2010 from http://www.lookoutmountaingroup.net/

Marrow, A. J. (1977). The practical theorist: The life and work of Kurt Lewin. New York: Teachers College Press.

McGlinn, J. M. (2003). The impact of experiential learning on student teachers. Clearing House, 76(3), 143-147.

McKenzie, R. T. (1932). Physical education at the University of Pennsylvania - and the Gates plan. Research Quarterly, 3(1) 19-20.

Meah, Y., Smith, E., \& Thomas, D. (2009). Student-run health clinic: Novel arena to educate medical students on systems-based practice. Mount Sinai Journal of Medicine, 76, 344-356.

Mehta, R., \& Sivadas, E. (1995). Comparing response rates and response content in mail versus electronic surveys. Journal of the Market Research Society, 4(37), 429440.

Mentkowski, M., \& associates. (2000). Learning that lasts: Integrating learning, development and performance in college and beyond. San Francisco: Jossey-Bass. 
Mentkowski, M., \& Strait, M. (1983). A longitudinal study of student change in cognitive development, learning styles and generic abilities in an outcome centered liberal arts curriculum (final report to the National Institutes of Education). Milwaukee, WI: Alverno College.

Merritt, S. (1983). Learning style preferences of baccalaureate nursing students. Nursing Research, 32(6), 367-372.

Metzger, S. V. (2002). Employers' perceptions of the benefits of college internship programs. Dissertation Abstracts International. UMI No. 3043264

Mintzberg, H. (2004). Managers not MBAs: A hard look at the soft practice of managing and management development. San Francisco: Berrett-Kochler.

Mintzberg, H. (2005). Managers not MBAs: Debating the merits of business education. Retrieved April 5, 2009, from http://mitworld.mit.edu/video/302/

National Association of Colleges and Employers. (2000). Principles for professional conduct for career services and employment professionals. $2000 \mathrm{NACE}$ Directory, p. xviii. Bethlehem, PA.

Palmer, P. (1998). The courage to teach. San Francisco: Jossey-Bass.

Pelsma, D. M., \& Borgers, S. B. (1986). Experience-based ethics: A developmental model of learning ethical reasoning. Journal of Counseling and Development, 64, $311-314$.

Prescott, H. M. (2007). Student bodies: The influence of student health services in American society \& medicine. Ann Arbor, MI: The University of Michigan Press.

Raycroft, J. E. (1914, May 15). Safeguarding the health of college students. Science, 39, $707-711$.

Reardon, R., Lenz, J., \& Folsom, B. (1998). Employer ratings of student participation in non-classroom-based activities: Findings from a campus survey. Journal of Career Planning and Employment, 58(4), 36-39.

Reynolds, A. J. (1991). Effects of an experiment-based physical science program on cognitive outcomes. Journal of Experiential Education, 84, 296-302.

Ricks, F., Cutt, J., Branton, G., Loken, M., \& VanGyn, G. (1993). Reflections on the cooperative education literature. Journal of Cooperative Education, 29(1), 6-23.

Rosen, G. (1977). Contract of lodge practice and its influence on medical attitudes to health insurance. American Journal of Public Health, 67(4), 374-378.

Rush, K. L, Peel, K., \& McCracken, B. (2004). Empowered learning on the inside: An externship experience. Nursing Education Perspective, 25(6), 284-294. 
Schaefer, D., \& Dillman, D. A. (1977). Development of a standard e-mail methodology: Results of an experiment. Public Opinion Quarterly, 62, 378-397.

Sheehan, A. (2001) E-mail survey response rates: A review. Retrieved December 26, 2009, from http://jcmc.indiana.edu/vol6/issue2/sheehan.html

Siegle, D. (2009). Instrument Reliability. Retrieved December 26, 2009, from http://www.gifted.uconn.edu/siegle/research/instrument.

Sims, R. R., \& Sauser, W. I., Jr. (1985). Guiding principles for the development of competency-based curricula. The Journal of Management Development, 4(5), 5165 .

Steven, R. (1989) In sickness and in wealth: American hospitals in the twentieth century. Baltimore: Johns Hopkins University Press.

StudentVoice (2010). Retrieved, March $5^{\text {th }}, 2010$ from http://www.studentvoice.com/app/views/about/company/history.aspx

Terenzini, P., \& Pascarella, E. (1994). Living with myths: Undergraduate education in America. Change, 28, 28-32.

Trochim, W. M. (2005). The research methods knowledge base (2nd ed.). Retrieved December 26, 2009, from http://trochim.human.cornell.edu/kb/index.htm

Turnock, C., Moran, P., Scammell, J., Mallik, M., \& Mulholland, J. (2005) The preparation of practice educators: an overview of current practice in five healthcare disciplines. Work Based Learning in Primary Care, 3, 218-235.

Veeser, P., Hembree, W., \& Bonner, J. (2008). The history of SHSAAMc: Student health services at academic medical centers. Journal of American College Health, 57, $115-120$.

Whitney, M., \& Caplan, R. (1978). Learning styles and instructional preferences of family practice physicians. Journal of Medical Education, 53, 684-686.

Winter, P. (2007). Lecture notes, July 8, 2007. Survey research and attitude measurement. Louisville, KY: University of Louisville. 


\section{Appendix A}

Experiential Learning: A Review of College Health Centers

Description: We will be running pre-trial runs first and then officially sending out in September. We will communicate if we want to keep pre-trial data and run a 2nd survey or delete the data.Communication for this survey needs to go to: libby.greaney@wku.edu kathryn.steward@wku.edu

kataun.boka@wku.edu jataun isenhower@wku edu

Date Created: 7/27/2009 5:44:10 PM

Date Range: 8/17/2009 12:00:00 AM - 10/30/2009 11:59:00 PM

Total Respondents: 294

Q1. Informed Consent for Survey Participation You are being invited to participate in a research study answering the following questions attached to the survey link attached. There are no known risks for your participation in this research study. The information you provide will provide baseline data and perceptions of health center directors regarding experiential learning (academic internships or clinical rotations) in college health centers. Your completed survey will be collected and stored electronically and anonymously by Student Voice. Individual results are completely anonymous to the investigators and all data will be destroyed after statistical tabulation of aggregate results. No personal identification is collected for respondents. Taking part in this survey is voluntary. By completing this survey you agree to take part in this research study. This study has met full reguirements for both the Human Subjects Review Board at Western Kentucky University and the Institutional Review Board (IRB) at the University of Louisville respectively. If you have concerns or complaints about the research or research staff and you do not wish to give your name, you may call 1-877-852-1167. This is a 24-hour hot line answered by people who do not work at either the University of Louisvilte or Western Kentucky University The intent of this option is to satisfy any concerns you may have for voluntarily answering the questions on this survey. By clicking "I agree to participate you acknowledge you have read and understand your rights as a participant and that you volunteer to participate. If you are interested in recelving the results of this survey, you may contact Libby Greaney to request them after an 8 week period. The contact information is libby greaney@wku.edu or (270) 745-3830. This survey will take 5-10 minutes to complete. THANK YOU:

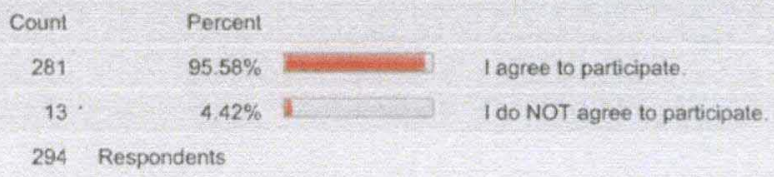

267 Respondents

Q3. What is your highest academic credential?

\begin{tabular}{|c|c|c|c|c|}
\hline Count & Percent & & & \\
\hline 44 & $16.48 \%$ & i. & \multicolumn{2}{|c|}{ Bachelors degree } \\
\hline 77 & $28.84 \%$ & wix $-2=2$ & \multicolumn{2}{|c|}{ Masters degree (Clinical) MSN, ARNP, MSW, etc } \\
\hline 49 & $18.35 \%$ & 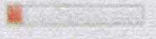 & \multicolumn{2}{|c|}{ Masters degree (Non-Clinical) } \\
\hline 20 & $7.49 \%$ & 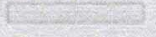 & \multicolumn{2}{|l|}{ PhD } \\
\hline 47 & $17.60 \%$ & 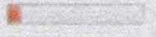 & \multicolumn{2}{|c|}{ MD or DO } \\
\hline 30 & $11.24 \%$ & $1=$ & \multicolumn{2}{|c|}{ Other (please specify) } \\
\hline & Count & Percent & & \\
\hline & 1 & $3.33 \%$ & 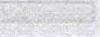 & 3 yr RN/2yr Jr college \\
\hline & 1 & $3.33 \%$ & $x^{2}=$ & Assoc. Degree RN RT \\
\hline & 1 & $3.33 \%$ & 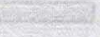 & associates \\
\hline & 1 & $3.33 \%$ & 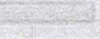 & Associates Degree \\
\hline & 1 & $3.33 \% 1$ & casised & Board certified in college health \\
\hline & 1 & $3.33 \%$ & 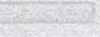 & CNP \\
\hline & 1 & $3.33 \%$ & 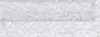 & College Health Nurse Practitioner Certificate \\
\hline & 1 & $3.33 \%$ t & 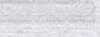 & currently attending LSSU \\
\hline & 1 & $3.33 \%$ & 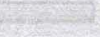 & Diploma in Nursing $8 \mathrm{SN}$ in progress \\
\hline & 1 & $3.33 \%$ & 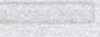 & DNP \\
\hline & 1 & $3.33 \%$ & $c^{5}$ & Doctor of Heatth \&amp; Safety (HSD) \\
\hline & 1 & $3.33 \%$ & 5 & Doctorate in Health \&amp: Safety (HSD) \\
\hline & 1 & $3.33 \% \%$ & 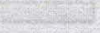 & DPT \\
\hline
\end{tabular}


Appendix A (continued)

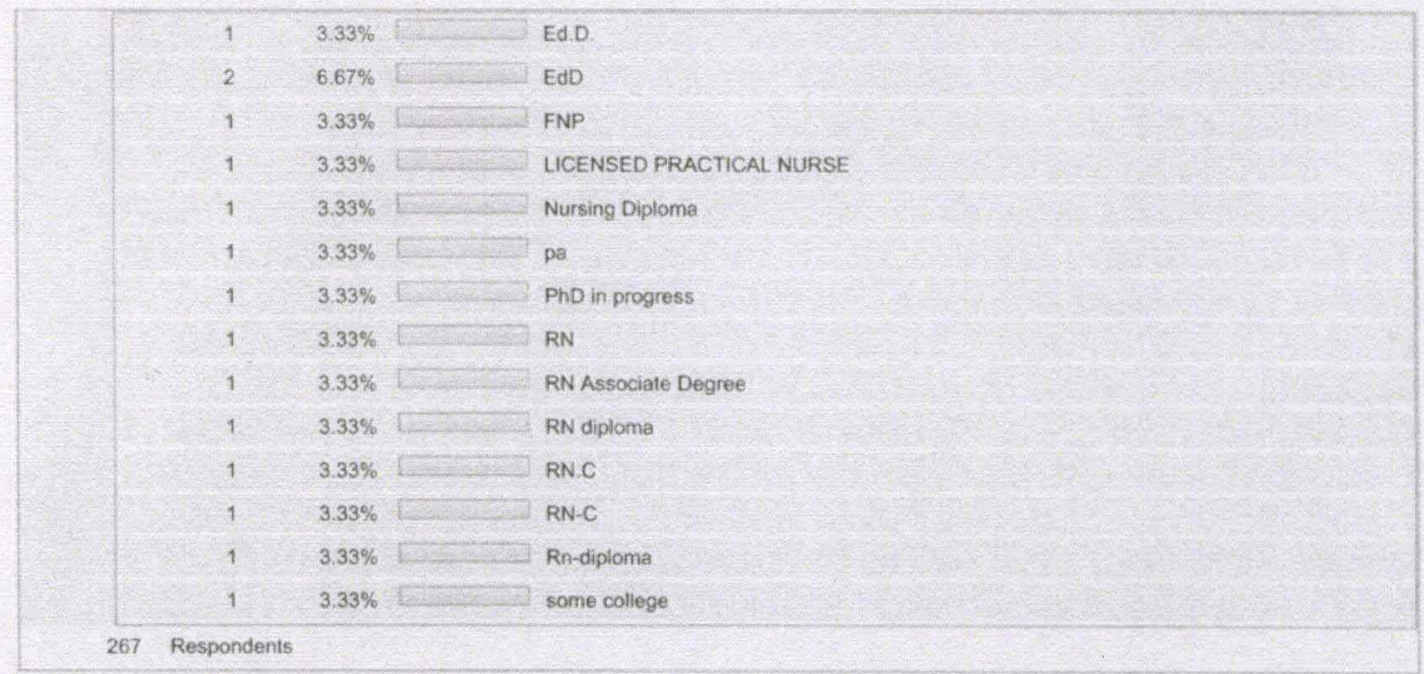

Q4. Do you teach academic classes?
\begin{tabular}{rrr|} 
Count & Percent & Yes \\
57 & $21.35 \%$ & No \\
210 & $78.65 \%$ & \\
267 & Respondents
\end{tabular}

Q5. How many years have you been the director of your health center?

\begin{tabular}{|c|c|c|c|c|}
\hline Count & Percent & & & \\
\hline 267 & $100.00 \%$ & \multicolumn{3}{|c|}{ 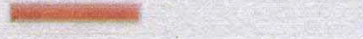 } \\
\hline & Count & \multicolumn{3}{|l|}{ Percent } \\
\hline & 1 & $0.37 \%$ & 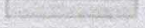 & $\$$ years \\
\hline & 3 & $1.12 \%$ & 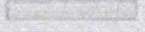 & 8lt:1 \\
\hline & 5 & $1.87 \%$ & 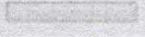 & 0 \\
\hline & 20 & $7.49 \%$ & $t=5$ & 1 \\
\hline & 1 & $0.37 \%$ & 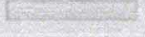 & 1 (Interim) \\
\hline & 6 & $2.25 \%$ & 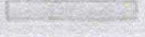 & 1.5 \\
\hline & 1 & $0.37 \%$ & $C^{2}=0$ & 1.5 years \\
\hline & 13 & $4.87 \%$ & 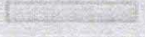 & 10 \\
\hline & 3 & $1.12 \%$ & ting & 11 \\
\hline & 2 & $0.75 \%$ & Les & 11 years \\
\hline & 1 & $0.37 \%$ & 120 & $1-1 / 2$ \\
\hline & 8 & $3.00 \%$ & 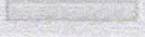 & 12 \\
\hline & 1 & $0.37 \%$ & $\sqrt{2}+x=5$ & 12 yrs. \\
\hline & 6 & $2.25 \%$ & 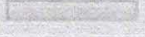 & 13 \\
\hline & 1 & $0.37 \%$ & 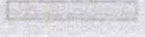 & $13 \mathrm{yrs}$ \\
\hline & 3 & $1.12 \%$ & Wan & 14 \\
\hline & 1 & $0.37 \%$ & 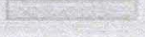 & $141 / 2$ years \\
\hline & 1 & $0.37 \%$ & 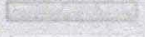 & 14 years \\
\hline & 2 & $0.75 \%$ & $f=5,7=?$ & 15 \\
\hline
\end{tabular}


Appendix A (continued)

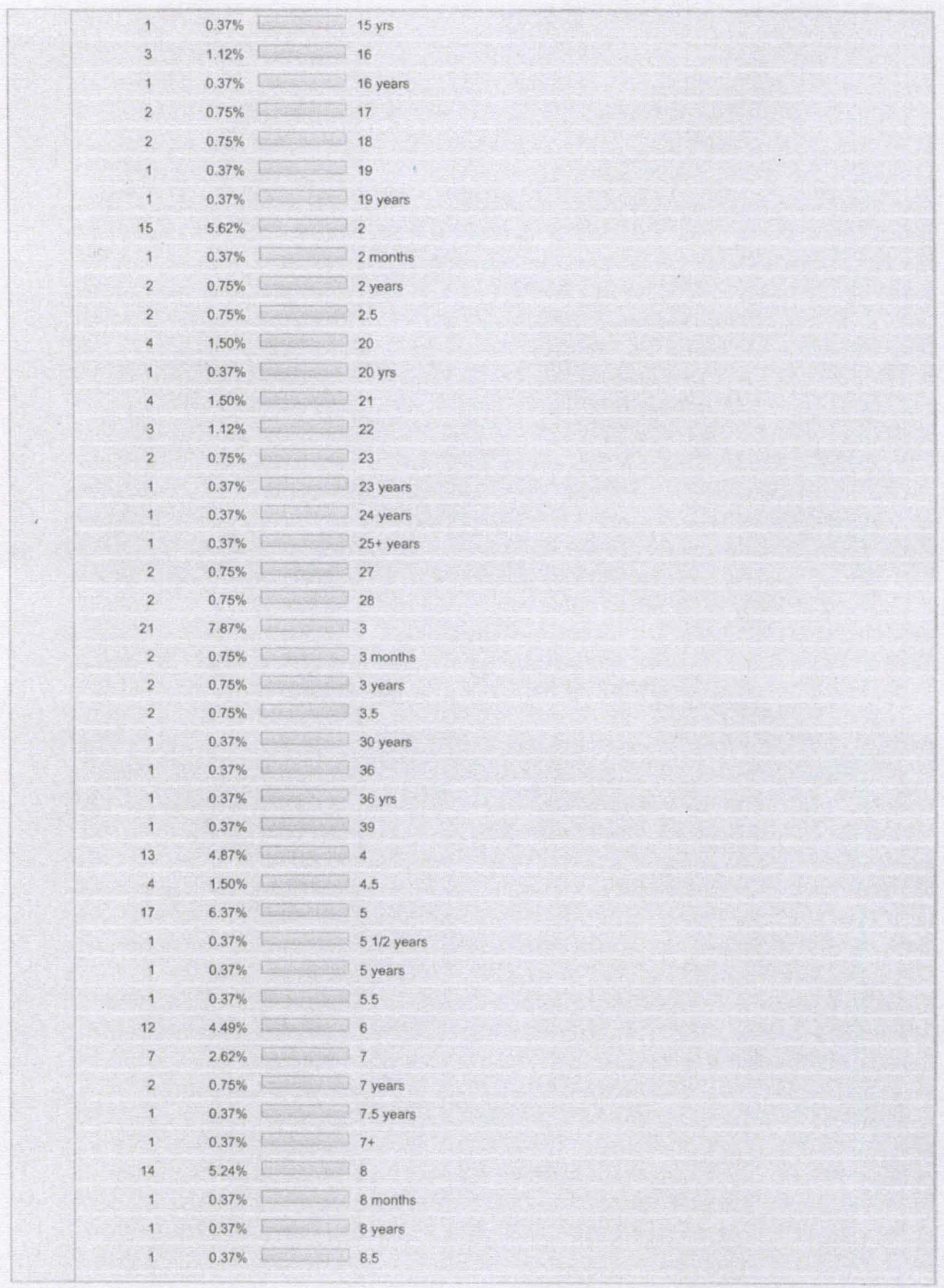




\section{Appendix A (continued)}

\begin{tabular}{|c|l|l|}
\hline 15 & $5.62 \%$ & 9 \\
\hline 1 & $0.37 \%$ & 9 years \\
\hline 1 & $0.37 \%$ & Admin. Director - 7 yrs \\
\hline 1 & $0.37 \%$ & almost 20 years \\
\hline 1 & $0.37 \%$ & Five \\
\hline 1 & $0.37 \%$ & four months \\
\hline 1 & $0.37 \%$ & Have been Associate Director for 3 years \\
\hline 1 & $0.37 \%$ & Not a Director \\
\hline 1 & $0.37 \%$ & Nurse supervisor- 20 years \\
\hline 1 & $0.37 \%$ & second year \\
\hline 1 & $0.37 \%$ & six \\
\hline 1 & $0.37 \%$ & three (22 total, including three other schools) \\
\hline 1 & $0.37 \%$ & three, but a total of 22 years as a Director at four universities \\
\hline Respondents & $0.37 \%$ & two years \\
\hline
\end{tabular}

Q6. What is the classification of your school?

Count Percent

$106 \quad 40.15 \%$ Dectoral/Research

$68 \quad 25.76 \%$ Masters

$87 \quad 32.95 \%$ Baccalaureate

$3 \quad 1.14 \%$ Associates or Community College

264 Respondents

Q7. Is your school public or private?

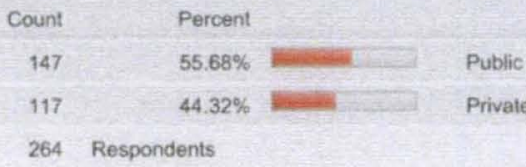

Q8. What is the scope of your health center's services?

\begin{tabular}{ccc} 
Count & Percent & \\
\hline 153 & $57.95 \%$ & Comprehensive (full time: MDs, Ancillaries, Health Education) \\
111 & $42.05 \%$ & Limited (part time: Nursing visits w/Triage, part-time MD hours) \\
264 & Respondents &
\end{tabular}

Q9. Does your school have a Nursing school?

\begin{tabular}{|c|c|c|}
\hline Count & Percent & \\
\hline 158 & $59.85 \%$ & 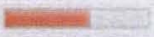 \\
\hline 106 & $40.15 \%$ & wes: \\
\hline
\end{tabular}

264 Respondents 


\section{Appendix A (continued)}

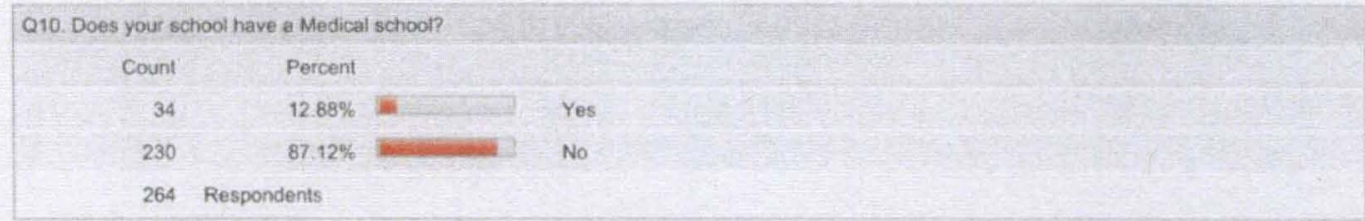

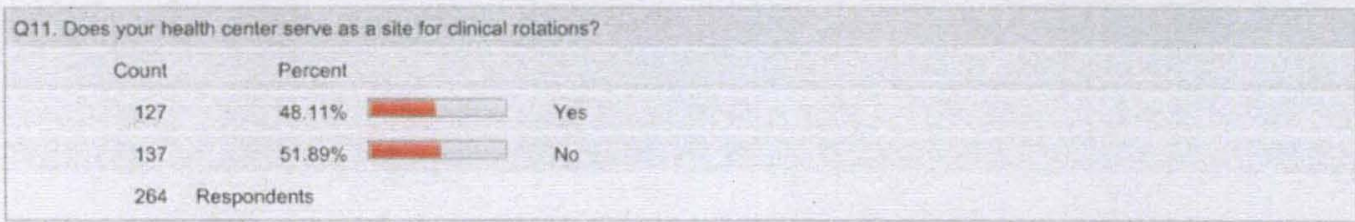

\begin{tabular}{|c|c|c|c|c|}
\hline Count & \multicolumn{2}{|c|}{ Respondent \% } & Response \% & \\
\hline 43 & \multicolumn{2}{|r|}{$34.68 \%$} & $14.58 \%$ & I Medical residents \\
\hline 83 & \multicolumn{2}{|r|}{$66.94 \%$} & $28.14 \%$ & Bin Nurse practitioners \\
\hline 22 & \multicolumn{2}{|r|}{$17.74 \%$} & $7.46 \%$ & Physician assistants \\
\hline 7 & \multicolumn{2}{|r|}{$5.65 \%$} & $2.37 \%$ & Physical therapy \\
\hline 29 & \multicolumn{2}{|r|}{$23.39 \%$} & $9.83 \%$ & C. Counseling/therapy \\
\hline$\theta$ & \multicolumn{2}{|r|}{$7.26 \%$} & $3.05 \%$ & Medical assistants \\
\hline 58 & \multicolumn{2}{|r|}{$46.77 \%$} & $19.66 \%$ & Nursing students \\
\hline 44 & \multicolumn{2}{|r|}{$35.48 \%$} & $14.92 \%$ & I. Other (please specity) \\
\hline & Count & Percent & & \\
\hline & 1 & $2.27 \%$ & 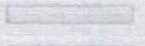 & 3 rd and 4 th yr medical students \\
\hline & 1 & $2.27 \%$ & i. $\quad 0=\sin 3$ & Athletic trainer students \\
\hline & 1 & $2.27 \%$ & Ex+ming & athletic trainers \\
\hline & 3 & $6.82 \%$ & 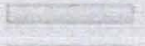 & Athletic trainers \\
\hline & 1 & $2.27 \%$ & 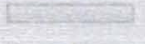 & Athletic Trainers \\
\hline & 1 & $2.27 \%$ & 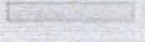 & Athletic trainers, Clinical Laboratory Sciences \\
\hline & 2 & $4.55 \%$ & 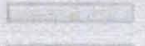 & athletic training \\
\hline & 1 & $2.27 \%$ & 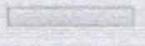 & Athletic training \\
\hline & 1 & $2.27 \%$ & 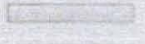 & athletic training students \\
\hline & 3 & $6.82 \%$ & Exton & Athletic Training Students \\
\hline & 1 & $2.27 \%$ & 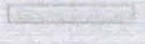 & athletic training students/Masters health education majors \\
\hline & 1 & $2.27 \%$ & 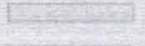 & Clinical Laboratory Science \\
\hline & 1 & $2.27 \%$ & in & Dietetics \\
\hline & 1 & $2.27 \%$ & 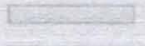 & Dietetics grad student \\
\hline & 1 & $2.27 \%$ & 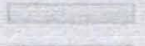 & dietietic \\
\hline & 1 & $2.27 \%$ & 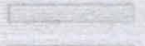 & exercise science students \\
\hline & 1 & $2.27 \%$ & 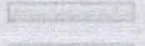 & lab techs \\
\hline & 1 & $2.27 \%$ & 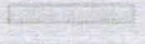 & Medical Assistant and Medical Billing Students \\
\hline & 1 & $2.27 \%$ & 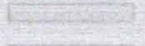 & medical assistants \\
\hline & 4 & $9.09 \%$ & 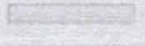 & medical students \\
\hline & 2 & $4.55 \%$ & Len & Medical students \\
\hline & 1 & $2.27 \%$ & Disinas & medical students in foundations of clncial medicine skills class \\
\hline
\end{tabular}




\section{Appendix A (continued)}

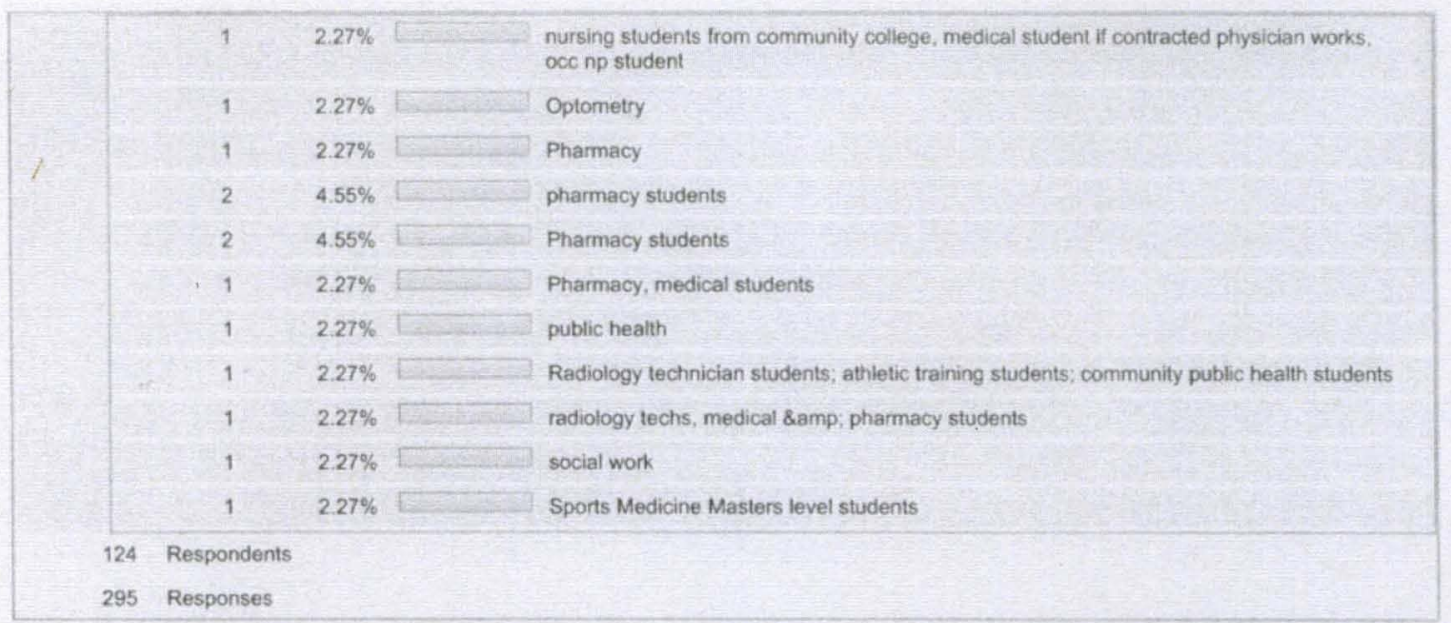

Q13. What is the average number of clinical rotations per year in your health center?

\begin{tabular}{rrr} 
Count & Percent & \\
\hline 10 & $8.06 \%$ & 1 \\
23 & $18.55 \%$ & 2 \\
18 & $14.52 \%$ & 3 \\
49 & $39.52 \%$ & $4+$ \\
24 & $19.35 \%$ & Varies
\end{tabular}

124 Respondents

Q14. Does your health center serve as a placement site for acadernic internships (non-clinical)?

\begin{tabular}{|rll}
\hline Count & Percent & \\
\hline 73 & $27.97 \%$ & Yes \\
188 & $72.03 \%$ & No \\
\hline 261 & Respondents & \\
\hline
\end{tabular}

Q15. What is the average number of academic intemship rate per year in your health center?

\begin{tabular}{|c|c|c|c|}
\hline Count & Percent & & \\
\hline 24 & $33.80 \%$ & Hean & 1 \\
\hline 16 & $22.54 \%$ & Ee & 2 \\
\hline 10 & $14.08 \%$ & Whin & 3 \\
\hline 14 & $19.72 \%$ & E & $4+$ \\
\hline 7 & $9.86 \%$ & 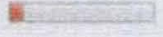 & Varies \\
\hline & & & \\
\hline
\end{tabular}

\begin{tabular}{|c|c|c|c|c|}
\hline Count & Respondent \% & Response \% & & \\
\hline 42 & $59.15 \%$ & $28.97 \%$ & antantan & Public health, Health Administration, Health Education \\
\hline 9 & $12.68 \%$ & $6.21 \%$ & 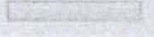 & Business Administration \\
\hline 5 & $7.04 \%$ & $3.45 \%$ & 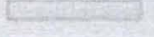 & Medical School \\
\hline 26 & $36.62 \%$ & $17.93 \%$ & 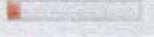 & Counseling/Psychology \\
\hline 20 & $28.17 \%$ & $1379 \%$ & Exingal & Student Affairs \\
\hline
\end{tabular}




\section{Appendix A (continued)}

\begin{tabular}{|c|c|c|c|c|}
\hline 17 & \multirow{2}{*}{\multicolumn{2}{|c|}{$\begin{array}{l}23.94 \% \\
36.62 \%\end{array}$}} & $11.72 \%$ & Nursing School \\
\hline 26 & & & $17.93 \%$ & I Other (please specify) \\
\hline & Count & Percent & & \\
\hline & 1 & $3.85 \%$ & 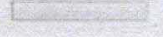 & Above Schools are not affilated with this university \\
\hline & 1 & $3.85 \%$ & Eisens & Dept of Education \\
\hline & 1 & $3.85 \%$ & 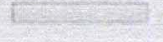 & Education, Communication Arts, Social Work, Exercise Physiology \\
\hline & 1 & $3.85 \%$ & 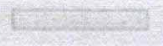 & exeercise science dept \\
\hline & 1 & $3.85 \%$ & 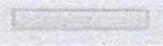 & Exercise Science, Pharmacy \\
\hline & 1 & $385 \%$ & 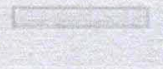 & $\begin{array}{l}\text { Health communication, SCHool of Media Arts \&amp; Design, Computer Information System; } \\
\text { Scientific \&amp; Technical Writings }\end{array}$ \\
\hline & 2 & $7.69 \%$ & 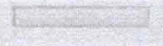 & Health Information Management \\
\hline & 1 & $3.85 \%$ & 5 & higher education \\
\hline & 1 & $3.85 \%$ & 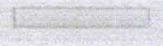 & HPERD (Health, Physical Education, Recreation, Dance) \\
\hline & 1 & $3.85 \%$ & 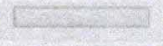 & Human Sexuality \\
\hline & 1 & $3.85 \%$ & $\sqrt{5+3 x-5}$ & Master's programs other campuses \\
\hline & 1 & $3.85 \%$ & 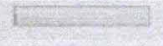 & MHA, HM \\
\hline & 1 & $3.85 \%$ & 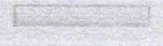 & Nutrition \\
\hline & 1 & $3.85 \%$ & 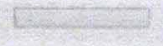 & outside medicine residency \\
\hline & 2 & $7.69 \%$ & 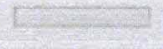 & Pharmacy \\
\hline & 1 & $3.85 \%$ & finiting & Pharmacy and Social Work \\
\hline & 1 & $3.85 \%$ & 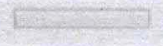 & Pharmacy School \\
\hline & 1 & $3.85 \%$ & 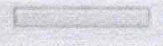 & Phys Asst program \\
\hline & 1 & $3.85 \%$ & 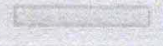 & school of social work \\
\hline & 3 & $11.54 \%$ & 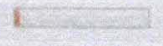 & social work \\
\hline & 1 & $3.85 \%$ & 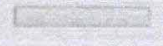 & social work, marketing, women studies, biology, sociology, english, biochemistry \\
\hline & 1 & $3.85 \%$ & 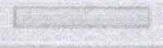 & Technical College - Medical Admininistrative Personnel \\
\hline 71 & Respondents & & & \\
\hline 145 & Responses & & & \\
\hline
\end{tabular}

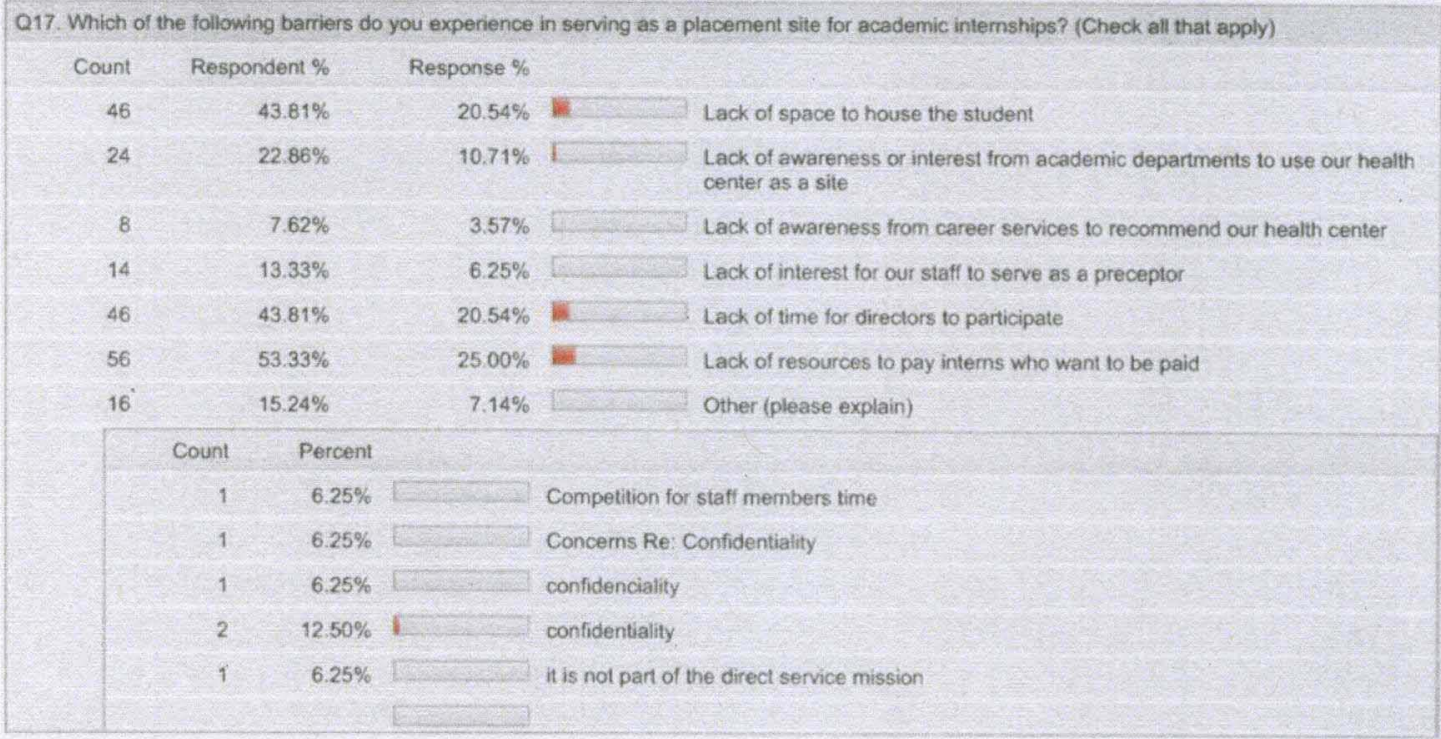




\section{Appendix A (continued)}

\begin{tabular}{|c|c|c|c|c|}
\hline & 1 & $6.25 \%$ & & tack of provider time to serve as preceptor \\
\hline & 1 & $6.25 \%$ & $y=\sin (1$ & Lack of time due to high demand for services. \\
\hline & 1 & $6.25 \%$ & 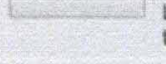 & $\begin{array}{l}\text { Limitations in staffing (NP's) and slowing down services to students while } \\
\text { teaching/supervising }\end{array}$ \\
\hline & 1 & $6.25 \%$ & 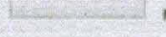 & $n / a$ \\
\hline & 1 & $6.25 \%$ & (b) & N/A \\
\hline & 1 & $6.25 \%$ & 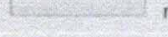 & no academic programs that are health related \\
\hline & 1 & $6.25 \%$ & $x-\sin 2$ & Too few professional staff \\
\hline & 1 & $6.25 \%$ & 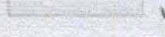 & we are not big enough to participale \\
\hline & 1 & $6.25 \%$ & 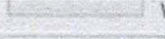 & We have no internships \\
\hline 14 & 13.33 & & $6.25 \%$ & 2. None of the above \\
\hline 105 & Respondents & & & \\
\hline 224 & Responses & & & \\
\hline
\end{tabular}

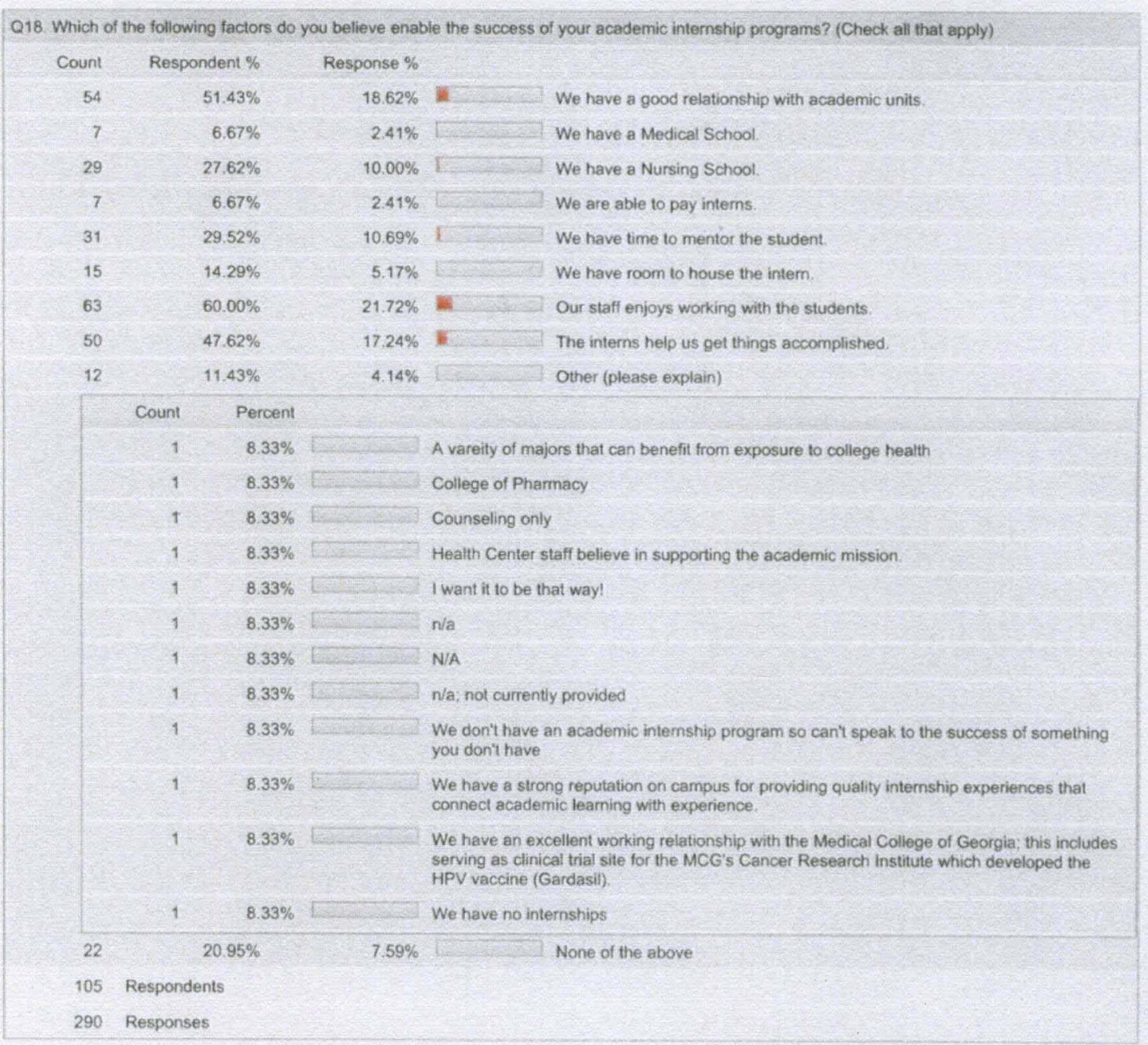




\section{Appendix A (continued)}

\begin{tabular}{l} 
Q19. How satisfied are you with the academic internship (non-cinicai) activites at your health center? \\
\begin{tabular}{rl|l|} 
Count & Percent & Very satisfied \\
37 & $35.24 \%$ & Somewhat satisfied \\
31 & $29.52 \%$ & Neither satisfied nor dissatisfied \\
35 & $33.33 \%$ & Somewhat dissatisfied \\
2 & $1.90 \%$ & Very dissatisfied \\
0 & $0.00 \%$ & \\
105 & Respondents
\end{tabular} \\
\hline
\end{tabular}

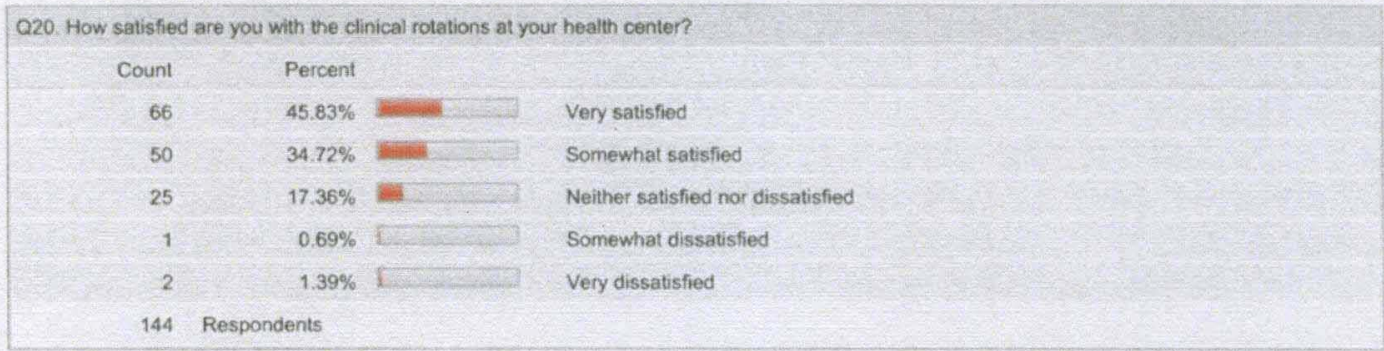

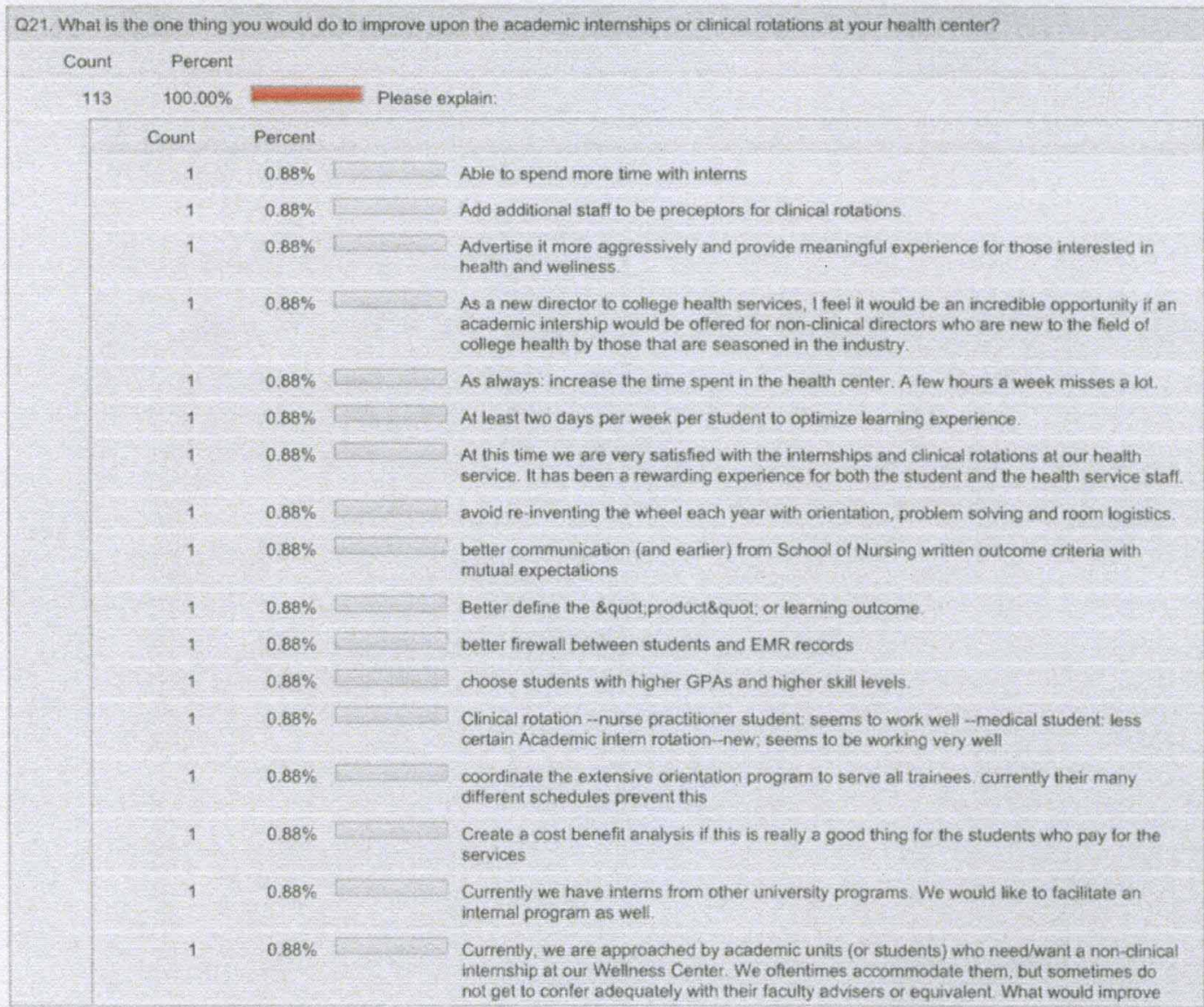




\section{Appendix A (continued)}

\begin{tabular}{|c|c|c|c|}
\hline & & & $\begin{array}{l}\text { our internships wouid be to come up with intemship ideas and \&quot,pitch\&quot, them to } \\
\text { academic units and/or students. Basically, have students competelapply for them. That way, } \\
\text { we can get the best students for our needs and initiate contact with academic units up front }\end{array}$ \\
\hline 1 & $0.88 \%$ & 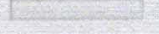 & Develop a program for clinical internshipsirotations to make them a part of our service \\
\hline 1 & $0.88 \%$ & 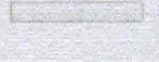 & $\begin{array}{l}\text { Develop a Student Health Center survey to assess in more detail what is helpful to the } \\
\text { student and what else we could do to improve the experience. }\end{array}$ \\
\hline 1 & $0.88 \%$ & 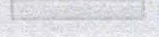 & Develop curriculum materials. \\
\hline 1 & $0.88 \%$ & 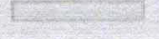 & Expand our physical space. \\
\hline 1 & $0.88 \%$ & 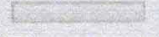 & Expand our space. \\
\hline 1 & $0.88 \%$ & 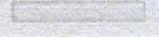 & explicit goals and expectations for the experience \\
\hline 1 & $0.88 \%$ & 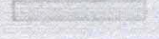 & Find a mechanism to allow increased staff time with learners. \\
\hline 1 & $0.88 \%$ & 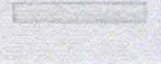 & $\begin{array}{l}\text { fully integrate into our holistic health model, collaborating between medical, counseling and } \\
\text { prevention services }\end{array}$ \\
\hline 1 & $0.88 \%$ & 2 & Funding needed for Counseling Service interns \\
\hline 1 & $0.88 \%$ & $\sqrt{1}=-197$ & group orientation prior to experience \\
\hline 1 & $0.88 \%$ & 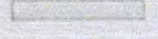 & have more clincial help so we could devote additional time to teaching the medical studnets \\
\hline 1 & $0.88 \%$ & 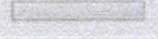 & Have more physical space \\
\hline 1 & $0.88 \%$ & 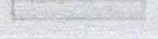 & Have more preceptor time available \\
\hline 1 & $0.88 \%$ & 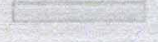 & have more space \\
\hline 1 & $0.88 \%$ & 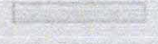 & Have more student participation from other schools \\
\hline 1 & $0.88 \%$ & 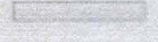 & Have more time to spend with them \\
\hline 1 & $0.88 \%$ & tis & Have more time with patients. \\
\hline 1 & $0.88 \%$ & $x^{2}=\cos ^{3}$ & $\begin{array}{l}\text { Have people interested in leaming about the services that are oflered and use as a clinical } \\
\text { rotation site }\end{array}$ \\
\hline 1 & $0.88 \%$ & 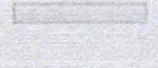 & $\begin{array}{l}\text { Have the rotations be longer term--a couple weeks is not worth our time to train the } \\
\text { students. }\end{array}$ \\
\hline 1 & $0.88 \%$ & $=x^{2}=\sin ^{3}$ & Having more input as to prior experience of interns coming to health center for rotation \\
\hline 1 & $0.88 \%$ & 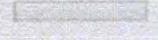 & Having the ability to spend a little more time with the interns/preceptorships \\
\hline 1 & $0.88 \%$ & 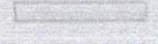 & Hire more preceptors (stafi). \\
\hline 1 & $0.88 \%$ & 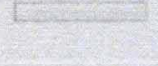 & $\begin{array}{l}\text { Ifeel the residents gel a good expenience here. They are usually in their last year of } \\
\text { residency and I leam as much from them as they do from the rotation. }\end{array}$ \\
\hline 1 & $0.88 \%$ & 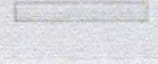 & $\begin{array}{l}\text { I need more staff to help with the rotations. We have a skeletal crew and students do slow } \\
\text { patient flow }\end{array}$ \\
\hline 1 & $0.88 \%$ & 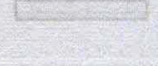 & $\begin{array}{l}\text { I would include the nurse practitioner students in more group clinical conversations or formal } \\
\text { conferences but we da not have the time. Counseling services is able to do this }\end{array}$ \\
\hline 1 & $0.88 \%$ & $5 x^{-2}-2$ & $\begin{array}{l}\text { I would like to see more of them and we hope to develop them. Currently we have been } \\
\text { challenged with changing the existing culture of the health center that has not traditionally } \\
\text { collaborated with academic depts. This is changing. }\end{array}$ \\
\hline 1 & $0.88 \%$ & Waras $=3$ & I would like to see the rotation longer \\
\hline 1 & $0.88 \%$ & 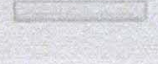 & $\begin{array}{l}\text { If we had the capacity, we would add another physician and another mental health clinician } \\
\text { to meet the time demand that internships and rotations use. }\end{array}$ \\
\hline 1 & $0.88 \%$ & 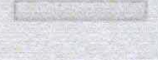 & $\begin{array}{l}\text { If we weren't so busy seeing patients, it would be nice if our nurse practitioners had more } \\
\text { time to teach after seeing each patient with the student nurse practitioner }\end{array}$ \\
\hline 1 & $0.88 \%$ & 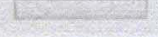 & Improve defined learning outcomes for each area \\
\hline 1 & $0.88 \%$ & 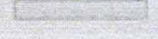 & Improved communication between academic instructors and health center expectations \\
\hline 1 & $0.88 \%$ & $4 x^{2}=0$ & Incentivize providers to show more interest in mentoring \\
\hline 1 & $0.88 \%$ & 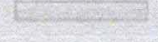 & Increase amount of time to work with the clinicalstaff. \\
\hline 1 & $0.88 \%$ & 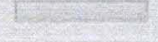 & Increase the amount of time per rotation so the nursing student gets a better experience. \\
\hline 1 & $0.88 \%$ & 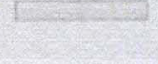 & $\begin{array}{l}\text { Increased coordination between the academic area and the clinical area in terms of rotation } \\
\text { content, logistics, etc. }\end{array}$ \\
\hline
\end{tabular}




\section{Appendix A (continued)}

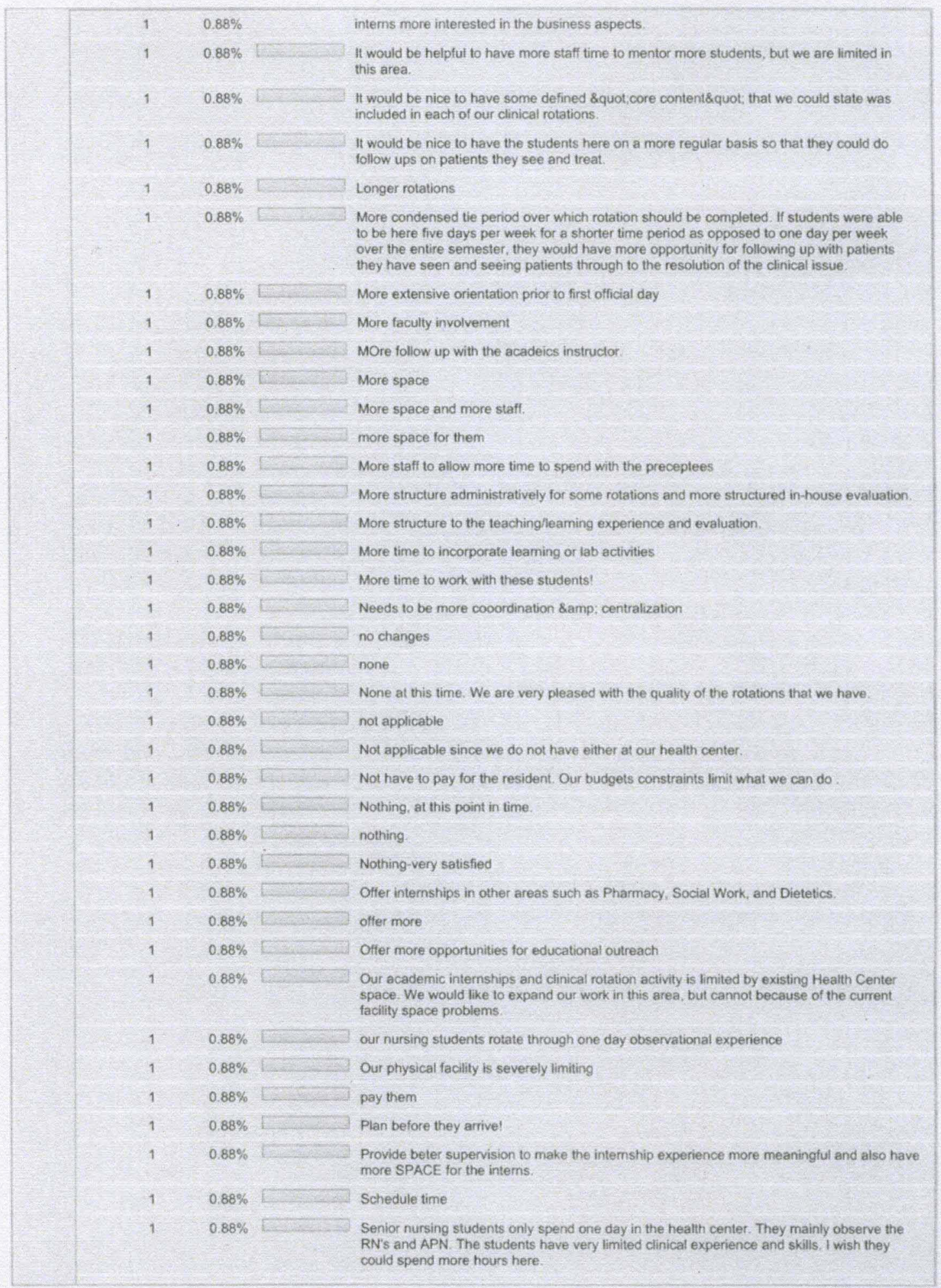




\section{Appendix A (continued)}

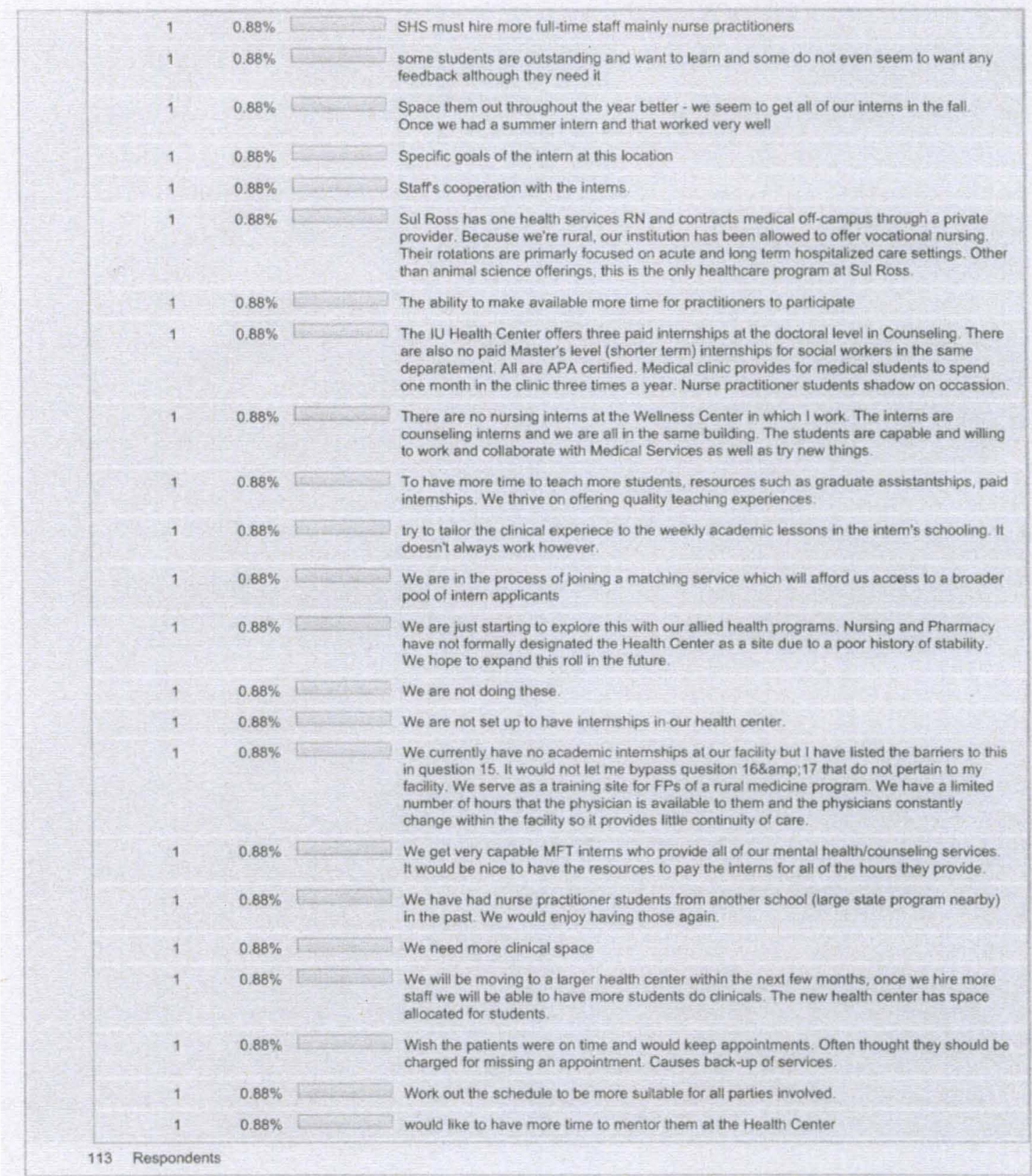




\section{Appendix B}

\section{草 \\ WKU.}

A LEADING AMERICAN UNTVERSTY WITH INTERNATIONAL. REACH

HUMAN SUBHCTS RIVILW BOAZD

In future correspondence, please refer to HS09-257, June 26, 2009

Libby Greaney

clo Dr. Randy Capps

Educational Administration, Leadership, \& Research

WKU

Libby Greaney:

Your research project, Experiential Learning: A Review of College Health Centers, was reviewed by the HSRB and it has been determined that risks to subjects are: (1) minimized and reasonable; and that (2) research procedures are consistent with a sound research design and do not expose the subjects to unnecessary risk. Reviewers determined that: (1) benefits to subjects are considered along with the importance of the topic and that outcomes are reasonable; (2) selection of subjects is equitable; and (3) the purposes of the research and the research setting is amenable to subjects' welfare and producing desired outcomes; that indications of coercion or prejudice are absent, and that participation is clearly voluntary.

1. In addition, the IRB found that you need to orient participants as follows: (1) signed informed consent is not required; (2) Provision is made for collecting, using and storing data in a manner that protects the safety and privacy of the subjects and the confidentiality of the date. (3) Appropriate safeguards are included to protect the rights and welfare of the subjects.

\section{This project is therefore approved at the Exempt.}

2. Please note that the institution is not responsible for any actions regarding this protocol before approval. If you expand the project at a later date to use other instruments please re-apply. Copies of your request for human subjects review, your application, and this approval, are maintained in the Office of Sponsored Programs at the above address. Please report any changes to this approved protocal to this office. A Continuing Review protocol will be sent to you in the future to determine the status of the project. Also, please use the stamped approval forms to assure participants of compliance with The Office of Human Research Protections regulations
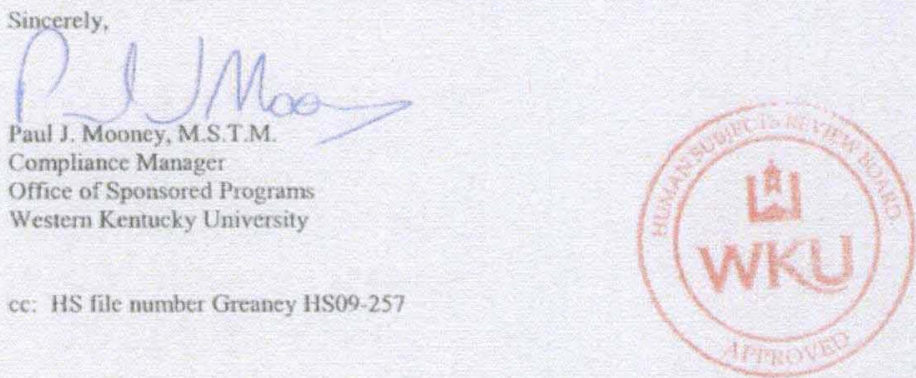

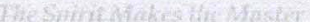

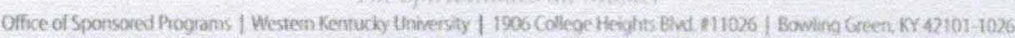

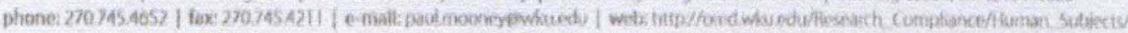




\section{Appendix C}

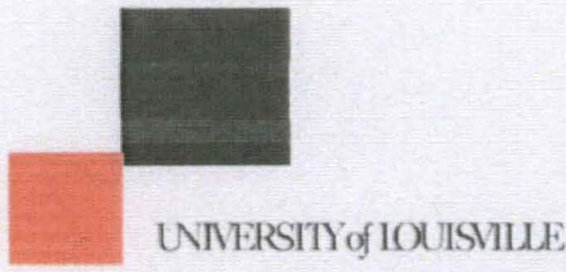

To:

From: $\quad$ The University of Louisville Institutional Review Board (IRB)

Date: Wednesday, July 22, 2009

Subject: IRB Correspondence

Tracking \#: 09.0324

Title: $\quad$ Experiential Learning: A Review of College Health

Centers
INSTITUTIONAL REVIEW BOARDS

University of Louisville

MedCenter One, Suite 200

501 E. Broadway

Louisville, Kentucky 40202-1798

Office: $\quad 502-852-5188$

Fax: $\quad 502-852-2164$

This study was reviewed on 07-21-09 and determined by the chair of the Institutional Review Board that the study is exempt according to 45 CFR 46.101 (b) under category (1) Research conducted in established or commonly accepted educational settings, involving normal educational practices, such as (i) research on regular and special education instructional strategies, or (ii) research on the effectiveness of or the comparison among instructional techniques, curricula, or classroom management methods. The study is exempt only if information that could identify subjects is not recorded

Since this study has been found to be exempt, no additional reporting, such as submission of Progress Reports for continuation reviews, is needed. If your research focus or activities change, please submit a Study Amendment Request Form to the IRB for review to ensure that the study still meets exempt status. Best wishes for a successful study. Please send all inquires and electronic revised/requested items to our office email address at hsppofc:louisville.edu.

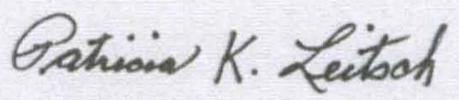


Appendix D

Dear Health Cemer Director

In the near finure we wsil be sending you an e-mail with a link to a sbont suncy:

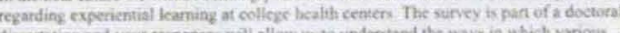

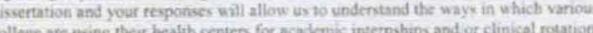

The suner is designed to take no mors than 5.8 minutes. Yeut assistasce and

willingnes to fill cut the suneris preativ appseciated. All responses afe confidentia? and agerezate data only with be ansilyzect

THANK YOL

Sincerely

Libby Gminos, Dirssto WKU Health Senice

Bowling Green, KY

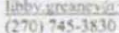

Health

wKU Services 


\title{
CURRICULUM VITAE
}

\author{
Libby Greaney \\ libby.greaney@wku.edu
}

PROFILE:

24 years work experience in health, recreation, wellness and medical services 14 years work experience in higher education, student affairs \& financial affairs Proven leader, strategic planner and collaborative decision maker Proven supervisory skills, personnel development and leadership Demonstrated business and financial acumen

A strong theoretical and applicable understanding of experiential learning and student development

Seasoned crisis management skills

EDUCATION:

Ph.D. Educational Leadership \& Organizational Development University of Louisville 2010

Dissertation: Experiential learning: A review of college health centers M.B.A. Western Kentucky University M.H.A. Western Kentucky University

M.S. Exercise Science. University of New Hampshire

Thesis: Cross-training and its effect on VO2 max

B.S. Health Education, K-12. University of Vermont

\section{EMPLOYMENT:}

Director, WKU Health Services, Western Kentucky University $\quad$ 01/2000-present

Director, Health Services and Intramurals \& Recreational Sports $\quad$ 01/03-05/08

Asst. Director, Health \& Fitness Lab, Intramurals \& Recreation

07/96-12/99

Health \& Wellness Counselor, Wellness Center, Health Service

02/94-07/96

Health Risk Manager, Employee Wellness, Blue Cross \& Blue Shield of New Hampshire, Manchester, N.H.

06/88-07/92 
High School Health Teacher, Mt Abraham Union H.S, Bristol, VT. $\quad$ 01/86-06/86 PROFESSIONAL ACTIVITIES:

Adjunct Faculty, Western Kentucky University 8/95-present

President, Kentucky College Health Association 4/08-present

Presentation: Billing: How it works. ACHA National Conference 05/09

San Francisco, CA.

Presentation: Third party billing in University Health Centers

ACHA National Conference, San Antonio, TX.

Poster Presentation: A Comparison of Aerodynamic Cycling Positions on

Ventilatory Reponses; By Wyatt, Crandall \& Greaney. American College of

Sports Medicine National Conference, Orlando, FL.

$06 / 98$

Webinar: Enhancing revenue in college health; Neusoft Inc.

$05 / 08$

KY Governor's Council on Physical Fitness and Wellness

96-01

\section{PROFESSIONAL DEVELOPMENT:}

Institute for Aspiring Sr. Student Affairs Officers (ASSAO)

$1 / 8-11 / 09$

Leadership Certificate, Western Kentucky University

$8 / 08$

College Business Management Institute (CBMI) Graduate;

$7 / 03,7 / 05,7 / 08$

MGMA Financial Management Assembly:

$8 / 07,2 / 02$

Napa, CA; San Francisco, CA.

National Intramurals \& Recreational Sports Association (NIRSA)

National Conference, Louisville, KY

KY Governor's Flu Pandemic Conference, Frankfort, KY.

Homeland Security Table Top Exercise, Warren County, KY;

$10 / 05,06 / 07$ 


\section{CERTIFICATIONS/ MEMBERSHIPS:}

\section{Certifications:}

Certified Medical Practice Executive (CMPE)

Certified Health Education Specialist (CHES)

National Incident Management System (NIMS) ICS; 100, 200, 700 \& IS 800.B FEMA

Basic Life Support (BLS)

Memberships:

National Association Student Personnel Administrators (NASPA)

American College Health Association (ACHA)

National Association College University Business Officers (NACUBO)

Medical Group Management Association (MGMA)

National Wellness Institute (NWI) 